UNITED STATES

ational Bureau of Standards ibrary, E-01 Admin. Bldg.

APR $2 \quad 1973$

\section{On the Utility of the $m-6-8$ Potential Function}

30

5753

U.S. ARTMENT OF MMERCE National Bureau of tandards 
The National Bureau of Standards ${ }^{1}$ was established by an act of Congress March 3, 1901. The Bureau's overall goal is to strengthen and advance the Nation's science and technology and facilitate their effective' application for public benefit. To this end, the Bureau conducts research and provides: (1) a basis for the Nation's physical measurement system, (2) scientific and technological services for industry and government, (3) a technical basis for equity in trade, and (4) technical services to promote public safety. The Bureau consists of the Institute for Basic Standards, the Institute for Materials Research, the Institute for Applied Technology, the Center for Computer Sciences and Technology, and the Office for Information Programs.

THE INSTITUTE FOR BASIC STANDARDS provides the central basis within the United States of a complete and consistent system of physical measurement; coordinates that system with measurement systems of other nations; and furnishes essential services leading to accurate and uniform physical measurements throughout the Nation's scientific community, industry, and commerce. The Institute consists of a Center for Radiation Research, an Office of Measurement Services and the following divisions:

Applied Mathematics-Electricity-Heat-Mechanics-Optical Physics-Linac Radiation ${ }^{2}$ - Nuclear Radiation²-Applied Radiation ${ }^{2}$ - Quantum Electronics ${ }^{3}$ Electromagnetics ${ }^{3}$-Time and Frequency ${ }^{3}$ - Laboratory Astrophysics ${ }^{3}$ - Cryogenics $^{3}$.

THE INSTITUTE FOR MATERIALS RESEARCH conducts materials research leading to improved methods of measurement, standards, and data on the properties of well-characterized materials needed by industry, commerce, educational institutions, and Government; provides advisory and research services to other Government agencies; and develops, produces, and distributes standard reference materials. The Institute consists of the Office of Standard Reference Materials and the following divisions:

Analytical Chemistry-Polymers-Metallurgy-Inorganic Materials-Reactor Radiation-Physical Chemistry.

THE INSTITUTE FOR APPLIED TECHNOLOGY provides technical services to promote the use of available technology and to facilitate technological innovation in industry and Government; cooperates with public and private organizations leading to the development of technological standards (including mandatory safety standards), codes and methods of test; and provides technical advice and services to Government agencies upon request. The Institute also monitors NBS engineering standards activities and provides liaison between NBS and national and international engineering standards bodies. The Institute consists of a Center for Building Technology and the following divisions and offices:

Engineering Standards Scrvices-Weights and Measures-Invention and Innovation-Product Evaluation Technology-Electronic Technology-Technical Analysis-Measurement Engincering-Fire Technology-Housing Technology ${ }^{4}$ -Federal Building Technology ${ }^{4}$-Building Standards and Codes Services ${ }^{4}-$ Building Environment ${ }^{4}$-Structures, Materials and Life Safety ${ }^{4}$-Technical Evaluation and Application ${ }^{4}$.

THE CENTER FOR COMPUTER SCIENCES AND TECHNOLOGY conducts research and provides technical services designed to aid Government agencies in improving cost effectiveness in the conduct of their programs through the selection, acquisition, and effective utilization of automatic data processing equipment; and serves as the principal focus within the executive branch for the development of Federal standards for automatic data processing equipment, techniques, and computer languages. The Center consists of the following offices and divisions:

Information Processing Standards-Computer Information-Computer Services -Systems Development-Information Processing Technology.

THE OFFICE FOR INFORMATION PROGRAMS promotes optimum dissemination and accessibility of scientific information generated within NBS and other agencies of the Federal Government; promotes the development of the National Standard Reference Data System and a system of information analysis centers dealing with the broader aspects of the National Measurement System; provides appropriate services to ensure that the NBS staff has optimum accessibility to the scientific information of the world, and directs the public information activities of the Bureau. The Office consists of the following organizational units:

Office of Standard Reference Data-Office of Technical Information and Publications-Library-Office of International Relations.

${ }_{1}$ Headquarters and Isaboratories at Gaithersburg, Maryland, unless othewise noted; mailing address W'ashington, D.C. 20234.

2 Part of the Center for Radiation Research.

3 Located at Bonlder, Colorado 80302.

- Part of the Center for Bullaing 'Vechnology. 


\title{
On the Utility of the $m-6-8$ Potential Function
}

\author{
H.J.M. Hanley
}

Cryogenies Division

Institute for Basic Standards

National Bureau of Standards

Boulder, Colorado 80302

Max Klein

Heat Division

Institute for Basic Standards

National Bureau of Standards

Washington, D.C. 20234

NBS Technical notes are designed to supplement the Bureau's regular publications program. They provide a means for making available scientific data that are of transient or limited interest. Technical Notes may be listed or referred to in the open literature.

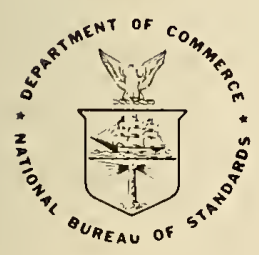

U.S. DEPARTMENT OF COMMERCE, Peter G. Peterson, Secretary NATIONAL BUREAU OF STANDARDS, Lawrence M. Kushner, Acting Director Issued November 1972 
National Bureau of Standards Technical Note 628 ,

Nat. Bur. Stand.(U.S.), Tech. Note 628, 77 pages (November 1972) CODEN: NBTNAE

For sale by the Superintendent of Documents, U.S. Government Printing Office, Washington, D. C. 20402 (Order by SD Catalog No. C13.46:628) 


\section{CONTENTS}

Page

1. Módel Potential Functions .................... . . . 1

2. The Four-Parameter, m-6-8, Potential ............ 4

2.1 Definition of the Reduced m-6-8 Potential . . . . . . . . 5

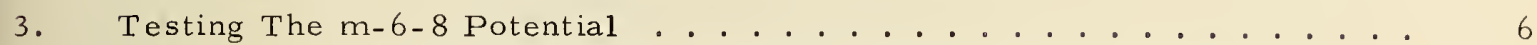

3.1 Fit to a Single Property: Satisfaction of Requirement (1),

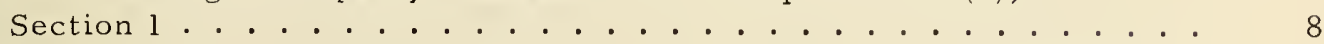

3.2 Simultaneous Fit of the Viscosity and Second Virial Coefficients:

Satisfaction of Requirement (2), Section l ......... 10

3.3 Deviation Curves for Argon . . . . . . . . . . . 12

4. Further Checks on the Use of the 11-6-8 $(\gamma=3.0)$ Potential for

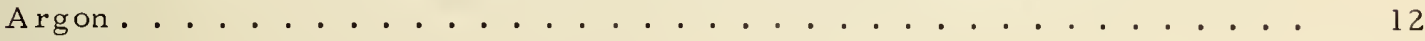

5. Tests on the Validity of the 11-6-8 $(\gamma=3.0)$ Potential ......... 14

5.1 Repulsion: The Potential for $r<\sigma \ldots \ldots 15$

5.2 Attraction: A Comparison of the Dispersion Coefficients . . . . 15

6. Application of the m-6-8 Potential to Krypton and Xenon . . . . . . 17

6.1 Deviation Curves for Krypton and Xenon . . . . . . . . . 18

7. Application to Polyatomic Molecules . . . . . . . . . . . 18

7. 1 Simultaneous $F$ it of the Second Virial Coefficient and Viscosity

Coefficient for Nitrogen . . . . . . . . . . . . . 19

7.2 Fits to Single Properties: The Viscosity Coefficient and the

Second Virial Coefficient . . . . . . . . . . . 19

7.3 Fits for Methane, Oxygen and Carbon Dioxide . . . . . . . 20

8. Kinetic Theory of Polyatomic Molecules . . . . . . . . . . . . 20

8. 1 Inelastic Collisions . . . . . . . . . . . . . . . 20

8.2 Nonspherical Potentials . . . . . . . . . . . . . 21

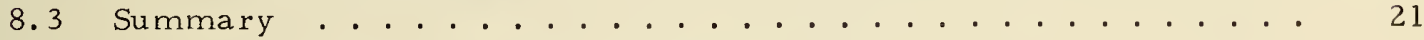

9. Thermal Conductivity of Polyatomic Molecules . . . . . . . . . 2 21

10. Thermal Diffusion of Polyatomic Molecules . . . . . . . . . . . 23

11. Conclusion . . . . . . . . . . . . . . . . . . 23

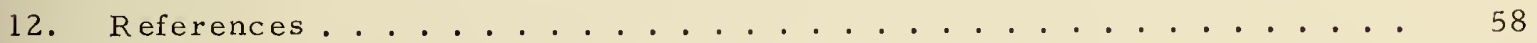

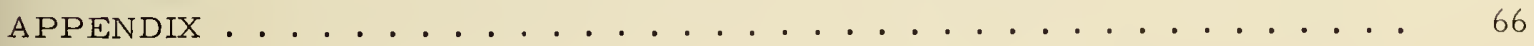


1. Plots of the m-6-8 potential computed from eq (10) to illustrate how the attractive part varies with (a) an increase in $m$ at fixed $\gamma$, (b) an increase in $\gamma$ at fixed $m . . . . . . . . . . .$.

2. Schematic plot of the solution of eq (13) for temperatures $\mathrm{T}_{1}, \mathrm{~T}_{2}, \mathrm{~T}_{3}$, and $\mathrm{T}_{4}$ given a potential function. The point at each temperature corresponds to the $b_{o}$ and $\epsilon / k$ values which give a simultaneous fit of the viscosity coefficient and second virial coefficient at that temperature .....................

3. Solutions of eq (13) for argon at several experimental temperatures for the m- 6 potential function. Note the "turn around," with respect to temperature, of the solutions at $129.56 \mathrm{~K}$ and $143.16 \mathrm{~K}$, circled in the

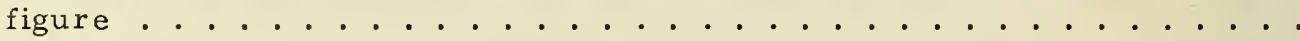

4. Solutions of eq (13) for argon at several experimental temperatures as in figure 3 . Note the very small area given by the 11-6-8 with $\gamma=3.0 \ldots \ldots \ldots \ldots . . \ldots \ldots$

5. Continuation of figure 4. Note the "turn around" for the 12-6-8,

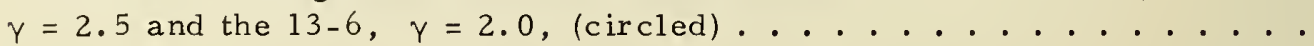

6. Deviation plot of experimental second virial coefficients for argon [17] compared to (corresponding) values determined from eq (12) using the $m-6-8$ potential with $m=11, \gamma=3.0, \sigma=3.292 \AA$, $\epsilon / k=153 \mathrm{~K} \ldots \ldots \ldots \ldots$

7. Percentage deviation plot of experimental dilute gas viscosity coefficients of argon compared to theoretical values determined from eq (11) with the $m-6-8$ potential: $m=11, y=3.0, \sigma=3.292 \AA$, $\epsilon / k=153 \mathrm{~K}$. Data $0[13], \Delta[14], \square[15], \nabla[16], \diamond[19], \bullet[20]$, $\Delta[21]$; not distinguished $[22,23] \ldots \ldots$

8. Percentage deviation plot of experimental dilute gas thermal conductivity coefficients for argon compared to eq (14) with the m-6-8 potential as for the viscosity and second virial coefficients.

$\bullet[25], \nabla[26], \diamond[27], \nabla[28], \nabla[29], \diamond[30], 0[31], \square[32]$, $\Delta[33], \ominus[34], \Delta[35] \ldots \ldots \ldots \ldots$

9. Percentage deviation plot of experimental self-diffusion coefficients of argon compared to theoretical values determined from eq (15) with the m-6-8 potential as for the viscosity and second virial coefficient $\Delta[36], \square[37], 0[38]$. Note: the data from [37] is relative to $\mathrm{D}$ at $298.15 \mathrm{~K}$. We used the calculated value for this reference point . . . . . . . . . . . . . . . .

10. Experimental and theoretical [eq (16)] thermal diffusion factors for argon. Data from [39]. We use the same m-6-8 potential as for the other transport coefficients................ 
11. The repulsive potential at small values of $r$. We compare the 11-6-8 $(\gamma=3.0)$ potential, found to be satisfactory for the dilute gas properties of argon, with the potential estimated from high energy scattering of beams of neutral argon atoms [41]. Also shown, as a matter of interest, are the curves for the well-known 12-6 and 18-6 potentials. [This latter represents the best three-parameter potential $\mathrm{fit}$ for argon at low temperatures]. . . . . . . . . .

12. Deviation plots for the second virial and viscosity coefficients of argon based on the m-6-8 potential with the inverse sixth power coefficient fixed at $\sim 60 \times 10^{-60} \mathrm{ergs} / \mathrm{cm}^{6}: \mathrm{m}=11, \gamma=2.0$, $\sigma=3.356 \AA, \epsilon / k=137 \mathrm{~K}$. Data not distinguished ..........

13. The m-6-8 potential with $m=11, \gamma=2.0, \sigma=3.356 \AA$ and $\epsilon / k=137 \mathrm{~K}$. This potential is the best potential that we have obtained which can approximately fit both the viscosity and second virial coefficient for argon and which gives approximately the correct coefficient for the sixth power dispersion term $\left(\mathrm{C}_{6}\right)$. Also shown is the multiparameter potential of Barker [43] for which $\mathrm{C}_{6}$ was chosen to be correct. . . . . . . . . . . . . . .

14. Deviation curves for the viscosity and second virial coefficients of krypton. Data for viscosity, $0[14], \Delta[15], \nabla[16], \square[44]$. Theoretical values determined for eqs (11) and (12) with the m-6-8 potential, parameters as given in table $1 \ldots . . . .$.

15. Deviation curves for the viscosity and second virial coefficients of xenon. Data for viscosity, $0[14], \Delta[15], \square[45], \nabla[46,47]$. See table $1 \ldots \ldots \ldots$

16. Deviation curve for the thermal conductivity of krypton. Theoretical values calculated in eq (14) with parameters given in table 1. Data: $[31], \bullet[35], 0[48], \Delta[49], \nabla[50], \square[51] \ldots . . .$.

17. Deviation curve for the thermal conductivity of xenon. Theoretical values calculated in eq (14) with parameters given in table 1. Data: $\quad[31], 0[48], \Delta[49], \nabla[50], \diamond[51], \square[52] \ldots . .$.

18. The isotopic thermal diffusion factor for krypton calculated from eq (16), using parameters given in table 1 , compared to

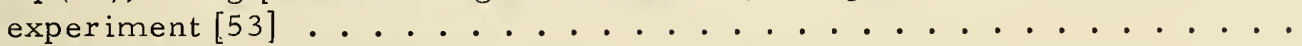

19. The isotopic thermal diffusion factor for xenon calculated from eq (16), using parameter given in table 1 , compared to

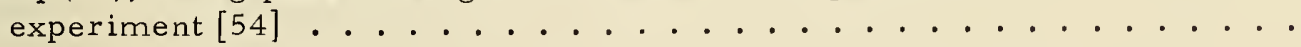

20. Deviation curve for the self-diffusion coefficient of krypton from eq (15) with the parameters given in table 1 , experiment from [55] . . . 
21. Deviation curves for the viscosity and second virial coefficients of nitrogen based on a simultaneous fit. Parameters: $m=10$, $\gamma=1.0, \sigma=3.694 \AA$ and $\epsilon / k=87.0 \mathrm{~K}$. Data (not distinguished):

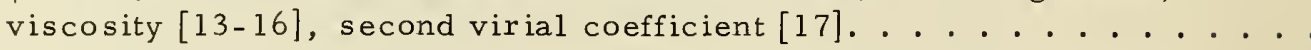

22. Fits of the viscosity and second virial coefficients of nitrogen based on a $\mathrm{fit}$ of the viscosity data. Parameters $m=12, \gamma=2.0$, $\sigma=3.54 \AA, \epsilon / k=118.0 \mathrm{~K}$. Viscosity data, $\nabla[13], \Delta[14], \square[15]$, $0[16], \square[22], \diamond[56], \Delta[57], \bullet[58] \ldots . . . . . . . .$.

23. Deviation curves for the viscosity and second virial coefficients of nitrogen based on a fit of the second virial coefficient alone. Parameters, $m=12, \gamma=2.0, \sigma=3.60 \AA, \epsilon / \mathrm{k}=118.0 \mathrm{~K}$. Note (a) the unusual deviation pattern for the viscosity, (b) that the potentials used here and in figure 22 differ only by a small a mount in $\sigma \ldots \ldots \ldots \ldots$

24. Deviation curve for the viscosity of methane based on the fit of viscosity data alone. Parameters, $m=11, \gamma=3.0, \sigma=3.68 \AA$, $\epsilon / \mathrm{k}=168 \mathrm{~K}$. Note that we have fitted both high and low temperature data with one set of parameters. Data: $0[56], \Delta[60]$, $\Delta[61], \square[63] \ldots \ldots \ldots \ldots$

25. Deviation curve for the viscosity of oxygen based on the fit of viscosity alone. Parameters, $m=10, \gamma=1.0, \sigma=3.437 \AA$, $\varepsilon / \mathrm{k}=113 \mathrm{~K}$. IMPORTANT NOTE: Some of the data have been adjusted. See the Appendix. Data: $\nabla[22], 0[47], \Delta$ [56 adjusted]. Not shown $[65,66] \ldots \ldots \ldots$

26. Deviation curve for the viscosity of carbon dioxide based on a fit of viscosity data alone. Parameters, $m=14, \gamma=1.0, \sigma=3.68 \AA$,

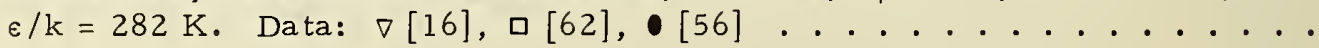

27. Deviation curve for the thermal conductivity of nitrogen based on the parameters found for viscosity. Calculated via eq (29). Potential parameters: Table 2. Data, 0 [27], $\nabla[28], \diamond[32], \bullet[35]$, $\Delta[70], \Delta[71], \nabla[72], \diamond[73], \diamond[74], \bullet[75], \Delta[76], \Delta[77] . . . .$.

28. Deviation curve for the thermal conductivity of oxygen based on the viscosity parameters, table 2. Calculated via eq (29). Data: 0 [27], $\Delta[78-80], \triangleleft[82], \square[81], \nabla[83], \Delta[74], \bullet[85], \square[84], \diamond[75] . . .$.

29. Deviation curve for the thermal conductivity of methane calculated via eq (29). Potential parameters from viscosity, table 2. Data: $0[27], \diamond[32], \square[81], \nabla[87], \Delta[88]$. Not shown [86], [34] ......

30. Isotopic thermal diffusion factor for nitrogen calculated from eq (16) with the potential parameters used for viscosity. Data from reference [92] . . . . . . . . . . . . . . . 
31. Isotopic thermal diffusion factor for oxygen calculated from eq (16) with the viscosity potential parameters. Data from

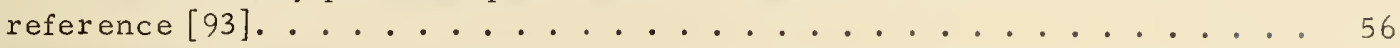

32. Isotopic thermal diffusion factor for carbon dioxide calculated from eq (16) with the viscosity potential parameters. Data from reference [94]. . . . . . . . . . . . . . . .

A1. Deviation plot between modern data for argon (open circles) and older data for argon (closed circles). Similar deviation curves could be constructed for most other common gases. We demonstrate this in the figure by showing representative deviations for helium, neon, krypton, xenon, air, methane and nitrogen (triangles)...... 68

List of Tables

Table

1. Values of the parameters of the m-6-8 potential function which fit both transport and equilibrium properties . . . . . . . . . .

2. Values of the parameters of the m-6-8 potential function which

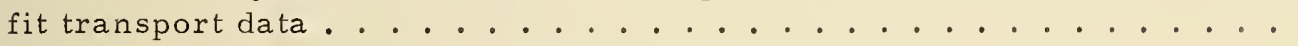

Al. Adjusted experimental viscosities for oxygen . . . . . . . . . . . 67 


\title{
ON THE UTILITY OF THE m-6-8 POTENTIAL FUNCTION*
}

\author{
H. J. M. Hanley ${ }^{\dagger}$ and Max Klein ${ }^{\dagger+}$
}

The calculation of transport and equilibrium properties of simple gases with the m-6-8 potential function is discussed. Properties referred to specifically are the viscosity, diffusion, thermal conductivity and second virial coefficients, and the thermal diffusion factor. Gases referred to are argon, krypton, xenon, nitrogen, oxygen, carbon dioxide and methane. We also discuss in detail the general behavior of a model potential with respect to the fitting of data and the selection of potential parameters. The $m-6-8$ appears to be the simplest model potential which can satisfactorily be used to fit data over a wide temperature range. The relationship of the potential to independent theory is briefly examined.

Key words: Dispersion coefficients; m-6-8 potential; parameter selection; second virial coefficients; transport properties.

*

This work was carried out at the National Bureau of Standards and supported by the Office of Standard Reference Data.

$+$

Cryogenics Division, Institute for Basic Standards, National Bureau of Standards, Boulder, Colorado 80302 .

t† Heat Division, Institute for Basic Standards, National Bureau of Standards, Wa shington, D. C. 20234. 


\section{Model Potential Functions}

In this paper we discuss a new model potential function, the m-6-8, and demonstrate how it can be used to correlate and predict experimental data. Before going into any details, however, we would like to review very briefly the general development of model functions and their relationship to experiment and statistical mechanics.

Roughly speaking, the evolution of model potential functions parallels theoretical developments in molecular structure and intermolecular forces. For example, the simplest concept of molecular structure is that of the hard spherical molecule and the corresponding potential accounts only for repulsion between molecules on contact. The potential has one parameter, the effective diameter of the spheres. While this concept is obviously too simple -- it cannot, for example, explain the stability of solids and liquids, or give a temperature dependence to the second virial coefficient - - it was nevertheless very useful, and remains so today. The hard sphere model can be modified to incorporate a simple inverse power repulsive term consistent with the picture of a "soft" repulsive spherical molecule whose diameter decreases as the energy of the molecular system increases.

Realistic potentials have to consider both the repulsion and attraction between molecules. This could be taken into account by using inverse power potentials of the type

$$
\Phi(r)=A / r^{m}-C / r^{n}
$$

generally associated with the name of Lennard-Jones. Here $\Phi(r)$ is the potential, a function of intermolecular separation, $r$, while $m$ and $n,(m>n)$ are fixed at arbitrary values, and $A$ and $C$ are parameters to be found from experiment. One method for finding such parameters is described below.

Several authors have attempted to be more specific by predicting values for $m$ and $n$. For example, details of the attraction between molecules were developed from quantum mechanical perturbation theory, i.e., attraction was seen to be equivalent to the concept of induced molecular polarizability. Specifically, quantum mechanics shows that the leading term of the induction effect varies as the inverse sixth power of $r$ thus suggesting that the attractive index, $\mathrm{n}$ of eq (1), should be taken as 6 . It is not possible, however, to come up with a satisfactory a priori value for the repulsive index $m$ from quantum mechanics, so $m$ is often taken to be 12 for mathematical convenience. With this choice of $\mathrm{m}$, we have the 12-6 or, as it is usually known, the Lennard-Jones potential:

$$
\Phi(r)=A / r^{12}-C_{6} / r^{6}
$$


where $\mathrm{A}$ and $\mathrm{C}_{6}$ - - the coefficients of $\mathrm{repulsion}$ and inverse sixth attraction, respectively -- are two parameters to be found from experiment as before. This potential has been the standard for many years and still serves as the model potential for many molecular theories.

In the last fifteen years or so, several three-parameter potential families have been proposed which try to add flexibility to the 12-6. Most often, the inverse sixth term is retained for the attraction but an extra parameter is introduced for the repulsion. The simplest example is the m-6 family of potentials with the form of eq (la) but m replacing the index 12 as a parameter; $m$ has then to be found from experiment along with $A$ and $\mathrm{C}_{6}$. Other examples of such three parameter potentials are the Kihara, the exp:6, and the Morse potentials [1] ${ }^{*}$. Unfortunately, the application of the three-parameter families to experiment often gave misleading or even erroneous results: thus, there seemed to be no definite criteria to judge how effectively a potential represented a given property -- in many cases, even, it was not clear if the introduction of the extra parameter led to a fit between theory and experiment which was an improvement over the corresponding fit with the 12-6. Consequently, it also was difficult to say which of the new three-parameter potential families was the most generally useful.

To try to clear up some of the confusion, we undertook a study [1-3] to investigate the relationship between certain experimental properties and the potential function as required by statistical mechanics. The main results of the study are of interest to the present work so they are discussed briefly here.

First of all, we found that temperature ranges exist for different properties in which these properties are only sufficiently sensitive to the details of the function to produce information about two parameters: in other words, in these temperature ranges, the properties are insensitive to any extra parameters which might be introduced. For equilibrium properties this range is, in reduced form, approximately

$$
2 \leq T_{12-6}^{*} \leq 10
$$

and for transport properties the range is approximately

$$
2 \leq \mathrm{T}_{12-6}^{*} \leq 5
$$

\footnotetext{
Numbers in brackets $r$ efer to references given at the end of the paper.
} 
where $\mathrm{T}_{12-6}^{*}=\mathrm{T} /\left(\epsilon_{12-6} / \mathrm{k}\right)$ with $\mathrm{T}$ the temperature in kelvin, $\mathrm{k}$ Boltzmann's constant and $\epsilon_{12-6}$ the maximum potential energy of attraction for the Lennard-Jones, $12-6$ potential $[4]$.

The definition of the insensitive temperature range enabled us to give a quantitative significance to the terms "high" and "low" temperature's - - terms which are important in discussions of the limiting behavior of potential functions. Thus, a high temperature is a temperature above $\mathrm{T}_{12-6}^{*} \approx 10$ for equilibrium properties (or 5 for transport properties) while a low temperature is a temperature below $\mathrm{T}_{12-6}^{*} \approx 2$.

Note that the insensitive temperature range covers the normal experimental range for most simple substances (e.g., the second virial coefficients of argon, oxygen, or nitrogen are insensitive to more than two parameters in the potential function in the temperature range $200 \lesssim T(K) \lesssim 1000$ ). In our opinion, many authors were not familiar with the insensitive temperature ranges and this lack of awareness led to most of the confusion in dealing with three-parameter functions. For example, use of data in the insensitive range alone often forces a decision in favor of one potential function based, in the final analysis, on the particular methods used for treating the experimental errors. The selection of the potential function can therefore be made on a totally irrelevant basis.

As a second result of our study, we found that all three-parameter function families are essentially equivalent as far as fitting low density data is concerned. This particular result can be used to advantage since one can choose any convenient threeparameter family, say the m-6, to be typical of all three-parameter functions. We have often done this in our previous work [3].

A third, and more negative, conclusion drawn was the clear recognition that the three-parameter functions, while an improvement over the two-parameter 12-6, were still not flexible enough to fit data as one would like. In particular, they failed to satisfy two important requirements:

(1) The ability to correlate data for a given substance and property at high and at low temperatures with the same set of parameters.

and

(2) The ability to correlate, for a given substance, two different properties using the same set of parameters in a sensitive temperature range. 
Other multiparameter functions, where the parameters are related to theory as far as possible, have been proposed by several authors. One recent attempt is that of Barker and Pompe [5]. Essentially, their potential is based on a series of exponential terms for the repulsion, which are determined empirically, along with a series of inverse powers for the attraction, which are estimated from quantum mechanical dispersion theory.

An alternative technique for developing a multiparameter function is to start with a large drawing of a reasonable potential and then, using tabular values read off the drawing, fit different properties simultaneously. By modifying the potential graphically in some consistent manner until the best overall agreement between theory and experiment is obtained [6,7], a function might possibly be selected out whose shape closely approaches that of the "actual" potential function. See in particular, the work of Dymond and Alder [7].

This covers a brief outline of the potential models used up to the time this work was undertaken. Very recently, potential functions have been determined from low energy scattering experiments and from spectroscopy. See, for example, reference [99].

\section{The Four-Parameter, m-6-8, Potential}

Although generally successful, the complex potentials, such as the multiparameter semi-theoretical potential of Barker and Pompe, or the numerical potential of Dymond and Alder, are very specialized. These potentials are derived for a particular substance and are not always easy to generalize to other substances. It is also not easy to take into account possible changes either in the assumptions or in the data on which these functions are based. We felt that one had to compromise between these somewhat inflexible complex potentials and procedures on the one hand, and the more flexible but over-simplified three-parameter functions on the other hand. Our approach is straightforward: we consider the addition of only one parameter to the three-parameter models used previously and, furthermore, select a parameter with a reasonable physical basis.

Extension of quantum mechanical perturbation theory indicates that, for separated molecules, the attractive part of the intermolecular potential function should be described by a series of inverse powers of the intermolecular distance, the first term of which depends on the inverse sixth power of the intermolecular separation, as already mentioned. The next term of the series depends on the inverse eighth power and is, therefore, a logical choice for an additional term for a model potential. Theoretical estimates have been made of the relative magnitudes of the coefficients of the inverse eighth and inverse sixth power terms for a number of substances [107], which enables one to introduce an inverse eighth power dependence in terms of the coefficient of the inverse sixth power 
term without additional parameterization. However, since the validity of the se theoretical estimates has not been clearly established, this cannot be done with certainty. It seems reasonable, therefore, to add an inverse eighth power term but to take the corresponding coefficient as an additional potential parameter, thereby defining a four-parameter function family.

The particular choice of a three-parameter potential function on which to add an inverse eighth power attraction is arbitrary because, as we have pointed out, all of the three-parameter functions are equivalent from the point of view of correlating data. The equivalence shows up especially in the arbitrary choice of the repulsive terms. One could argue, however, based on our knowledge of high energy scattering data, that a shielded coulomb form for this repulsion would be most suitable. Nevertheless, we decided to continue to use the single term inverse power repulsion contained in the m-6 function. This choice was made because (a) such a form is simple, and (b) adding an inverse eighth power to an m-6 potential is a natural extension of the work we already have done with the $m-6$.

\section{1 Definition of the Reduced m-6-8 Potential}

The definition of the m-6-8 potential follows from eq (1):

$$
\Phi(r)=A / r^{m}-C_{6} / r^{6}-C_{8} / r^{8}
$$

where $m$ is the repulsive index, and $A, C_{6}$, and $C_{8}$ are the coefficients for repulsion and for the sixth and eighth power attraction terms respectively. We introduce the more convenient reduced form of potential (3) as follows.

If $r_{m}$ denotes the intermolecular separation at the maximum attractive energy, then we define $\Phi\left(r_{m}\right)=-\epsilon$. Using that at $r_{m}, d \Phi / d r=0$, one can show that

$$
\Phi(r)=\frac{m \epsilon}{m-6} x+\frac{C_{8}}{r_{m}^{8}}\left(\frac{1}{m-6}\right) y-\frac{C_{8}}{r_{m}^{8}}\left(\frac{1}{r^{\prime}}\right)^{8}
$$

where

$$
\begin{aligned}
& x=\frac{6}{m}\left(\frac{1}{r^{\prime}}\right)^{m}-\left(\frac{1}{r^{\prime}}\right)^{6} \\
& y=2\left(\frac{1}{r^{\prime}}\right)^{m}+(m-8)\left(\frac{1}{r^{\prime}}\right)^{6}
\end{aligned}
$$


with $r^{\prime}=r / r m^{\prime}$. We now define a parameter, $\gamma$, characteristic of the inverse eighth term,

$$
Y=-C_{8} / \in r_{m}^{8}
$$

thus

$$
\Phi(r)=\frac{\epsilon}{m-6}[6+2 \gamma]\left(\frac{1}{r^{\prime}}\right)^{m}-\frac{\epsilon}{m-6}[m-\gamma(m-8)]\left(\frac{1}{r^{\prime}}\right)^{6}-\epsilon \gamma\left(\frac{1}{r^{\prime}}\right)^{8}
$$

The potential is given in eq (8) in terms of $r^{\prime}$, i.e., scaled by $r_{m}$ ' but it is frequently more convenient to work in terms of the effective hard sphere diameter, $\sigma$, defined by $\Phi(\mathrm{r})=0$. Introduction of the definitions

$$
\mathrm{d}=\mathrm{r}_{\mathrm{m}} / \sigma \text { and } \mathrm{r} *=\mathrm{r} / \sigma
$$

then converts eq (8) into

$$
\Phi *(r *)=\frac{[6+2 y]}{m-6}\left(\frac{d}{r *}\right)^{m}-\frac{[m-\gamma(m-8)]}{m-6}\left(\frac{d}{r *}\right)^{6}-\gamma\left(\frac{d}{r *}\right)^{8}
$$

where we have defined $\Phi *(r *)$ as $\Phi(r *) / \epsilon$. Potentials $(8)$ and $(10)$ are, of course, equivalent. Care must be taken, however, when converting from one form to the other to ensure that the factor $d$ is used properly. We will work with potential (10).

The m-6-8 potential is sketched in figure l. Figure la shows how the attractive part is affected by an increase in $m$ with $\gamma=0.0$. Figure $1 b$ shows how the attractive part is affected by increasing $\gamma$ with $m$ constant. Note that increasing $\gamma$ at constant $m$ has roughly the same effect as increasing $m$ at constant $\gamma$. [We have not shown the associated small changes in the repulsive part of the potential, such changes being very small when compared to the changes in the attractive part.]

\section{Testing The m-6-8 Potential}

We next outline our approach for testing the potential. We clarify what we propose to do: Any potential function obtained from fitting data alone is only the "best" function associated with a particular functional form, a particular set of experimental data, and a particular criterion of best fit. A successful potential function, from a correlation point of view, is therefore not necessarily a valid one from a theoretical viewpoint, although the reverse must always be true, i.e., a valid theoretical potential must, of necessity, correlate good data. When testing with experimental data, we therefore refer to testing 
the utility of a function rather than testing its validity. Of course, if the potential parameters are then found to be compatible with independent theoretical estimates, the potential takes on a significance beyond its ability to fit the data.

Substances: Since the potential function assumied is spherical, the necessary first test has to be made with monatomic molecules because the potential function can, in principle, describe the interactions between such molecules without further approximation. [Non-sphericity not only involves the potential function, but also a description of the interactions between the internal degrees of freedom of the molecules.] We exclude quantum fluids for now. Hence, initial tests should be made with argon, krypton and xenon. Of these, argon is the most convenient because argon data for several properties are available outside the reduced insensitive temperature ranges defined by eq (2). Since this is not always the case for the heavier rare gases, much of this paper will refer to comparisons between predicted and experimental values for argon.

Properties: There are a number of fundamental theoretical expressions which give macroscopically measurable properties in terms of potential functions and which can, in principle, be used to test the utility of such potentials. Only a few of these are practical, however. The reason is simply that the corresponding experimental data must be available and, furthermore, must be precise enough to allow for a choice to be made among potential functions $[1-3,9]$. In practice, the usable expressions are those for the viscosity coefficient, $\eta$, and the second virial coefficient, $B$. Of the two, the viscosity is usually to be preferred since the insensitive range, eq (2), covers a smaller range of temperature than does the corresponding range for the second virial. Thus, data for a given substance covering a given experimental temperature range are more likely to overlap both high and low temperature regions for the viscosity coefficient than for the second virial coefficient. This must, however, be balanced against the fact that, of the two properties, the second virial coefficient is the more sensitive to the potential at low temperatures.

The expressions connecting these quantities with the potential function are [10]: Viscosity (to the first Chapman-Enskog approximation [11])

$$
\eta=\frac{5}{16} \frac{\sqrt{\pi m k T}}{\pi \sigma^{2} \Omega^{(2,2) *}(T *)}
$$




$$
\mathrm{B}=\mathrm{b}_{\mathrm{O}} \mathrm{B} *(\mathrm{~T} *)
$$

where

$$
b_{0}=\frac{2}{3} \pi N \sigma^{3}
$$

In eqs (11) and (12), the intermolecular potential function enters via $\Omega^{(2,2) *}(\mathrm{~T} *) \ldots$ the collision integral accounting for the dynamics of a binary collision in the viscosity process, and $B *(T *)$ - - the reduced second virial coefficient. For a given potential function, $\Phi(r)$, both $\Omega^{(2,2) *}(T *)$ and $B *(T *)$ can be calculated as functions of $T *$, where $\mathrm{T}^{*}=\mathrm{T} /(\epsilon / \mathrm{k})$ with $\epsilon$ the maximum well-depth for the given potential. Also, in these equations, $m$ is the mass of a molecule, $N$ is Avagadros' number and $\sigma$ has been defined previously.

Data: The argon data selected for test purposes [12] were extracted from the following sources: viscosity [13-16]; second virial [17]. We have carefully evaluated these data and they appear to be the best available at this time. There are problems, nevertheless: values of both the viscosity and second virial coefficients at the lower temperatures $(T \lesssim 100 \mathrm{~K})$ remain uncertain. Also, the reliability of the published viscosity coefficients at high temperatures has been questioned recently. [This latter problem, however, now seems resolved [12].]

\section{Collision Integrals and Reduced Second Virial Coefficients: Collision integrals} and reduced second virial coefficients have been computed for the m-6-8 potential with $9 \leq m \leq 18$ for values of $\gamma$ such that $0 \leq[m-\gamma(m-8)]$. The calculation procedure and tables are available in another publication [8].

\subsection{Fit to a Single Property: Satisfaction of Requirement (1), Section 1}

We began our investigation by studying how the $m-6-8$ potential can be used to fit a single property, namely the viscosity. The dilute gas viscosity coefficients were examined separately at low temperatures, at high temperatures, and at all temperatures.

Several techniques are available for optimizing potential function parameters. For example, one can select the parameters which give the best fit of theory to experime according to least squares. We use a graphical technique, however, which we have four to be both successful and instructive. To illustrate this approach, let us first consider argon viscosity data in a given temperature range. 
In our fitting procedure, a potential with particular values of $m$ and $Y$ is first selected, i.e., only $\varepsilon$ and $\sigma$ are to be varied initially. $\sigma$ is then also fixed initially at some sensible preliminary value. This leaves only $\epsilon$ to be determined. Let us consider a particular experimental temperature $T$. Given experimental data for $\eta$ and $T$ and the initial choice of $\sigma$, eq (11) can be used to obtain an experimental reduced collision integral $\Omega^{(2,2) *}$ at that value of $T$. Our purpose is to make a correspondence between such "experimental collision integrals" obtained at the experimental temperatures and calculated from (11), and those calculated theoretically (as in [8]) for the particular choice of $m$ and $\gamma$ at theoretical temperatures $T *$. The correspondence results in a value of $\epsilon / k$ for the given experimental temperature $T$ from the relation between $T$ and $T *$. This is accomplished by interpolating in the calculated set listed as a function of $T *$ for the $m$ and $\gamma$ values chosen for the value of the "experimental collision integral" found using (11). Using the value of $T^{*}$ corresponding to this value of the theoretical collision integrals, the experimental temperature $T$ and the relation $\epsilon / k=T / T *$, a value of $\epsilon / k$ is obtained for T. Proceeding in this way for all of the experimental temperatures, we then obtain $\epsilon / k$ as a function of $T$. If, now, the value taken for $\sigma$ is changed, a second set of values of $\epsilon / \mathrm{k}$ is obtained as a function of $\mathrm{T}$. Proceeding in this way a set of curves is obtained, one for each value of $\sigma$. These curves represent the variation of $\epsilon / k$ with $T$ and $\sigma$ for the given choices of $m$ and $\gamma$. Now, if the potential function were valid and the "correct" value of $\sigma$ used, $\epsilon / k$ would not vary with temperature. Hence, a reasonable criterion for selecting the best $\sigma$ value is to choose that one which is associated with the least variation of $\epsilon / k$ with $T$. The appropriate value of $\epsilon / k$ to take is one within its range of variation with $T$ for that $\sigma$. Thus, this procedure leads to a best pair, $\varepsilon / k$ and $\sigma$, for the particular $m$ and $\gamma$. By repeating the process for different $m, \gamma$ pairs, one can select the $\sigma, \epsilon / \mathrm{k}, \mathrm{m}, \gamma$ combination which gives the smallest overall variation of $\epsilon / k$ with temperature.

\section{$\underline{\text { Results }}$}

Both at high and at low temperatures, fitted separately, we were able to find several sets of $\mathrm{m}, \gamma$ and $\sigma$ which gave a constant $\epsilon / \mathrm{k}$ (constant within experimental error). This is just the kind of result found with the three-parameter functions. We were, however, able to reduce the possibilities to a single set of $\mathrm{m}, \gamma$, $\sigma$ by requiring that the same values of $\sigma$ and $\epsilon / k$ be applicable to both high and low temperatures. Values thus obtained for argon were $\mathrm{m}=11, \gamma=3.0, \sigma=3.29 \AA, \epsilon / \mathrm{k}=153 \mathrm{~K}$ (1 $\left.\AA=10^{-10} \mathrm{~m}\right)$.

This result was encouraging since it meant that the m-6-8 potential can satisfy requirement (1) of Section 1 - - the simplest function found thus far to do so. It is 
important to remark, however, that, in order to do this, data are required for both the high and low temperature ranges. In other words, a fit of data at low temperatures only is not necessarily applicable to data at high temperatures, and vice versa.

\subsection{Simultaneous Fit of the Viscosity and Second Virial Coefficients:}

Satisfaction of Requirement (2), Section 1

In a previous paper [2] we mentioned another graphical and interpolation scheme whereby a simultaneous fit of the viscosity and second virial coefficient for a given gas could be used to give potential parameters and which would, at the same time, demonstrate how the fit was modified as the parameters change. This discussion is repeated briefly here.

From eqs (11) and (12), one can obtain a single relation which needs to be satisfied for a simultaneous fit of the experimental second virial and viscosity coefficients at the experimental temperature, T. This relation is

$$
\frac{\eta(T)^{3 / 2} B(T)}{T^{3 / 4}}=\frac{K M^{3 / 4} B *(T *)}{\Omega^{(2,2) *(T *)}}
$$

where $K$ is a constant: $K=137.93 \times 10^{-10} \mathrm{c.g} . \mathrm{s} .$, units, and $M$ is the molecular weight. The left-hand-side of eq (13) is a function of the experimental temperature, T, whereas the right-hand-side is a function of the reduced temperature, $T *$. The equation is used as follows: We tabulate the right-hand-side as a function of $\mathrm{T} *$ for a chosen potential. At a given experimental temperature, $T_{1}$, the left-hand-side is evaluated from experiment. By interpolation in the values tabulated for the right-hand-side, a value of $T *$, say $T_{1} *$, is obtained for which the right-hand-side of (13) equals the left-handside. Using $\epsilon / k=\mathrm{T}_{1} / \mathrm{T}_{1} *$ we thus find $\epsilon / \mathrm{k}$ at $\mathrm{T}_{1}$ and also the corresponding value of $\sigma$ (or $b_{0}$ ) from either eq (11) or (12). In a graphical sense, the pair of values $\sigma$ (or $b_{0}$ ) and $\epsilon / k$ can be represented by a point in a graph having $\sigma$ (or $b_{0}$ ) and $\epsilon / k$ as axes. This point represents the simultaneous solution of eqs (11) and (12) and necessarily corresponds to a simultaneous fit of the viscosity and second virial coefficients at the experimental temperature $T_{1}$. One can determine points for each of several experimental temperatures, $\mathrm{T}_{1}, \mathrm{~T}_{2}, \mathrm{~T}_{3}, \mathrm{~T}_{4}$. If the data are exact and the potential perfect, $\sigma$ and $\epsilon / k$ values obtained at all temperatures are identical and there results a single point in a plot of $\epsilon / k$ versus $\sigma$ as a function of $T$. In an actual calculation process, however, an area is traced out since, obviously, the data are not exact and the potential is not perfect. Thus, both $\epsilon / k$ and $\sigma$ are temperature dependent. See figure 2. If, however, the potential is reasonable, i.e., if one could use it to fit both 
second virial and viscosity coefficients simultaneously within experimental error with the same parameters at all temperatures, then the scatter in figure 2 would be small and of a size consistent with the scatter in the experimental data.

\section{Application to Argon}

We illustrate how this method works for argon. [We are restricted here to the low and insensitive temperature ranges since the high temperature range for the second virial coefficient, as given by eq (2a), is inaccessible if one requires data of the necessary precision [11].]

The m-6 Potential: The method was first applied to the three-parameter potentials of the m- 6 family (corresponding to the value $y=0$ in the four-parameter m-6-8 function family). Figure 3 shows the curves for $m=9,12,17$ and 24. As already described, and as sketched in figure 2 , each of the points on these curves corresponds to a solution of eq (13) at a given experimental temperature. Notice, (a) no curve is reduced to a common solution point independent of temperature; or, more realistically, there is no small area whose size could be described as a point consistent with the experimental error; (b) there is, however, a "turn around" with respect to temperature as a function of m. For example, examine the relative positions of the solutions for the experimental temperatures 129.56 $\mathrm{K}$ and $143.16 \mathrm{~K}$ for the 9-6 and the 24-6 functions [18]. From this one can surmise that, if a common solution point were to exist, it would have to be found for $m$ less than 24.

The m-6-8 Potential: We indicated in Section 2.1 and figure 1 that increasing the $\gamma$ parameter (which represents the strength of the inverse eight attraction) effectively tends to increase $\mathrm{m}$. For instance, an $11-6$ potential with $\gamma=2.0$ is similar to a $12-6$ potential with $\gamma=1.0$. Thus, based on the curves for the $\mathrm{m}-6$ potential shown in figure 3 , a common solution point cannot occur with the $m-6-8$ potential for $m \geq 24$ (and, possibly, based on an examination of figure 3, cannot occur for $m \geq 17$ ) since removing the restriction $\gamma=0$ is equivalent, in this sense, to increasing $m$. This initial crude selection process is helpful since it results in a reduction in the number of m-6-8 functions which need to be tested for argon. In keeping with this, we concentrated our attention on potentials with $m$ values between 9 and 18 and show the particular results obtained for $m=10,11,12$ and 13 for various values of $\gamma$ in figures 4 and 5 . We found that a "turn around" is observed for the 12-6-8 and 13-6-8 potentials at high values of $\gamma$. This turn around indicates an upper limit for $\gamma$ associated with each $m$, i. e., for the 12-6-8, $y \leq 2.0$ and for the 13-6-8 $y \leq 1.5$. We also found that the common solution area became progressively larger as $m$ increased beyond $m=12$ no matter what value 
of $y$ was selected. Based on this latter behavior, therefore, we can further restrict the parameter range and say that, for the m-6-8 potential, $m$ must be less than 12 for argon. Closer examination showed, with very little doubt, that the graph of $\epsilon / k$ versus $b_{0}$ had the smallest common solution area for the $11-6-8$ with $y=3.0$, i.e., this is the potential for which the best simultaneous fits are obtained for the viscosity and second virial coefficients for argon over the widest temperature range.

From within the common solution area obtained in an $\epsilon / k$ versus $b_{0}$ plot for the 11-6-8 potential with $y=3.0$, we then chose the parameters $b_{0}=45 \mathrm{~cm}^{3} / \mathrm{mol}$ $[\sigma=3.292 \AA]$, and $\epsilon / k=153 \mathrm{~K}$, table 1 . We have therefore been able to satisfy requirement (2) for argon and with parameters which fit the viscosity data of argon simultaneously at high and at low temperatures. This is a very strong argument in favor of using this potential for argon.

One might argue that, because we now have four parameters, a unique solution to the problem of producing a simultaneous fit to the viscosity and second virial coefficients is not possible. In other words, although we find the 11-6-8, $\gamma=3.0$ potential to be the best potential, we might equally well have chosen another as best, e.g., the 10-6-8, $y=4.5$ (say) or the 9-6-8, $Y=6$. Collision integrals were not available to check on this but, in any case, if multiple solutions occur, they most probably indicate that the data are not sufficiently precise to make a truly definitive choice of the potential possible. The data are, however, sufficiently precise to reduce the number of possibilities quite drastically. For instance, we have already ruled out any solutions for $m \geq 13$, regardless of the value of $\gamma$.

\subsection{Deviation Curves for Argon}

Given the potential $\mathrm{m}=11, \gamma=3.0$, with $\sigma=3.29 \AA\left(1 \AA=10^{-10} \mathrm{~m}\right)$ and $\epsilon / k=153 \mathrm{~K}$, we constructed deviation curves for the dilute gas viscosity coefficients [13-16, 19-23] and the second virial coefficient [17], figures 6 and 7. We regard them as satisfactory.

4. Further Checks on the Use of the 11-6-8 $(\gamma=3.0)$ Potential for Argon

Thermal Conductivity: The statistical mechanical expression for the thermal conductivity coefficient of a dilute monatomic gas, $\lambda^{\prime}$ involves the same collision integrals as does the viscosity coefficient:

$$
\lambda^{\prime}=\frac{25}{32} \frac{\sqrt{\pi m k T}}{\pi \sigma^{2} \Omega^{(2,2) *}(T *)} \frac{c_{v}^{\prime}}{m}
$$




$$
\lambda^{\prime}=\frac{15}{4} \frac{\mathrm{k}}{\mathrm{m}} \eta
$$

where $c_{v} 1 / m=\frac{3}{2} \mathrm{k} / \mathrm{m}$ is the translational specific heat per molecule. A check on thermal conductivity thus serves as a cross check on the viscosity and thermal conductivity data and not necessarily as a check on the potential function. Figure 8 gives the deviation curve for the thermal conductivity. Data are taken from references [24-35].

Self-Diffusion Coefficient D: This coefficient is of more importance than the thermal conductivity as a check on the potential because a collision integral other than $\Omega^{(2,2) *}(\mathrm{~T} *)$ enters into the theoretical expression. This expression is:

$$
\rho D=\frac{5}{8} \frac{\pi m k T}{\pi \sigma^{2} \Omega^{(1,1)^{*}}\left(T^{*}\right)}
$$

where $\rho$ is the mass density of the gas and $\Omega^{(1,1) *}$ (T*) is the collision integral for diffusion. Figure 9 gives a plot of deviations of self-diffusion data, references [36-38], and values calculated from eq (15) using the 11-6-8 ( $\gamma=3.0)$ potential.

Isotopic Thermal Diffusion Factor, $\alpha_{0}$ : Since combinations of collision integrals are required by the kinetic theory expression for this property, it is especially sensitive to the potential function. According to Kihara [3],

$$
\alpha_{0}=\alpha_{0}^{\prime}(1+\delta)
$$

where

$$
\alpha_{0}^{\prime}=\frac{15(6 C *-5)(2 A *+5)}{2 A *(16 A *-12 B *+55)}
$$

with $\delta$ given by

$$
\begin{aligned}
\delta=I *\left\{\frac{2 A *}{(35 / 4)+7 A *+4 F *}[H *\right. & +\frac{1}{2}\left(\frac{7(5-6 C *)+A * I *}{5+2 A *}\right) \times\left(\frac{(35 / 8)+28 A *-6 F *}{21 A *}\right) \\
& \left.-\frac{5}{7}\left[H *-\frac{7}{5}\left(\frac{5-6 C *}{5+2 A *}\right)-\frac{31 *}{10}\right]\right\}
\end{aligned}
$$


where

$$
I *=8-8 E^{*}
$$

and

$$
H *=\frac{(35 / 4)-3 B *-6 C *}{5-6 C *}
$$

The potential function enters into the equation for $\alpha_{0}$ via the collision integrals which here are expressed as ratios, $\mathrm{A} * \mathrm{~B} * \mathrm{C} * \mathrm{E} *$ and $\mathrm{F} *$ given by

$$
\begin{aligned}
& \mathrm{A} *=\Omega^{(2,2) *} / \Omega^{(1,1) *} ; \\
& \mathrm{B} *=\left(^{(1,2) *}-4 \Omega^{(1,3) *}\right) / \Omega^{(1,1) *} ; \\
& \mathrm{C} *=\Omega^{(1,2) *} / \Omega^{(1,1) *} ; \\
& \mathrm{E} *=\Omega^{(2,3) *} / \Omega^{(2,2) *} ; \\
& \mathrm{F} * \Omega^{(3,3) *} / \Omega^{(1,1) *} .
\end{aligned}
$$

Figure 10 shows a plot of $\alpha_{0}$ determined from eq (16) compared to the data of Paul et al. [39]. Since thermal diffusion data are difficult to obtain with precision, we regard the fit indicated by this figure as satisfactory.

\section{Tests on the Validity of the 11-6-8 $(\gamma=3.0)$ Potential}

Our results, as illustrated by the deviation curves, give us confidence that we have indeed reached an important goal, that is, we now have a useful, relatively simple, analytical model potential function for argon. As we shall show later, this same model potential is also satisfactory for the other heavy rare gases and very reasonable for simple polyatomic molecules. However, it is interesting to check on how valid our argon potential is; i.e., to see how close it comes to fulfilling requirements other than those associated with the fitting of equilibrium and transport data [99]. For example, the repulsive part of the model potential can be compared with results from molecular beam scattering experiments and the coefficients of the attractive part, i.e., $\mathrm{C}_{6}$ and $\mathrm{C}_{8}$, with independent semitheoretical quantum mechanical calculations [101]. Independent checks on the values of $\epsilon / k$ and $\sigma$ are also possible. For example, the value of $\sigma$ can be compared to that obtained from the crystal lattice [5] and the value of $\epsilon / k$ can be compared with a value found appropriate in a theory of the liquid state [40]. In both these latter cases, however, one has to introduce the concept of non-additivity of the pair potentials which introduces an extra uncertainty [43]. 


\section{1 Repulsion: The Potential for $\mathrm{r}<\sigma$}

The repulsive part of the pair potential for argon at small separations has been estimated from molecular beam scattering data [41] and we plot a composite curve obtained from these data as the heavy solid line in figure 11 . The curve for the 11-6-8 $(y=3.0)$, was calculated and is shown as a lighter solid curve. The two curves begin to separate at $\mathrm{r} \sim 2.8 \AA$ or $\Phi(\mathrm{r}) \sim 0.1 \mathrm{eV}$. [Also shown as a matter of interest are the curves for the 12-6 function, long used as a good first approximation potential for the description of high temperature argon data, and for the 18-6 which is typical of all three parameter potentials which can be used to describe low temperature argon data [3, 17].] Taken literally this comparison indicates a need for a potential at small $r$ which is much softer than the 11-6-8. This conclusion must be taken with caution, however, because repulsive contributions do not dominate the interaction potential in this region. For example, our potential for argon has a magnitude of approximately $1 \mathrm{eV}$ at $\mathrm{r} *=0.75$. For this value of $r *$, the attractive inverse eighth term has a magnitude which is $38 \%$ of that of the inverse eleventh and the attractive inverse sixth term has a magnitude which is $2 \%$ of the inverse eleventh. Thus, if our potential for argon is at all valid, it follows that the analysis of scattering data in terms of pure repulsion can produce misleading results.

An idea of the error introduced by neglecting attraction can be estimated as follows. At each value of $r *$, let us, in the style of the scattering experiments, represent our potential function by a pure inverse power repulsion. Thus

$$
\Phi(\mathrm{r} *)=\mathrm{A} / \mathrm{r} * \mathrm{~m}^{\prime}
$$

If this were a true representation of the function, an effective repulsive exponent could then be obtained simply by calculating $m^{\prime}=\frac{r *}{\Phi} \frac{d \Phi}{d r *}$. But, for example, at $r *=0.75$ this leads to an effective value for our potential of $m^{\prime}=13$ : different from the value $\mathrm{m}=11$ associated with the repulsive branch of the complete potential.

\subsection{Attraction: A Comparison of the Dispersion Coefficients}

The expressions for the dispersion coefficients, $C_{6}$ and $C_{8}$, for the m-6-8 potential function are, from eq (10):

$$
\begin{gathered}
C_{6}=\frac{\epsilon}{(m-6)}[m-\gamma(m-8)] \sigma^{6} d^{6} \\
C_{8}=\epsilon y \sigma^{8} d^{8}
\end{gathered}
$$


For argon we have found that $m=11, \gamma=3.0, \epsilon=153 \mathrm{~K}$ ergs and, $\sigma=3.29 \times 10^{-8} \mathrm{~cm}$. Also, $d=1.14462$. Using these values in eqs $(21)$ and $(22)$ one obtains $C_{6} \cong 21 \times 10^{-60}$ $\mathrm{ergs} / \mathrm{cm}^{6}$ and $\mathrm{C}_{8} \cong 2000 \times 10^{-76} \mathrm{ergs} / \mathrm{cm}^{8}$. Semitheoretical quantum mechanical calculations, however, indicate that $C_{6} \cong 60 \times 10^{-60}$ ergs $/ \mathrm{cm}^{6}$ and $C_{8} \cong 120 \times 10^{-76} \mathrm{ergs} / \mathrm{cm}^{8}$ [42]. The coefficient $C_{6}$ is believed to be known quite accurately (within 5\%), $C_{i}$ is known somewhat less well, but is about twice $\mathrm{C}_{6} \mathrm{r}^{2}$.

Obviously, our 11-6-8 potential for argon is not giving the correct value for the inverse sixth power coefficient $\mathrm{C}_{6}$. Let us then see what happens to the data correlation if the $\mathrm{C}_{6}$ of our potential is forced to have a value approximately equal to $60 \times 10^{-60}$ ergs $/ \mathrm{cm}^{6}$. In so doing, we effectively fix one of the four parameters. This we choose to do by fixing $\gamma$ for a given $m$. From the simultaneous fits shown in figure 5 we select $m=11$, and $y=2$ which gives $C_{6} \cong 55 \times 10^{-60}$ ergs $/ \mathrm{cm}^{6}$ - - sufficiently close to theory. Corresponding best values of $\sigma$ and $\epsilon / k$ are found from the graph to be $3.356 \AA$ and $137 \mathrm{~K}$, respectively. Deviation curves for the second virial and viscosity using this 11-6-8 $(\gamma=2.0)$ potential are presented in figure 12. One sees that these curves are not unreasonable, that is, the fit is within three percent, except for the second virial coefficient at very low temperatures. They do, however, show systematic deviations and are definitely inferior to the curves given in figures 6 and 7 .

These results can be summarized in three remarks.

1. The numerical values of $C_{6}$ and $C_{8}$ for the $m-6-8$ potential are very sensitive to the choice of $m$ and $Y$ because of the particular functional forms used, i. e., eq (21). The quantity $\sigma$, which is also part of the expressions, is found from experiment. Since $\sigma$ is raised to the sixth and eighth power respectively, uncertainty in it obviously leads to increased uncertainty in $\mathrm{C}_{6}$ and $\mathrm{C}_{8}$.

2. A convenient argument says that our potential is not sufficiently flexible to fit data while simultaneously giving a good value for $\mathrm{C}_{6}$ (and to a lesser extent $\mathrm{C}_{8}$ ). That our potential is not flexible enough is obviously true -- it is only meant to approximate the true potential (whatever that is). This argument, though necessary, is not sufficient, however, to recommend the need for additional parameters. We can show this by referring to a recent potential function due to Barker [43]. Because it has additional parameters, Barker's potential is very flexible when compared with ours but, according to figure 13, the attractive part of the 11-6-8 $(\gamma=2.0)$ is close to Barker's potential even though his $\mathrm{C}_{6}$ is fixed at the correct value. Consequently, it can be assumed that simply adding parameters to the m-6-8 for greater flexibility might not result in a $\mathrm{C}_{6}$ which approaches the theoretical value. In fact, it is possible that the requirement of fitting 
data as well as we have done in figures 6 and 7 might be incompatible with the requirement for a value of $\mathrm{C}_{6}$ in reasonable agreement with theory [99].

3. Since we regard the data we have fitted as reliable, the m-6-8 potential thus fails in that it cannot give the dispersion coefficients correctly. We must emphasize, however, that this failure must not be taken out of context. The m-6-8 potential, being a model function, can only be approximate. Its advantage is in its utility and not necessarily in its ability to give correct theoretical predictions for the form of the potential itself -- although it would obviously be a very powerful property of the potential if this were so.

\section{Application of the m-6-8 Potential to Krypton and Xenon}

We have tested the m-6-8 potential for krypton and xenon in the same manner as described for argon. For both gases, dilute gas viscosity data and second virial data were simultaneously fitted using eq (13). Plots were obtained similar to figures 4 and 5 .

The data for viscosity were taken from references [14-16,44] for krypton, and references $[14,15,45-47]$ for xenon. The second virial data for both gases were taken from reference [17].

For both krypton and xenon there was little doubt that the use of an m-6-8 with $m=11, \gamma=3.0$ resulted in an $\epsilon / k-b_{0}$ plot with the smallest area, this being our criterion for the best solution of eq (13). In this way we obtained the best potential parameters given in table 1 .

Viscosity data for both high and low temperatures and second virial data for all temperatures were fitted separately for each gas. We confirmed that our choices of parameters based on the simultaneous fits to all data were also valid for the individual properties. Thus we found that the m-6-8 potential can be used to satisfy requirements (1) and (2) of section 1 for krypton and xenon, just as it could for argon.

Corresponding States: We have, incidently, thereby verified that, by our criteria, the corresponding states principle is applicable to argon, krypton and xenon. The law of corresponding states postulates that for fluids with molecules whose pairwise interactions obey a spherical potential $\Phi(r)$, one can write

$$
\Phi(r)=\epsilon f(r / \sigma)
$$

where $\epsilon$ and $\sigma$ are the energy and distance parameters respectively, and $f$ is the same function for all fluids. Since the only potential parameters which differ for each of the gases argon, krypton, and xenon are $\sigma$ and $\epsilon / k$, corresponding states is valid by this criterion. 
The Coefficient $\mathrm{C}_{6}$ : We have already pointed out for argon that the coefficient of the inverse sixth power term, when allowed to behave as a parameter in fitting data, was found to be about $1 / 2-1 / 3$ of the numerical value predicted by quantum mechanics. We have found this to be also true for krypton and xenon: (theoretical values in brackets [42]) $\mathrm{Kr}, \mathrm{C}_{6} \sim 43[\sim 107]$ and $\mathrm{Xe}, \mathrm{C}_{6} \sim 100[\sim 236]$, all values times $10^{60}$.

\subsection{Deviation Curves for Krypton and Xenon}

Figures 14 and 15 give deviation curves for the viscosity and second virial coefficients of krypton and xenon, respectively. Figures 16 and 17 are curves for the thermal conductivity coefficients determined by eq (14) is compared to experiment $[31,35,48,49,50-52]$. Figures 18 and 19 are deviation curves for the thermal diffusion coefficients for the two gases $[53,54]$. In figure 20, we include a deviation curve for the recently measured [55] self-diffusion coefficient of krypton.

\section{Application to Polyatomic Molecules}

The evidence presented in the previous sections indicates that the $\mathrm{m}-6-8$ potential is satisfactory for the monatomic molecules. However, the function would be more important as a practical tool if it could also be successfully applied to polyatomic molecules. Unfortunately, this extension is not straightforward since two very basic complications are introduced:

1. In principle, the spherically symmetric m-6-8 potential (or any spherical potential) can never properly depict the interaction between two polyatomic molecules; the potential for such molecules must be dependent on the relative orientation of the colliding molecules.

2. Even if one has a potential which can account for orientation dependent interactions, the statistical mechanical expressions should allow that collisions between polyatomic molecules will be inelastic, that is, the molecular internal degrees of freedom have to be considered.

The most common way to resolve these problems is to ignore them unless it is very obvious that one cannot do so (when considering ions, for example). This oversimplified approach can be justified in a way which we shall describe below. Let us, therefore, investigate the application of the m-6-8 potential to the viscosity coefficient and the second virial coefficient of the polyatomic gas, nitrogen, using the same expressions and procedure as given for the rare gases. The sources for nitrogen data are: viscosity, references [13-16,22,56-58] and second virial, reference [17]. 
7.1 Simultaneous Fit of the Second Virial Coefficient and Viscosity

Coefficient for Nitrogen

We followed the procedure described in section 3.2 by comparing the second virial and viscosity coefficients for nitrogen to calculated values based on the m-6-8 using eq (13). Recall again that we were seeking values for $m$ and $\gamma$ which give values for $b_{0}$ and $\epsilon / k$ which are essentially independent of temperature when allowance is made for a reasonable amount of experimental scatter.

Partial success was achieved: it was possible to show that solutions for $m \geq 13$ did not seem likely, but we were unable to select that m-6-8 potential for $m \leq 12$ which gave the smallest area in $a b_{0}-\epsilon / k$ plot. A possible choice is $m=10, \gamma=1.0$, $\sigma=3.694 \AA, \epsilon / k=87 \mathrm{~K}$. Deviation plots for the viscosity and second virial coefficients determined from these parameters are shown in figure 21 .

These curves, although showing evidence of systematic error, are actually not unreasonable, i.e., above $200 \mathrm{~K}$ both $\eta$ and $B$ are fitted to within $2 \%$. We have, nevertheless, been unable to achieve results for nitrogen as satisfactory as were those obtained for the rare gases. It thus appears that requirement (2) of section 1 is not satisfied for the polyatomic molecule nitrogen.

\subsection{Fits to Single Properties: The Viscosity Coefficient and the Second Virial Coefficient}

We next follow the procedure outlined in section 3.1, i. e., the correlation of the viscosity coefficient individually. Here we do have a significant result: for nitrogen as for argon, a single set of parameters was found which enables the viscosity coefficient to be fitted simultaneously at low and at high temperatures. These parameters are $\mathrm{m}=12, \gamma=2.0, \sigma=3.54 \AA, \epsilon / \mathrm{k}=118 \mathrm{~K}$, see table $2[59]$. In other words, the $\mathrm{m}-6-8$ potential can satisfy requirement (1) of section 3 . Figure 22 gives the deviation curve for the fit for viscosity and also shows the corresponding fit of the second virial coefficient for these same parameters. The latter plot indicates highly systematic deviations.

The second virial coefficient can also be fitted by itself and we have done this in figure 23 using the parameters $m=12, y=2.0, \sigma=3.60 \AA, \epsilon / \mathrm{k}=123 \mathrm{~K}$. The corresponding viscosity deviation curve is also shown in figure 23. Note the deviation pattern which shows that the percentage deviation is essentially independent of temperature! 


\subsection{Fits for Methane, Oxygen and Carbon Dioxide}

We found essentially the same results for these gases as we did for nitrogen; an attempt to fit both second virial and viscosity data simultaneously gave parameters which produced only a moderately good representation of such data. Just as for nitrogen it was possible to $\mathrm{fit}$ the viscosity at both high and at low temperature with a single set of parameters, see table 2. The parameters required for such fits were found not to be suitable for the second virial coefficients, however. The converse was also true, parameters obtained from a best fit of the second virial data, were not satisfactory in the corresponding fit for viscosity. In fact, deviation curves were obtained similar to figure 23 for nitrogen.

Deviation curves for the viscosity of these gases are shown in figures 24-26. Sources of data: for oxygen, see the appendix and references $[22,47,56,64-66]$, for methane, references $[56-60,61,63]$ and for carbon dioxide, references $[16,56,62]$.

\section{Kinetic Theory of Polyatomic Molecules}

The two problems introduced when statistical mechanical expressions are applied to polyatomic molecules have been discussed by Mason and his coworkers [67]. Let us simply list his conclusions and verify that our results with nitrogen, oxygen, methane and carbon dioxide are consistent with them.

\section{1 Inelastic Collisions}

The effect of inelastic collisions on the statistical mechanical expressions are as follows:

Viscosity Coefficient: The evidence indicates [98] that inelastic collisions have little effect on the viscosity.

Diffusion Coefficient: Formal expressions for the diffusion coefficient of polyatomic molecules are available [98] but it appears that they differ from the corresponding monatomic gas expression by a factor which is very close to unity.

Thermal Diffusion: Approximate calculations [91] indicate that the expression for the isotopic thermal diffusion factor as given by eq (16) is not complete for polyatomic molecules and should be modified. At the present time, it is not clear how to do this, however, so that it is common practice to use eq (16) without alteration.

Thermal Conductivity: The thermal conductivity equation, eq (14), is definitely incomplete and has to be modified for polyatomic gases. We discuss this in a separate section. 


\subsection{Nonspherical Potentials}

A nonspherical potential can be written as the sum of a spherical contribution, which is independent of the relative orientations of the colliding molecules, and a nonspherical contribution, which depends on this relative orientation. In an exact calculation, the relative orientations must be considered to change during a collision. Because of this, a proper determination of the second virial coefficient and collision integrals can become very complicated. In practice, however, a simplification is made based essentially on the fact that a statistical averaging must eventually be performed. Thus, one assumes that the molecules collide with a fixed relative orientation and collision integrals are calculated for each orientation independently. The final values of the collision integrals are then determined by a statistical averaging over all these possible orientations [102].

A potential of interest to $u$ is the 12-6 with a term added to allow for quadrupolequadrupole interactions:

$$
\Phi=\Phi(12-6)+\Phi(\text { quadrupole }- \text { quadrupole })
$$

Collision integrals for eq (23) have been calculated [97] and were found to be very close to the corresponding collision integrals for the 12-6 alone. [However, the combinations of the collision integrals required for the thermal diffusion factor are significantly different from their equivalents for the 12-6.] Second virial coefficients for several gases have also been determined from eq (23). [Although, in this case, extra terms were added to account for other nonspherical effects.] Unlike the collision integrals, the second virial coefficients were found to be substantially different from their counterparts calculated with the 12-6 alone.

\subsection{Summary}

Returning to our fitting procedures: one would conclude from the above comments that the viscosity could be fitted satisfactorily with a spherical m-6-8 potential but a simultaneous fit of the viscosity and second virial coefficients then obtained would not be satisfactory. This is what was observed. Work is in progress to modify the m-6-8 potential to include nonspherical effects.

\section{Thermal Conductivity of Polyatomic Molecules}

It is known that the simple equation for the thermal conductivity, eq (14), is not valid for polyatomic molecules. Several modifications have been proposed, but the most satisfactory from a theoretical viewpoint is the relatively simple expression obtained by Mason and Monchick who approximated the Wang-Change-de Boer theory for a dilute 
polyatomic gas [67]. Mason and Monchick showed that the conductivity can effectively be separated into two parts: a part depicting the transfer of thermal energy by the translational motion of the molecules, and a part depicting the transfer of energy by changes in the internal energy of the molecules:

$$
\lambda=\lambda^{\prime}+\lambda^{\prime \prime}
$$

where $\lambda^{\prime}$ is given by eq (14). Splitting the specific heat into a translational piece and a piece associated with internal degrees of freedom

$$
\mathrm{c}_{\mathrm{v}}=\mathrm{c}_{\mathrm{v}}^{\prime}+\mathrm{c}_{\mathrm{v}}^{\prime \prime}
$$

Mason and Monchick write:

$$
\begin{aligned}
& \lambda^{\prime}=\frac{5}{2} \eta\left(\frac{c_{v}^{\prime}}{m}-\Delta\right) \\
& \lambda^{\prime \prime}=\rho D_{\text {int }}\left(\frac{c_{v}^{\prime \prime}}{m}+\Delta\right)
\end{aligned}
$$

were $D_{\text {int }}$ is a diffusion coefficient for internal energy and $\Delta$ is a term accounting for the intercharge of internal and translational energy. According to Mason and Monchick, $\Delta$ is given by

$$
\Delta=\frac{2 c_{v}^{\prime \prime}}{\pi Z m}\left(\frac{5}{2}-\frac{D_{\text {int }}}{\eta}\right)\left[1+\left(\frac{2}{\pi Z}\right)\left(\frac{5}{3}-\frac{c_{v}^{\prime \prime}}{k}+\frac{\rho D_{\text {int }}}{\eta}\right)\right]^{-1}
$$

where $\mathrm{Z}$ is the collision number for rotation, related to the number of collisions required for the interchange of rotational and translational energy.

If one assumes that $D_{\text {int }}$ can be replaced by the self-diffusion coefficient of eq (13) (It is not clear what difference this assumption makes) then the formula for the conductivity of a dilute polyatomic gas becomes

$$
\lambda=\frac{5}{2} \eta \frac{c_{v}^{\prime}}{m}+\rho D \frac{c_{v}^{\prime \prime}}{m}-\frac{2 \eta}{\pi}\left(\frac{5}{2}-\frac{\rho D}{\eta}\right) \frac{c_{v}^{\prime \prime}}{m z}
$$

Although eq (29) is not new and has often been quoted, it has rarely been used to determine numerical values of the thermal conductivity. The reasons for not using it were uncertainty in the potential function and the lack of information for $Z$. Today, however, these reasons are much weaker: we have presented an argument as to why the m-6-8 potential can be used to evaluate the viscosity and diffusion coefficients for a simple polyatomic 
gas; and several experimental determinations of $Z$ have now been published. [Some of these $Z$ values are based on acoustical measurements [68] and others on thermal transpiration studies [69].]

We were unable to find reliable values of $Z$ for carbon dioxide. There are, however, values of $Z$ given in reference [69] for nitrogen, oxygen, and methane. Using these and the potential parameters for the viscosity, table 2, we computed the thermal conductivity from eq (29) for these latter gases. Corresponding deviation curves are given in figures 27-29. Sources of data: for nitrogen, references $[27,28,32,35,70-77]$; for oxygen, references [27,74,75,78-85]; and for methane, references $[27,32,34,81,86-88]$. Values of $c_{v}^{\prime \prime}$ were taken from NBS Circular 564 [89] and reference [90].

Although there is some evidence of systematic error, we are generally satisfied with these curves.

\section{Thermal Diffusion of Polyatomic Molecules}

Realizing that the equation for the thermal diffusion factor, $\alpha_{0}$, may not be complete, and that the collision integral combinations from the m-6-8 potential may not be adequate for polyatomic molecules, let us, nevertheless, consider a comparison of $\alpha_{0}$ with experiment for nitrogen, oxygen and carbon dioxide using the unmodified eq (16) and the potential parameters obtained for viscosity. The experimental results are interesting because they indicate that $\alpha_{0}$ can be negative for temperatures below critical. Curves comparing theory with experiment are given in figures 30-32. Data: nitrogen [92], oxygen [93], and carbon dioxide [94]. One sees that $\alpha_{0}$ is correctly predicted to go through zero for oxygen but negative values are not obtained for carbon dioxide or nitrogen. [See reference [95], however.] We do not draw conclusions from these figures: In addition to the theoretical problems, the experimental data must not be regarded as reliable [96].

\section{Conclusion}

The four-parameter m-6-8 potential function has been derived and we have demonstrated how it represents the viscosity, thermal conductivity, second virial and diffusion coefficients, and the thermal diffusion factor for the gases argon, krypton, xenon, nitrogen, oxygen, carbon dioxide and methane. It appears the m-6-8 potential is the simplest model function which can represent the above mentioned properties for the rare gases with a single set of parameters used for each gas for all properties. It can also represent the transport properties for the polyatomic gases listed, but is less successful when simultaneously applied to the viscosity and second virial coefficient (although the second virial can be fitted by itself). For the polyatomic gases, it will be 
necessary to include nonspherical characteristics of the intermolecular interactions in the potential. Work in this direction is in progress. Work is also in progress to modify the m-6-8 potential to allow for quantum effects.

On the basis of a comparison between the repulsive part of the argon $m-6-8(m=11)$ potential and molecular beam experiments, and between values we find for the dispersion coefficients and the equivalent values estimated from quantum mechanics, it seems that the $\mathrm{m}-6-8$ is too simple to represent the argon-argon interaction from a theoretical standpoint. However, we show that it is not clear that simply adding additional parameter $s$ to the m-6-8 will resolve this. 


\section{TABLE 1}

Values of the parameters of the $m-6-8$ potential function which fit both transport and equilibrium properties

gas

Ar

$\mathrm{Kr}$

$\mathrm{Xe}$

$\mathrm{m}$

$\gamma$

$\sigma$

$\AA\left[\equiv 10^{-10} \mathrm{~m}\right]$

$\varepsilon / k$
11

3

3

3. 292

3.509

3.841

K

153

216

11

295

\section{TABLE 2}

Values of the parameters of the $m-6-8$

potential function which fit transport data

gas
$\mathrm{N}_{2}$
$\mathrm{CH}_{4}$
$\mathrm{O}_{2}$
$\mathrm{CO}_{2}$

$\mathrm{m}$

12

11

10

14 $\gamma$

2

3

1

1 $\sigma$

3. 54

3.68

3.437

3.68 $\varepsilon / \mathrm{k}$

118

168

113

282 


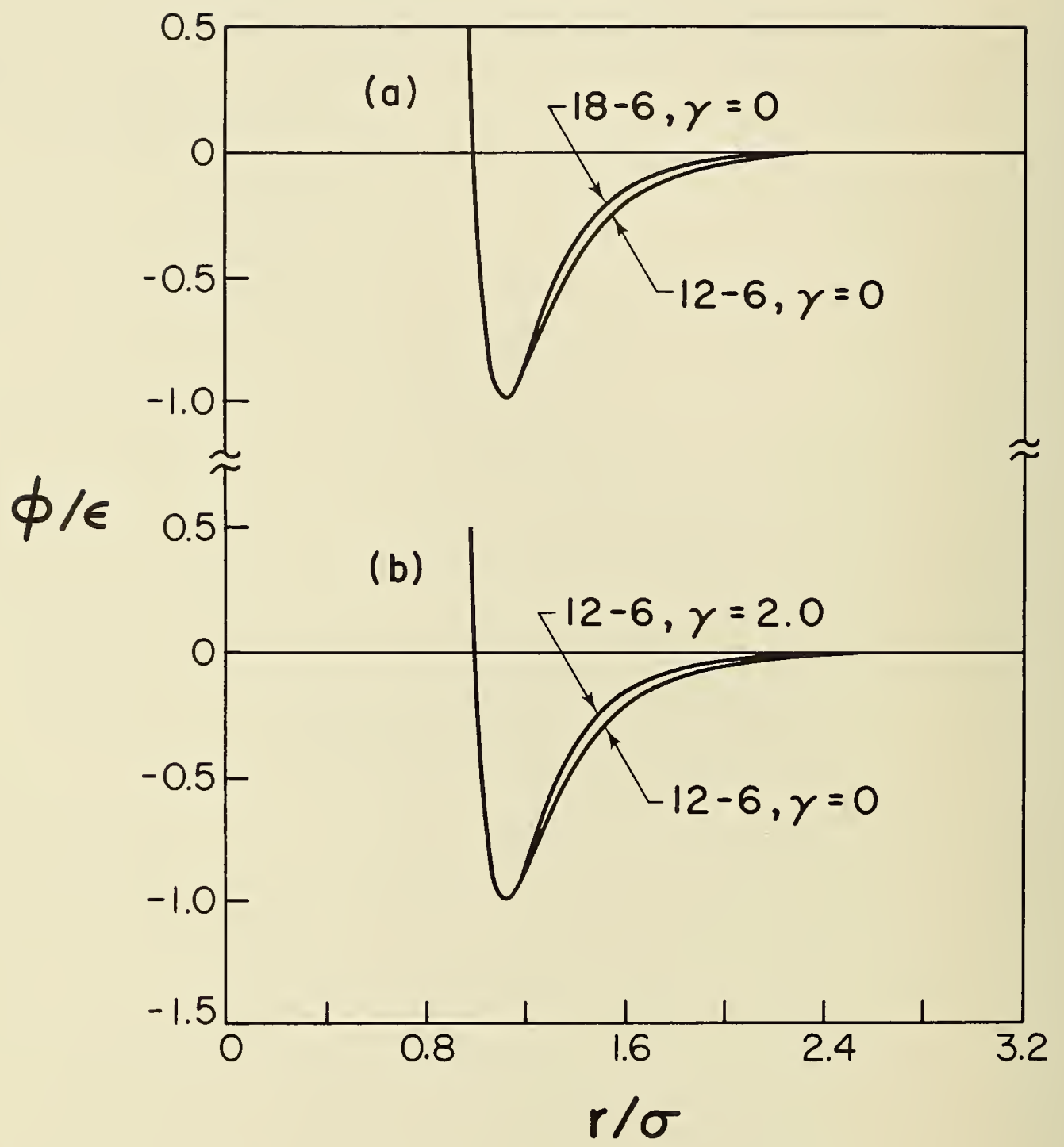

Figure 1. Plots of the m-6-8 potential computed from eq (10) to illustrate how the attractive part varies with (a) an increase in $m$ at fixed $\gamma$, (b) an increase in $\gamma$ at fixed $\mathrm{m}$. 

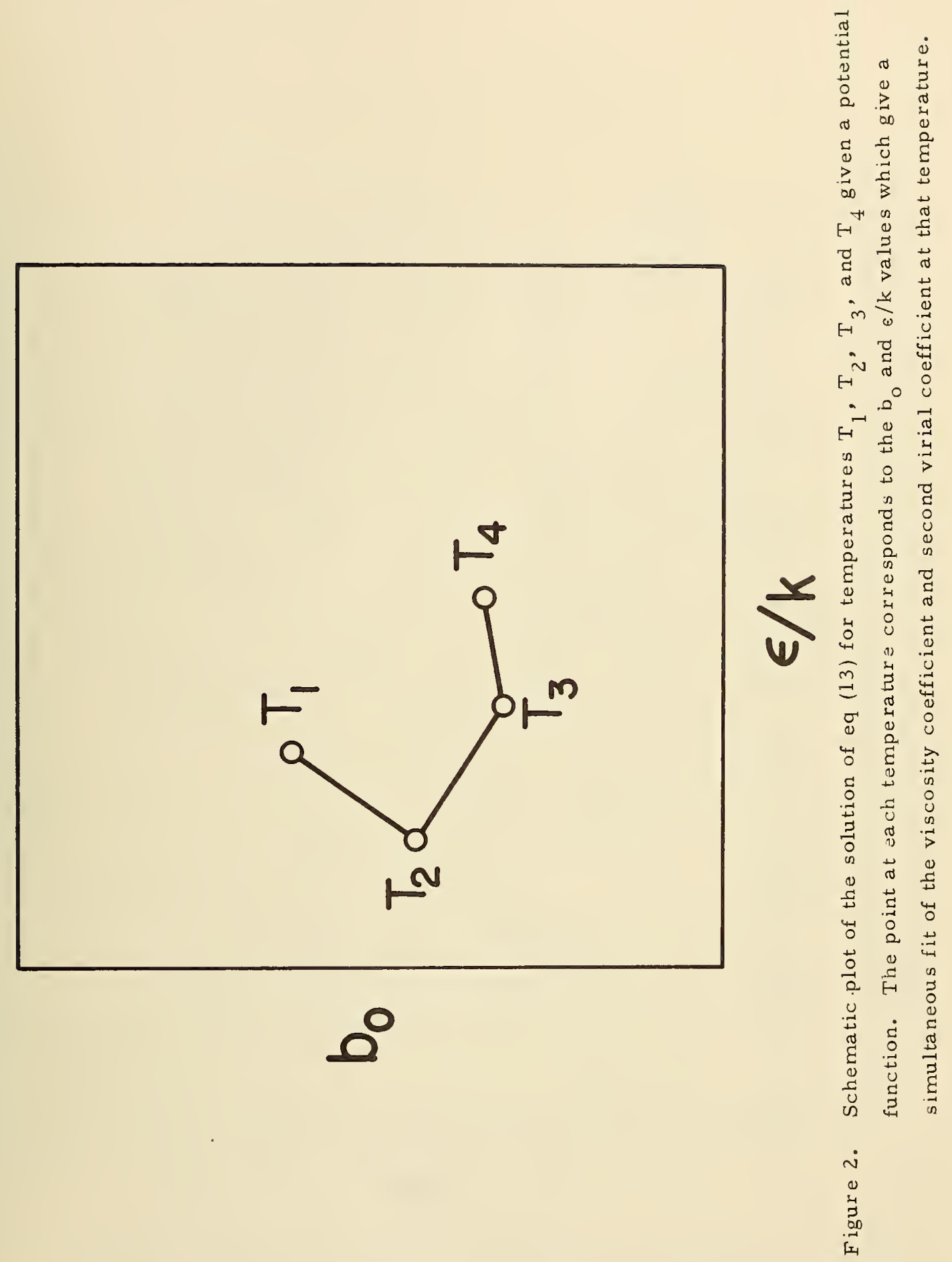


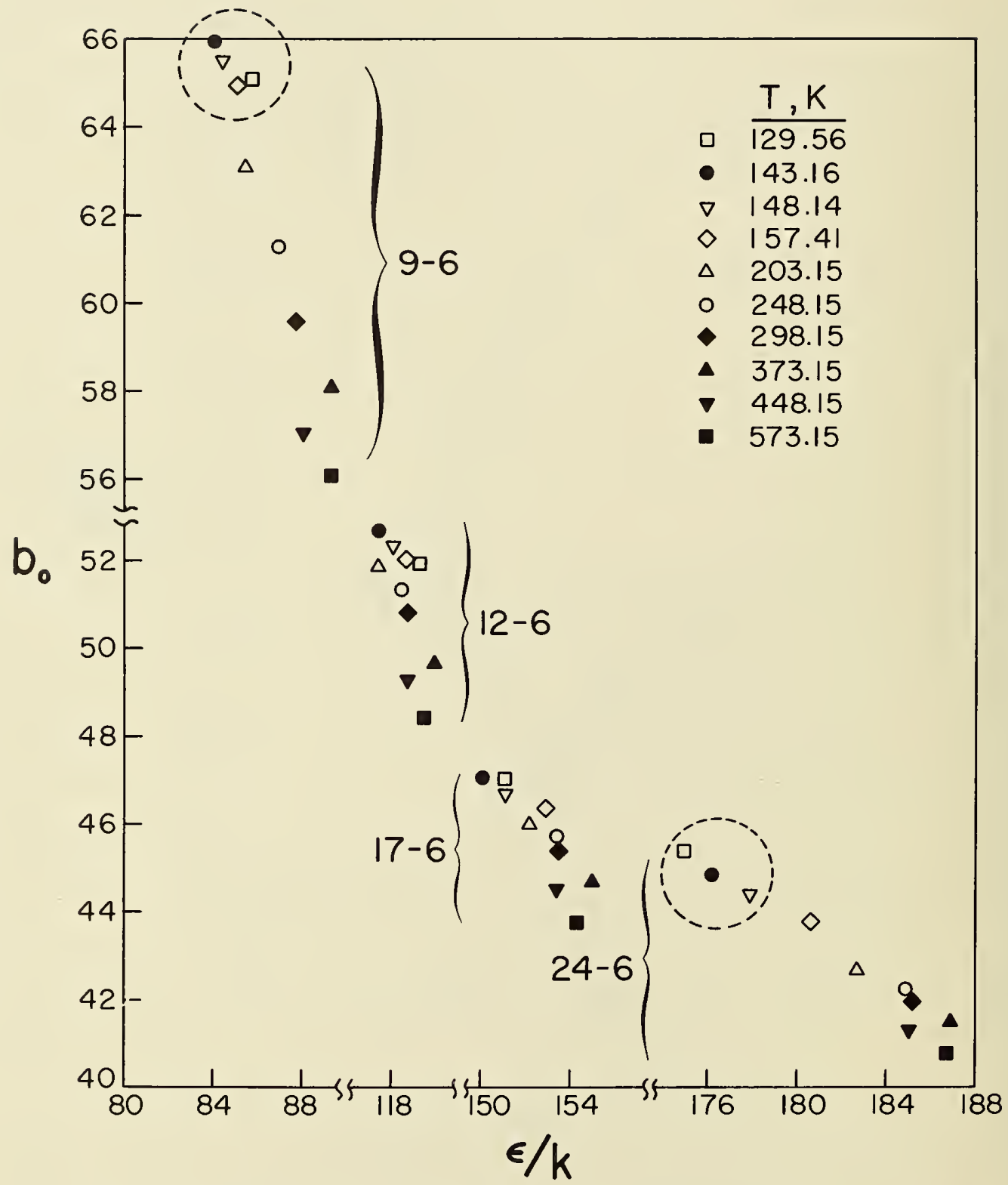

Figure 3. Solutions of eq(13) for argon at several experimental temperatures for the m-6 potential function. Note the "turn around", with respect to temperature, of the solutions at $129.56 \mathrm{~K}$ and $143.16 \mathrm{~K}$, circled in the figure. 

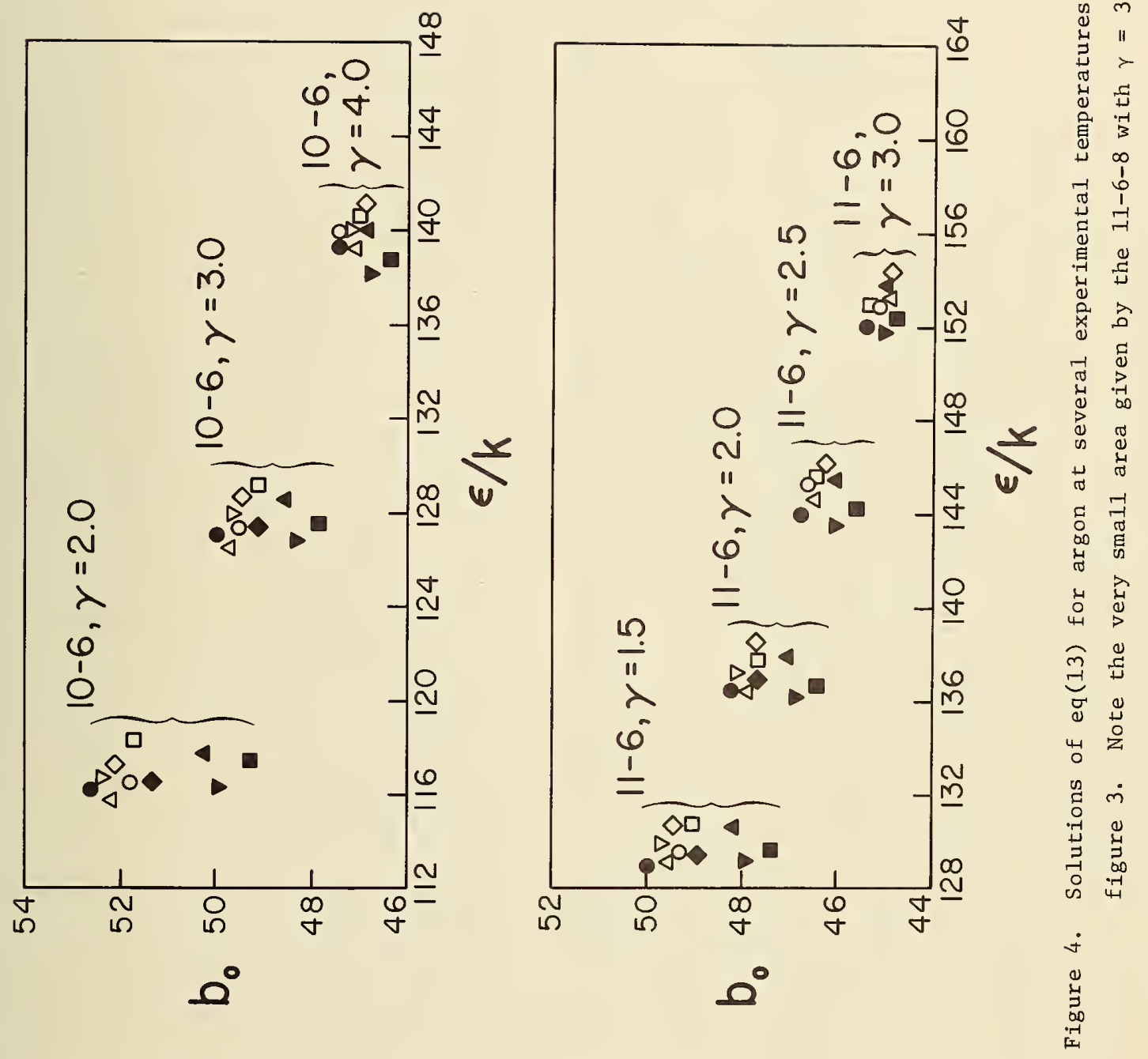

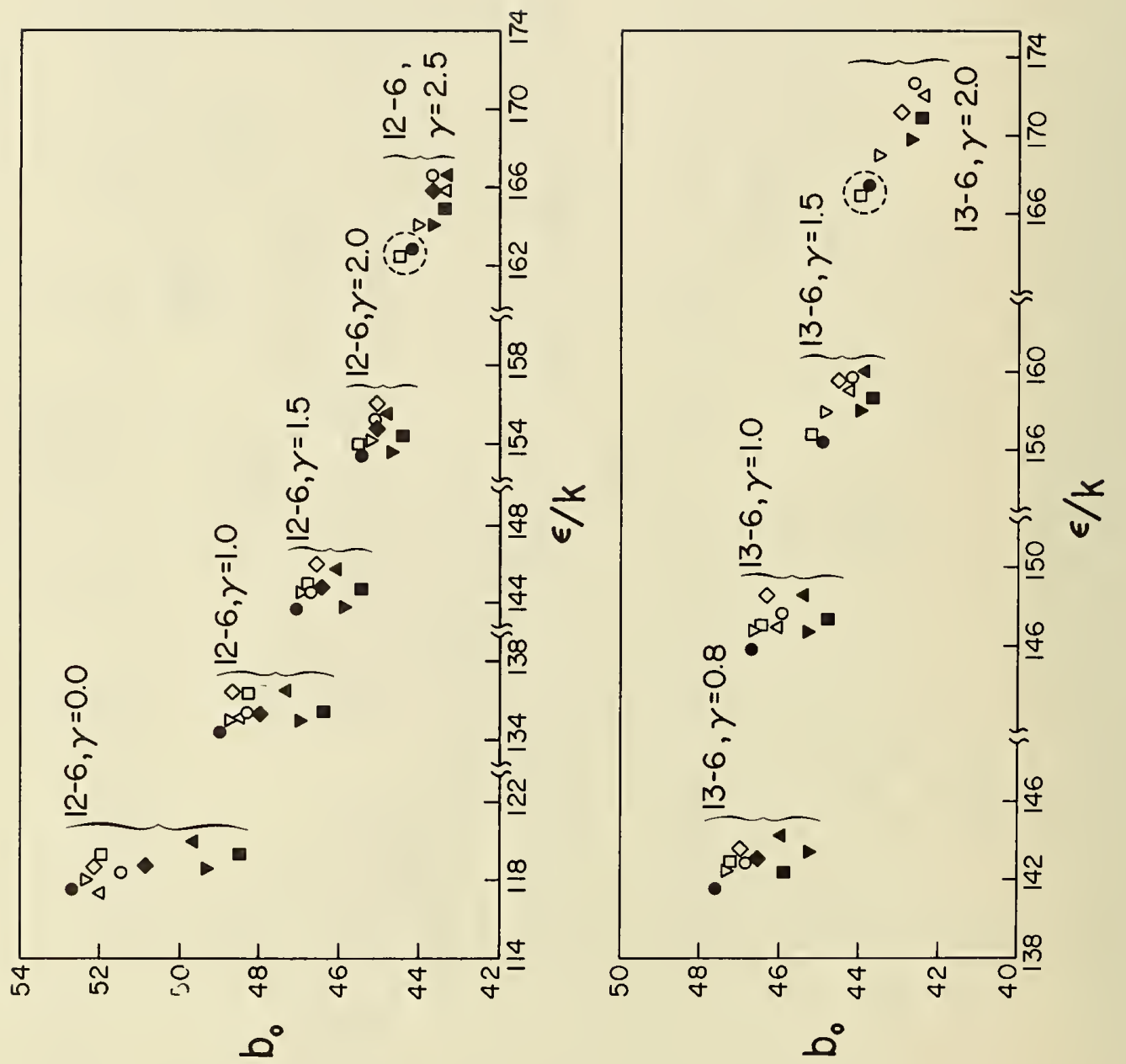

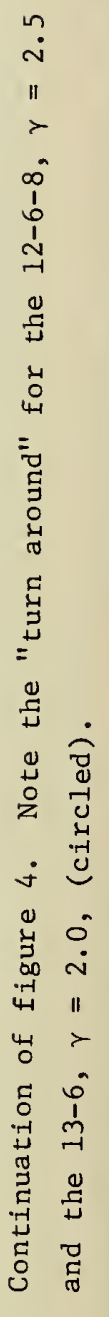
เก 章 


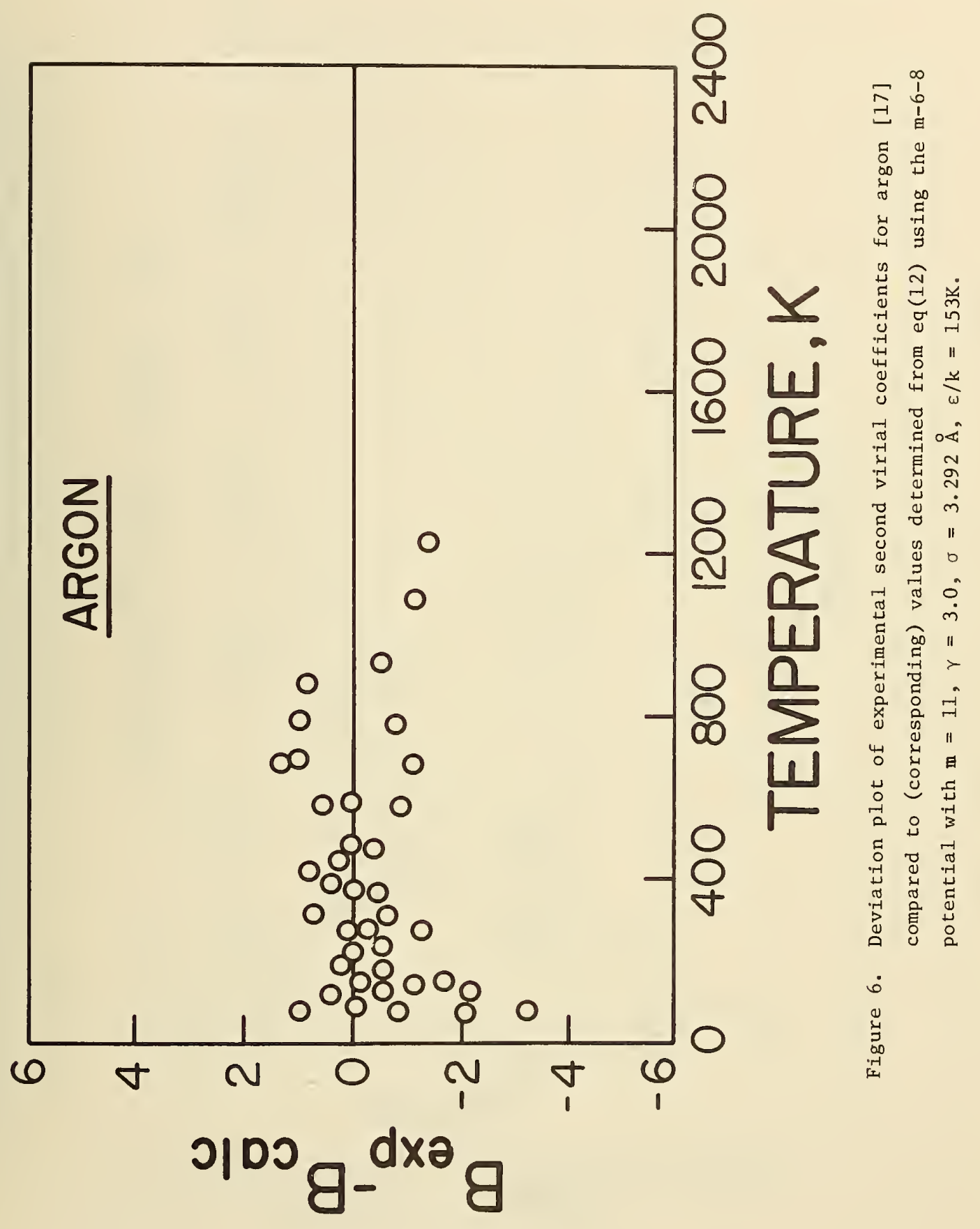




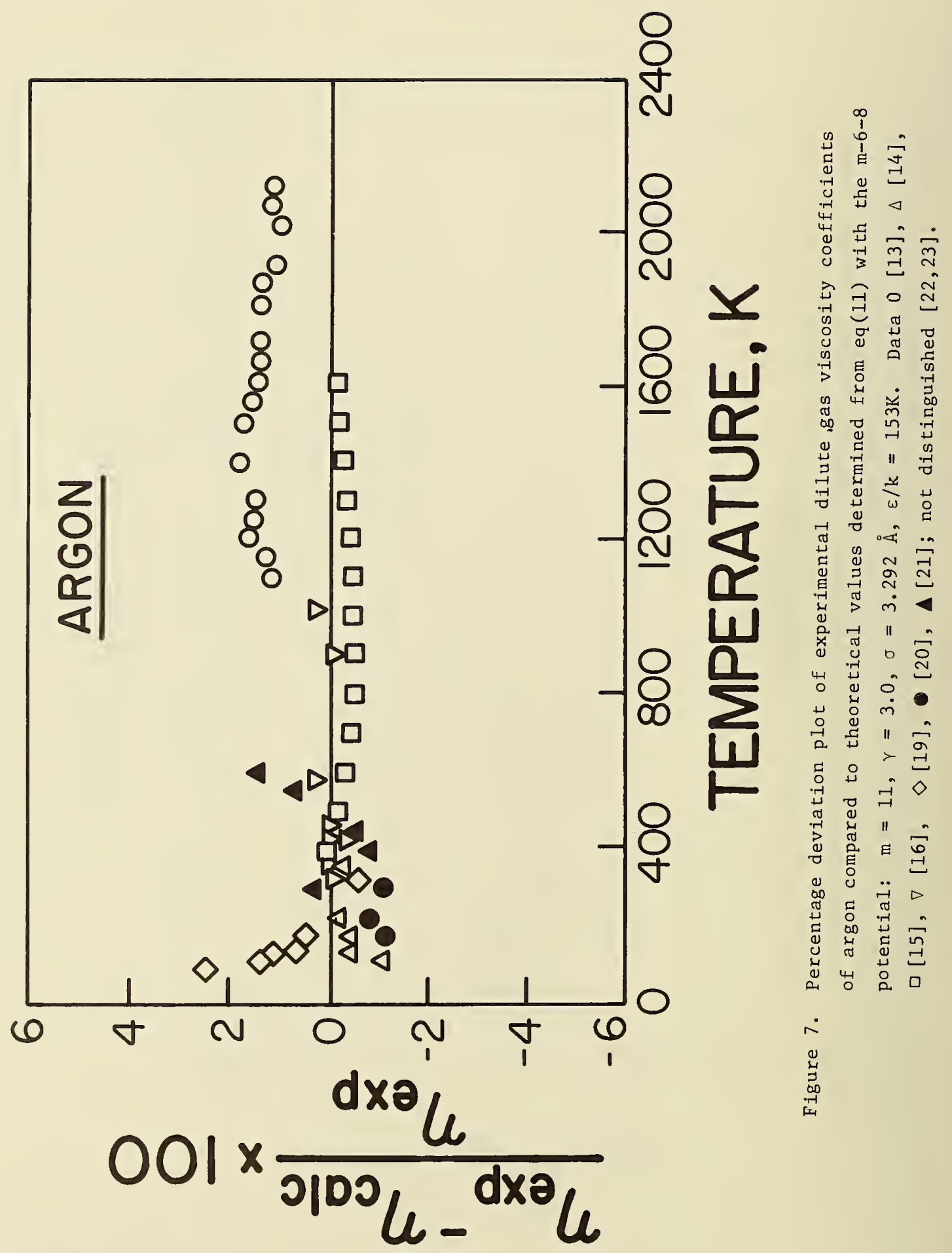




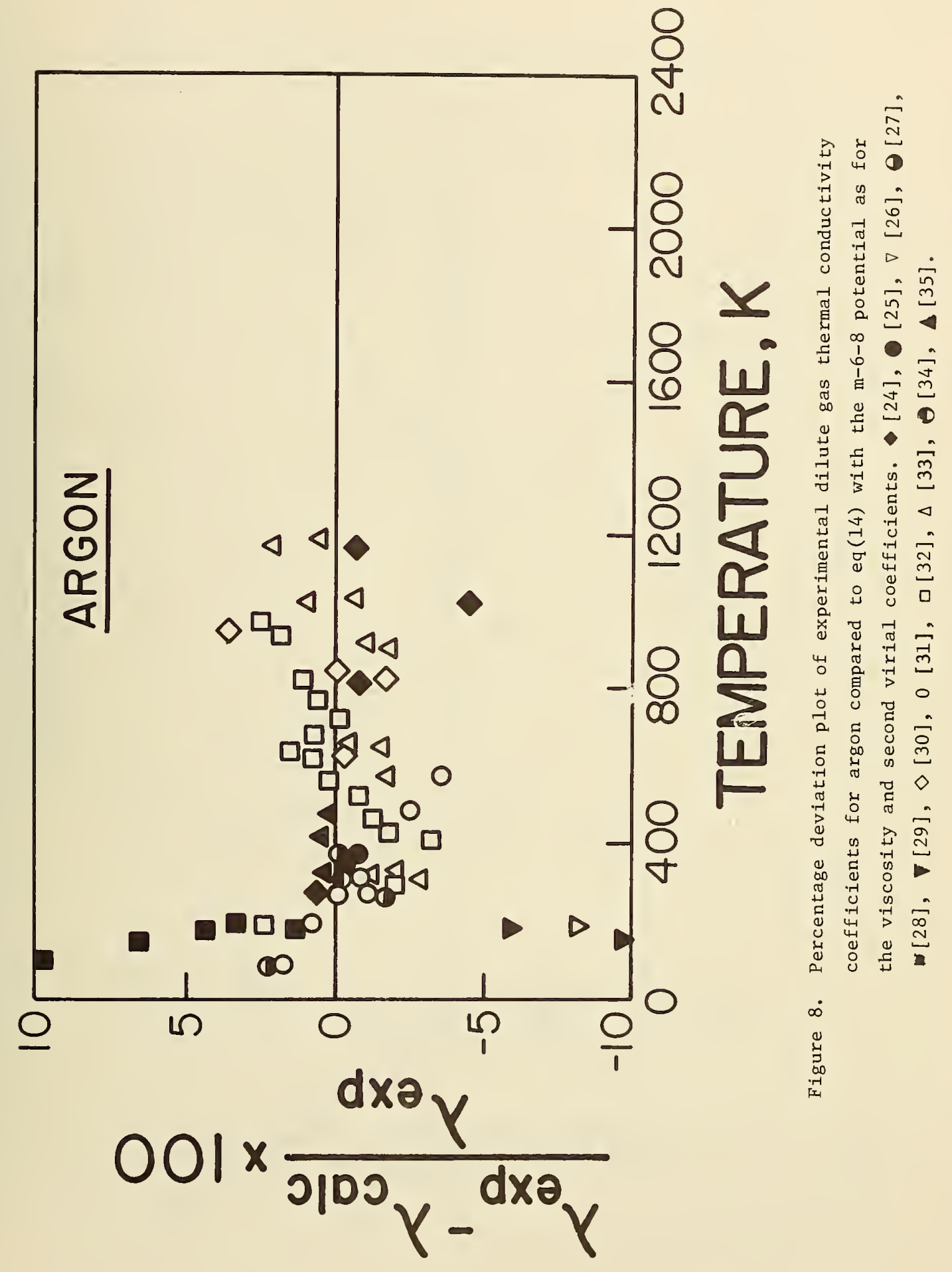




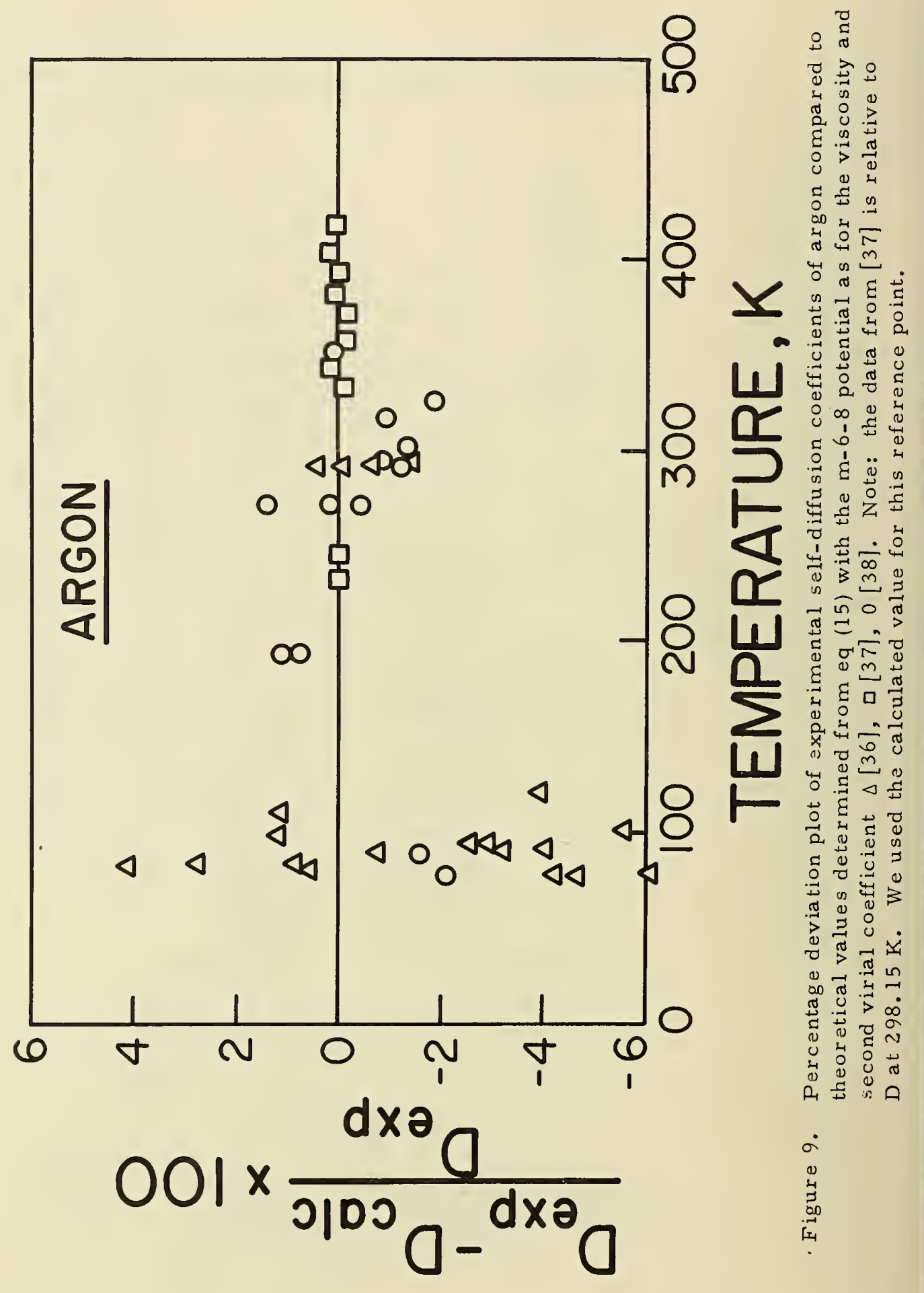




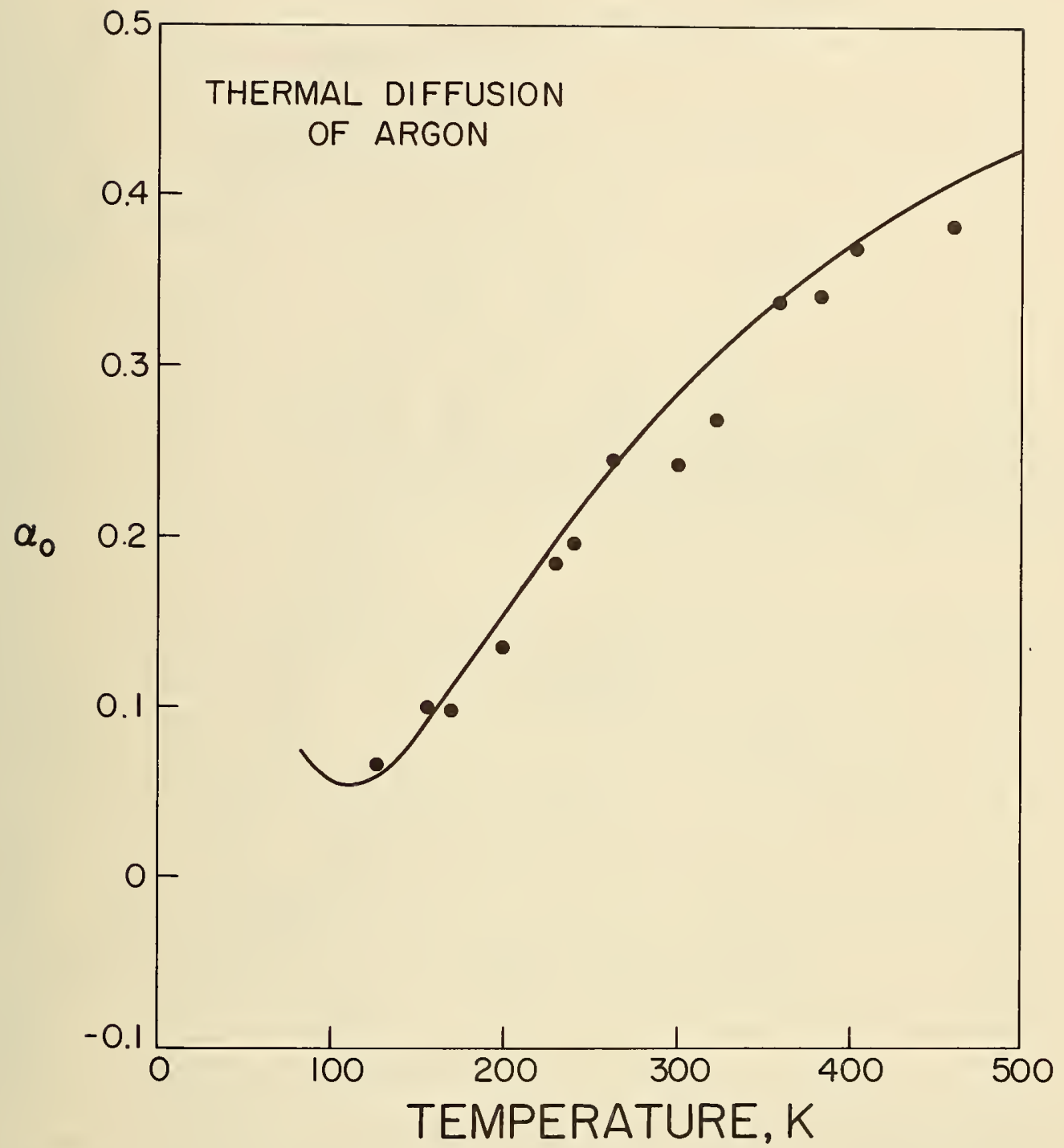

Figure 10. Experimental and theoretical [eq(16)] thermal diffusion factors for argon. Data from [39]. We use the same $m-6-8$ potential as for the other transport coefficients. 


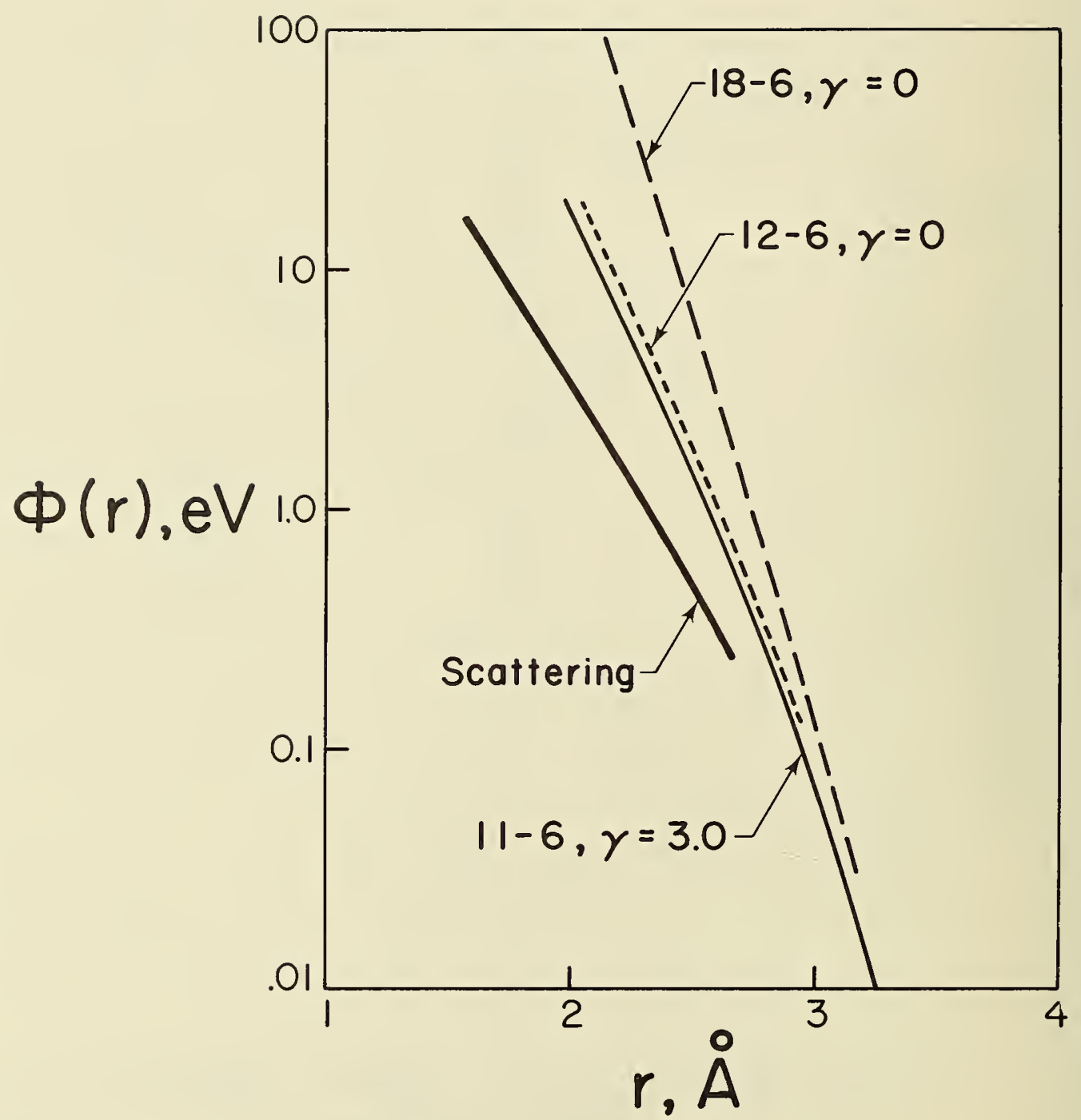

Figure 11. The repulsive potential at small values of $r$. We compare the $11-6-8(\gamma=3.0)$ potential, found to be satisfactory for the dilute gas properties of argon, with the potential estimated from high energy scattering of beams of neutral argon atoms [41]. Also shown, as a matter of interest, are the curves for the well-known 12-6 and 18-6 potentials. [This latter represents the best threeparameter potential fit for argon at low temperatures] 

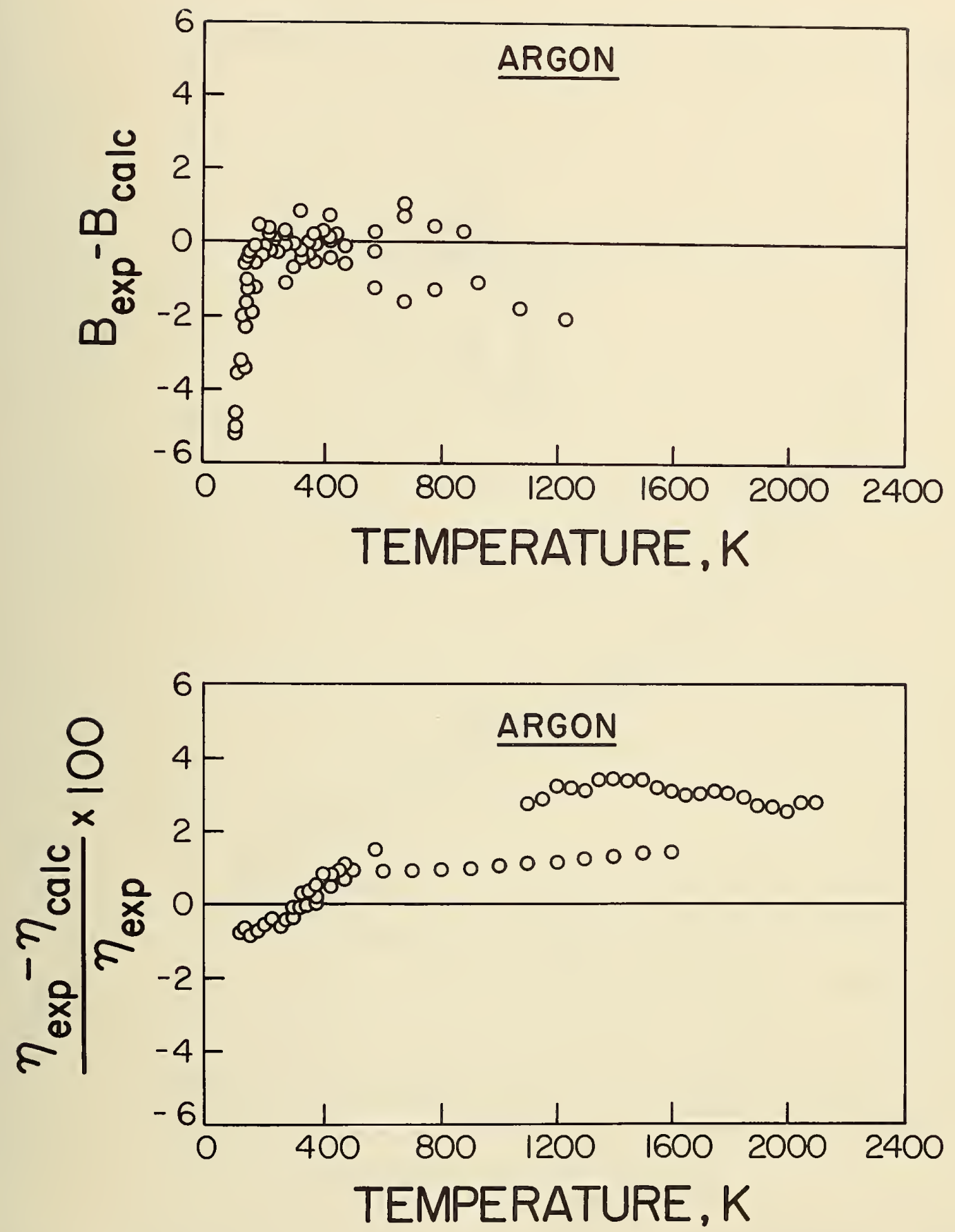

Figure 12. Deviation plots for the second virial and viscosity coefficients of argon based on the m-6-8 potential with the inverse sixth power coefficient fixed at $\sim 60 \times 10^{-60}$ ergs $/ \mathrm{cm}^{6}: m=11, \gamma=2.0, \sigma=3.356 \AA$, $\epsilon / k=137 \mathrm{~K}$. Data not distinguished. 


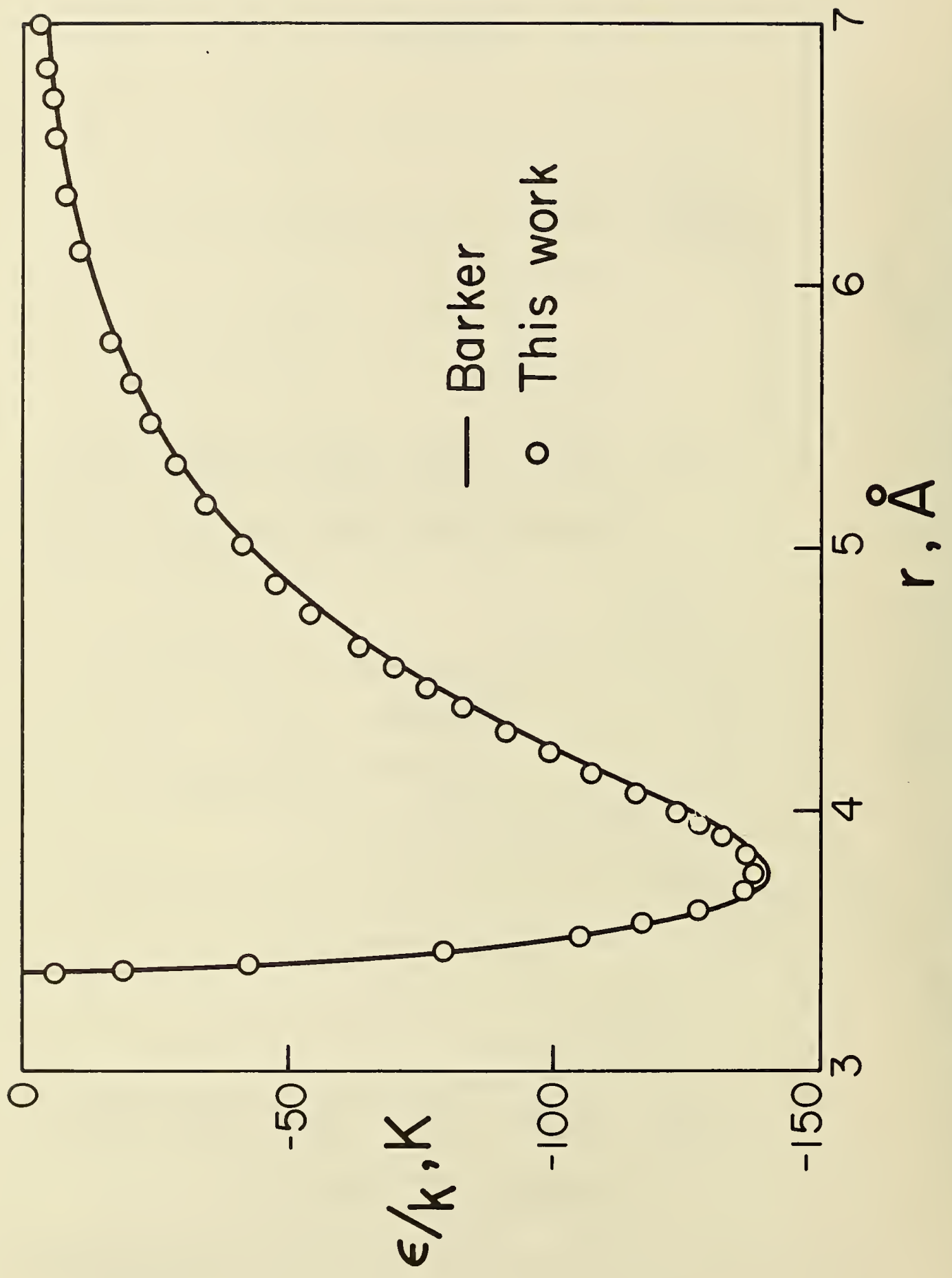

苛 is 0

อ

- 0 मे

I

(2) .

-1.7 un 0

0.

ڤ 己

๑ 요

尺 010

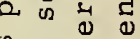

थ 3 थ

Е ते

. 爷垫

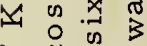

$\therefore \quad u \quad 0$

$\rightarrow \underset{\perp}{\rightarrow} U$

II 0 \& 4

또 언

$\omega$ 도

ฮ

๘山.

出嵌

বح

in

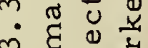

iा 4 क

- 0 م

- 4 U 4

- 20 0

이듀

글

11000

$>$ त वे

a $-\vec{y}$ \&

二 B

॥ वै

ह 2

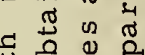

$\stackrel{1}{ \pm} 0 \stackrel{1}{1}$

3 a

न ब

त. $=0$

¿ $0 \frac{1}{3}$

म 5 i

口 Ш

$\infty$ 吾 ั

b $\Rightarrow 50$

1. त क त

ट मै

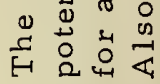

a) 

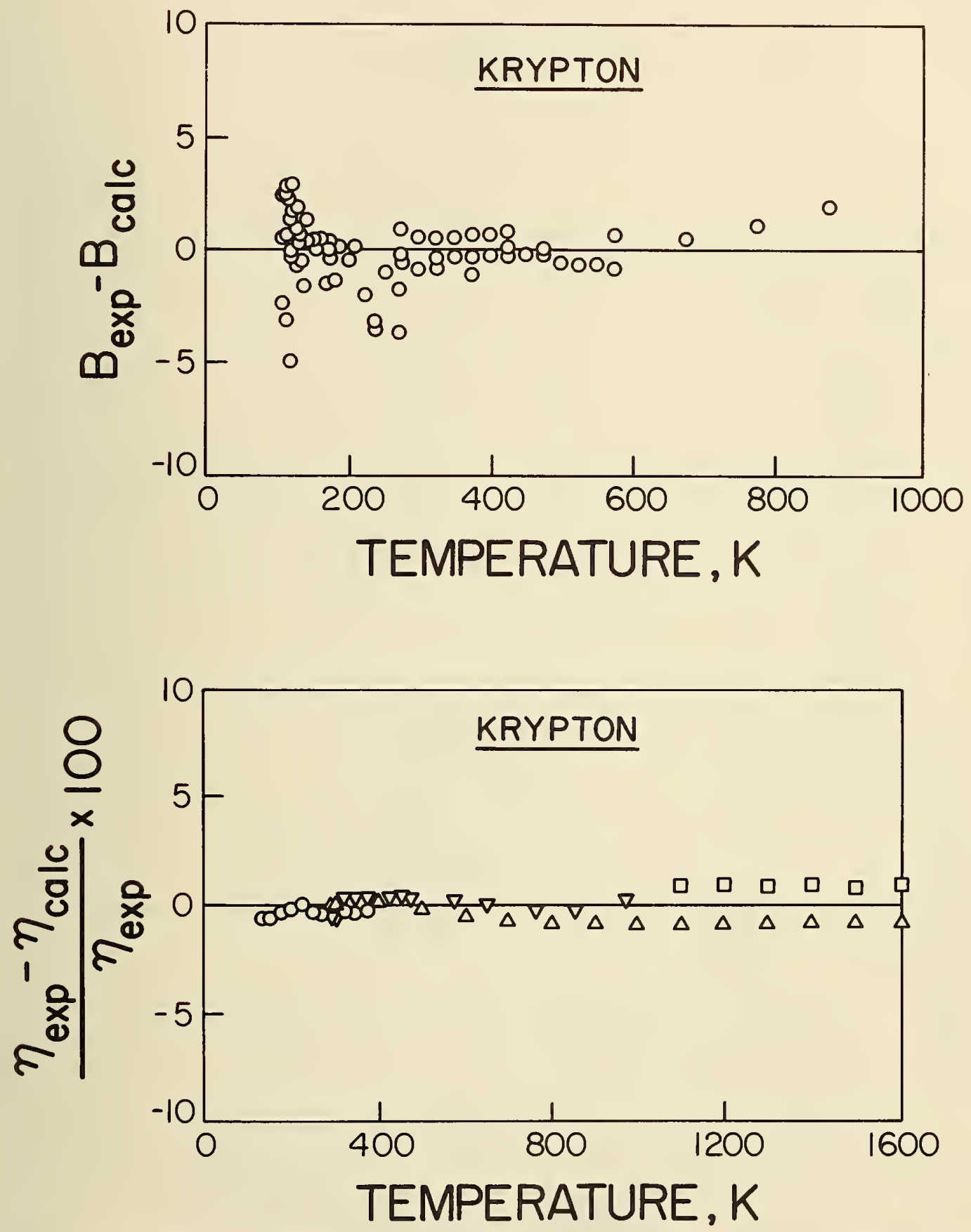

Figure 14. Deviation curves for the viscosity and second virial coefficients of krypton. Data for viscosity, $0[14], \Delta[15], \nabla[16], \quad$ [44]. Theoretical values determined for eqs (11) and (12) with the m-6-8 potential, parameters as given in table 1. 

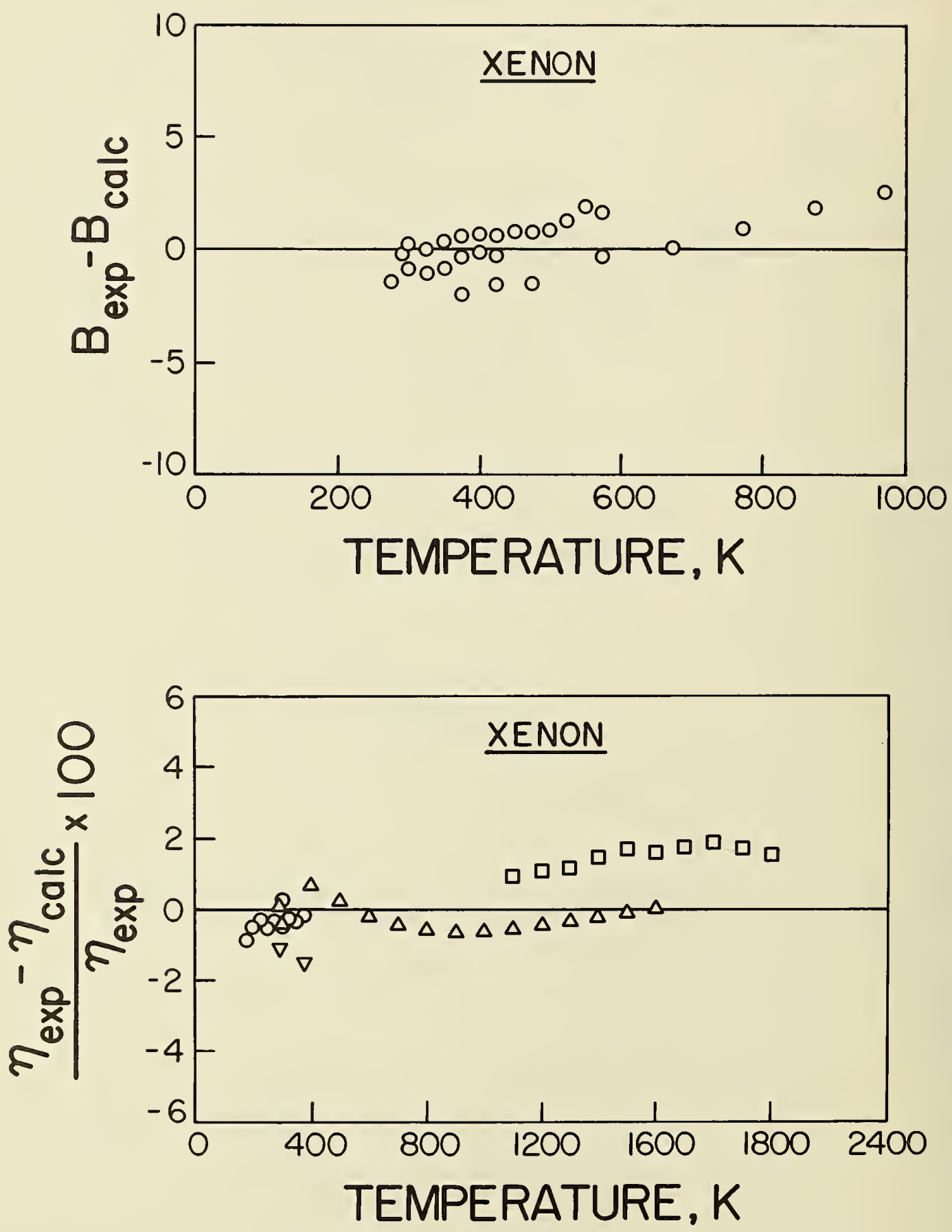

Figure 15. Deviation curves for the viscosity and second virial coefficients of xenon. Data for viscosity, $0[14], \Delta[15], \square[45], \nabla[46,47]$. See table 1 . 


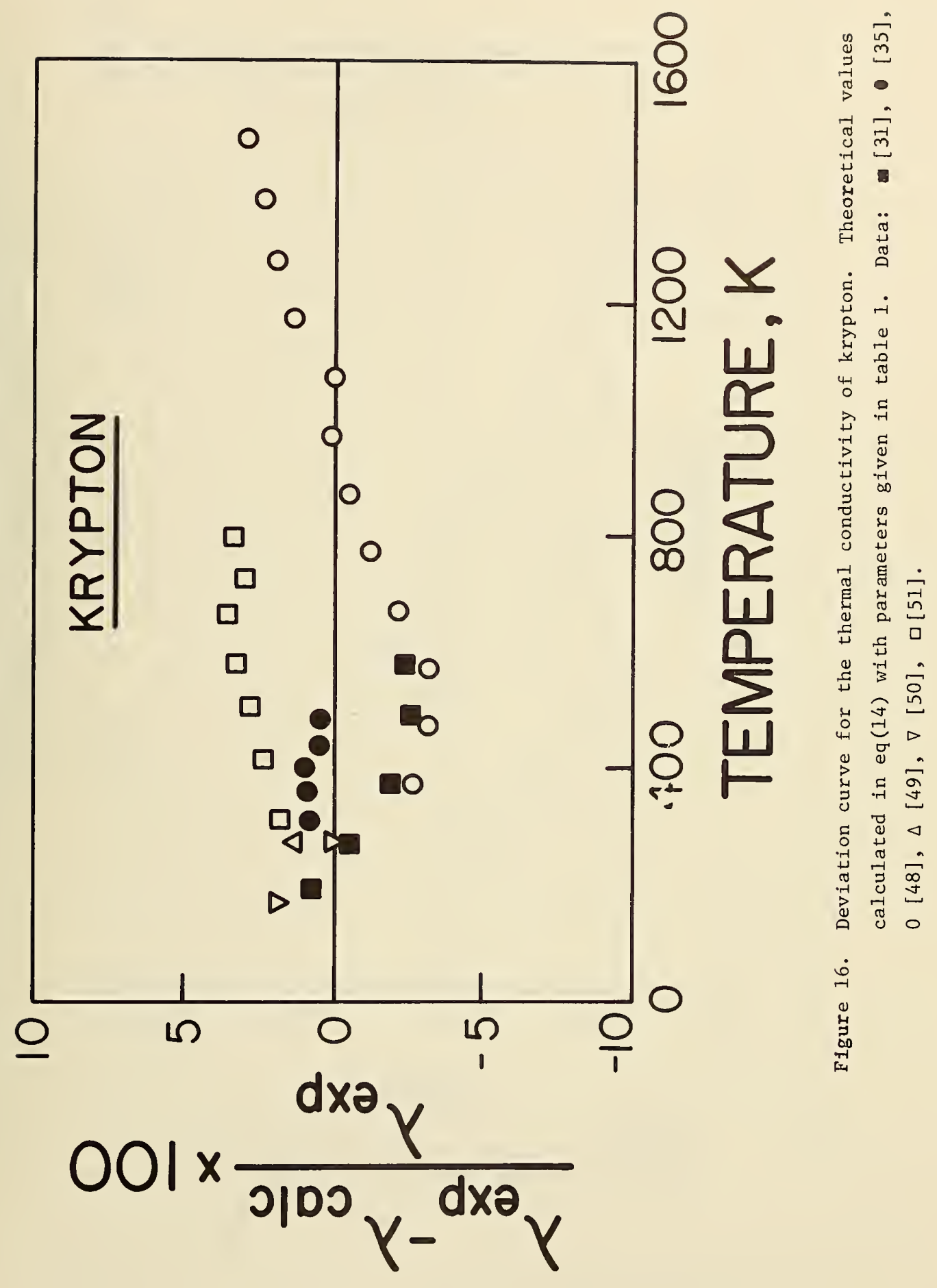




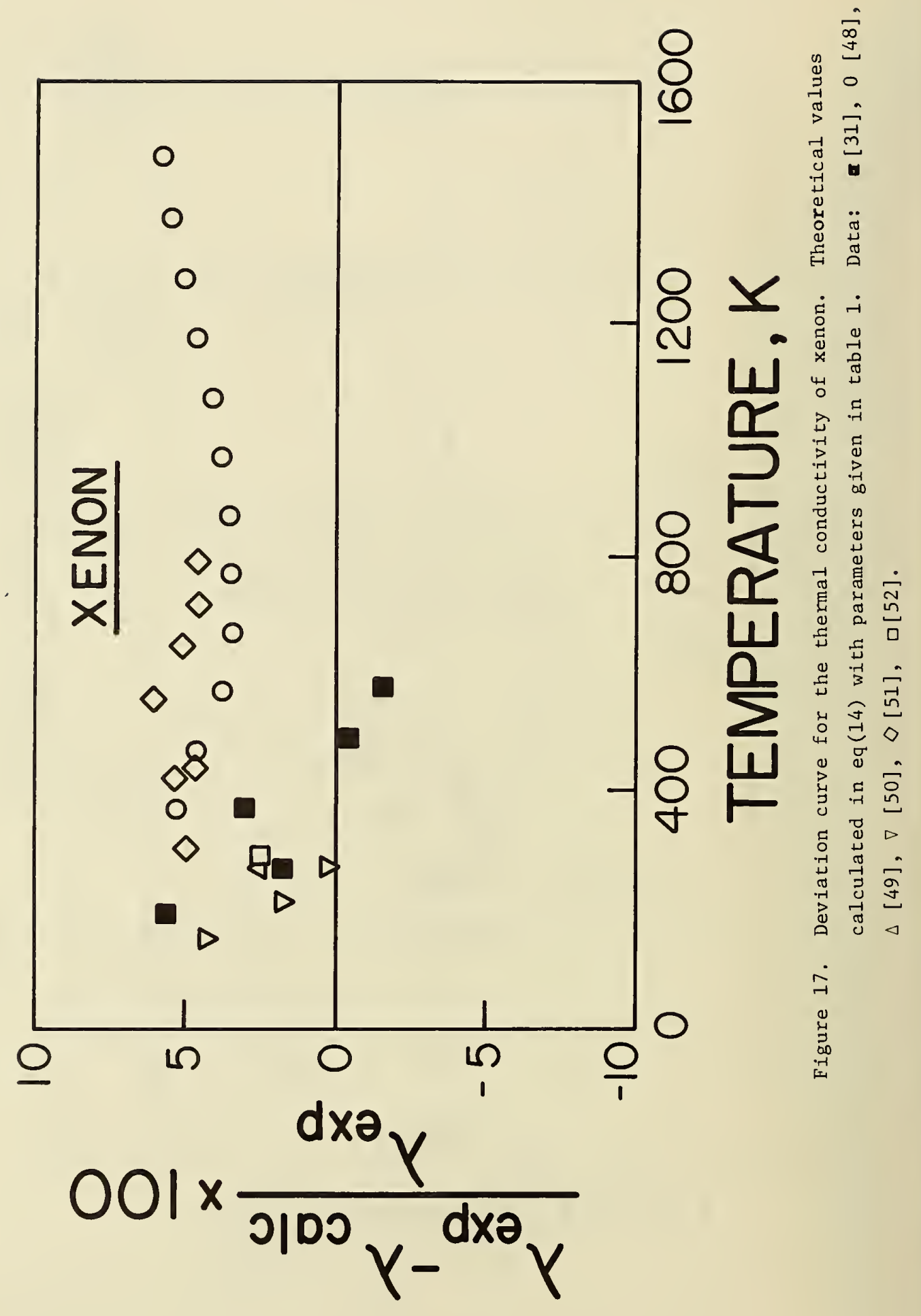




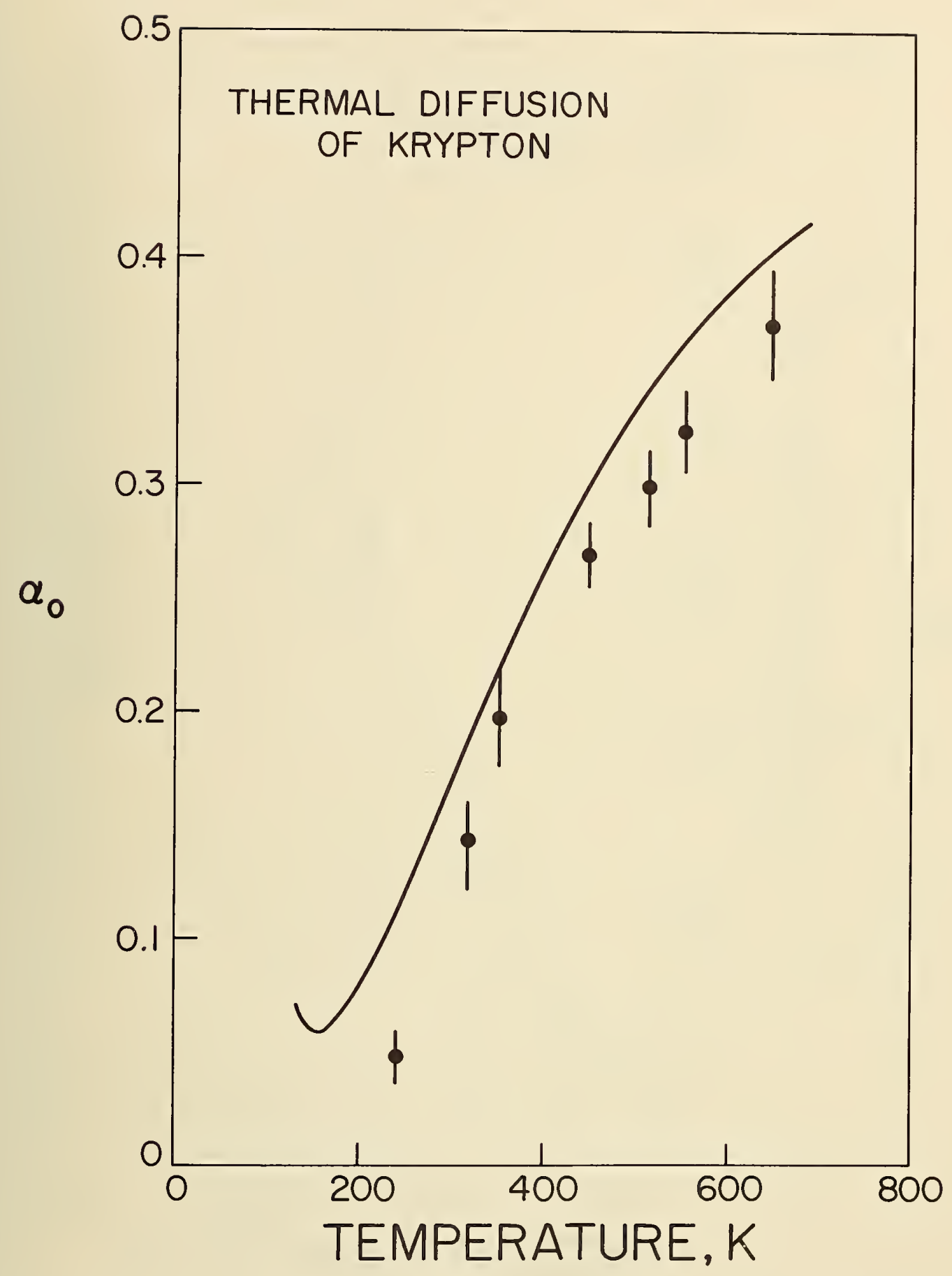

Figure 18. The isotopic thermal diffusion factor for krypton calculated from eq(16), using parameters given in table 1, compared to experiment [53]. 


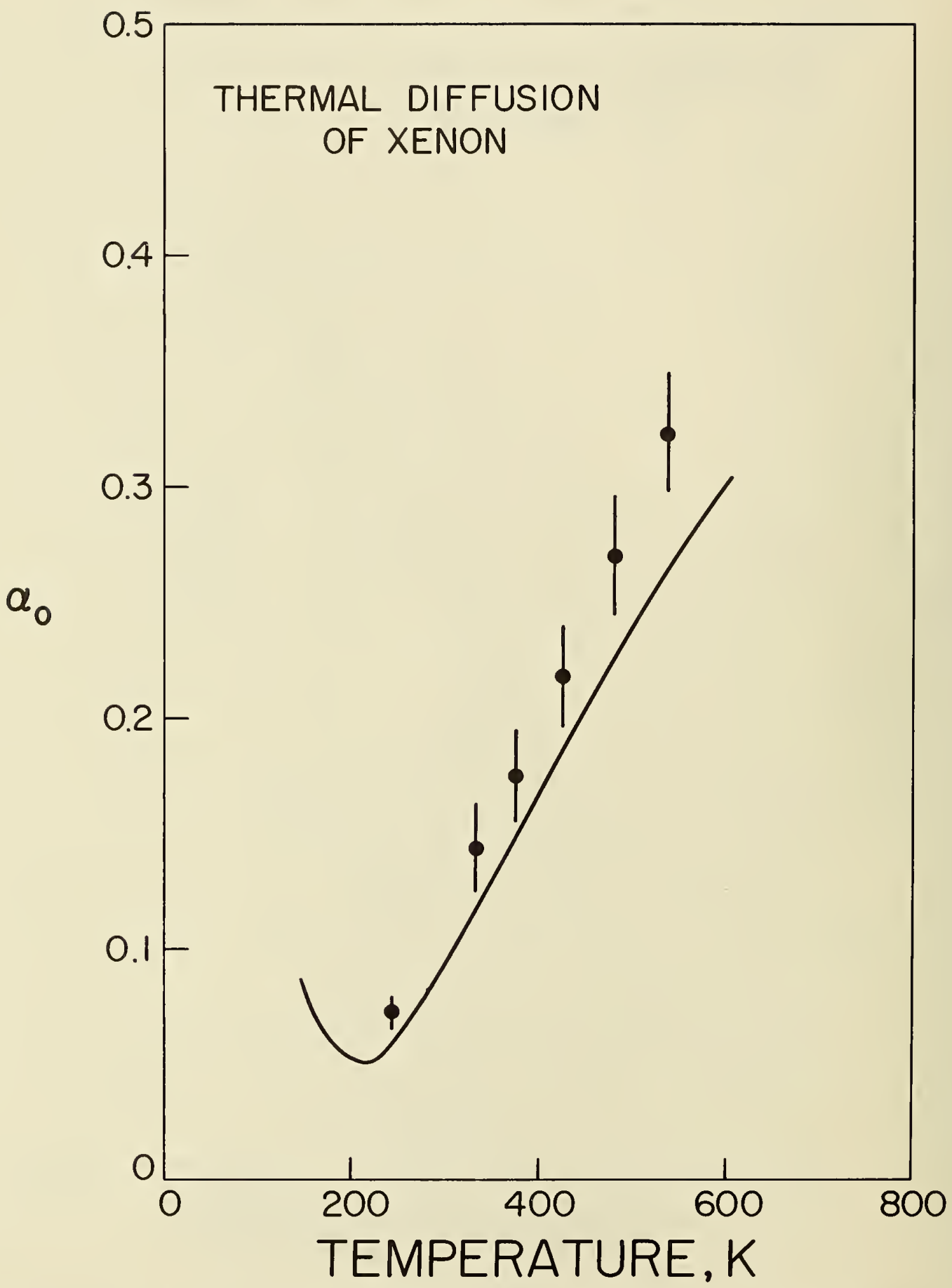

Figure 19. The isotopic thermal diffusion factor for xenon calculated from eq(16), using parameter given in table 1 , compared to experiment [54]. 


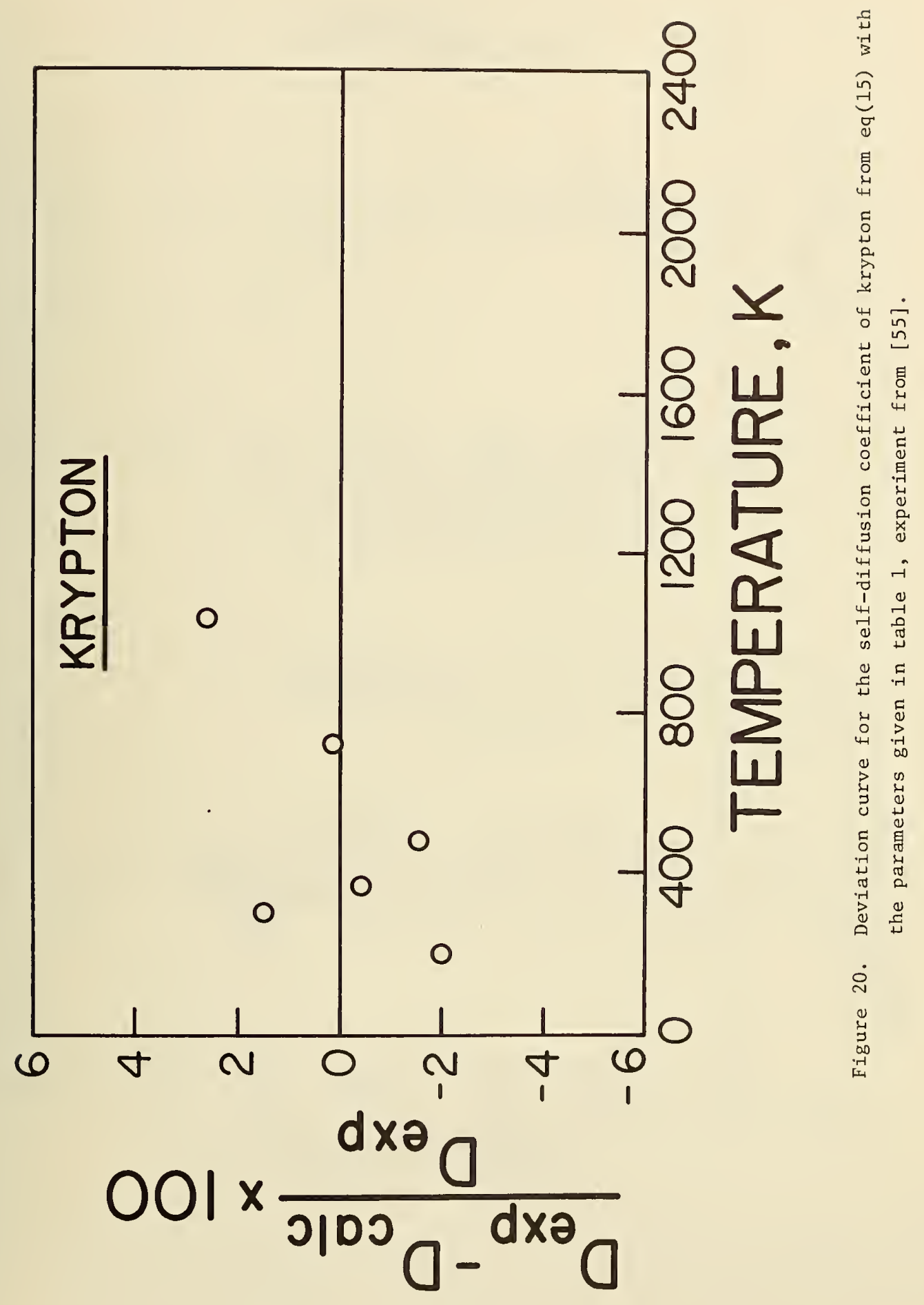



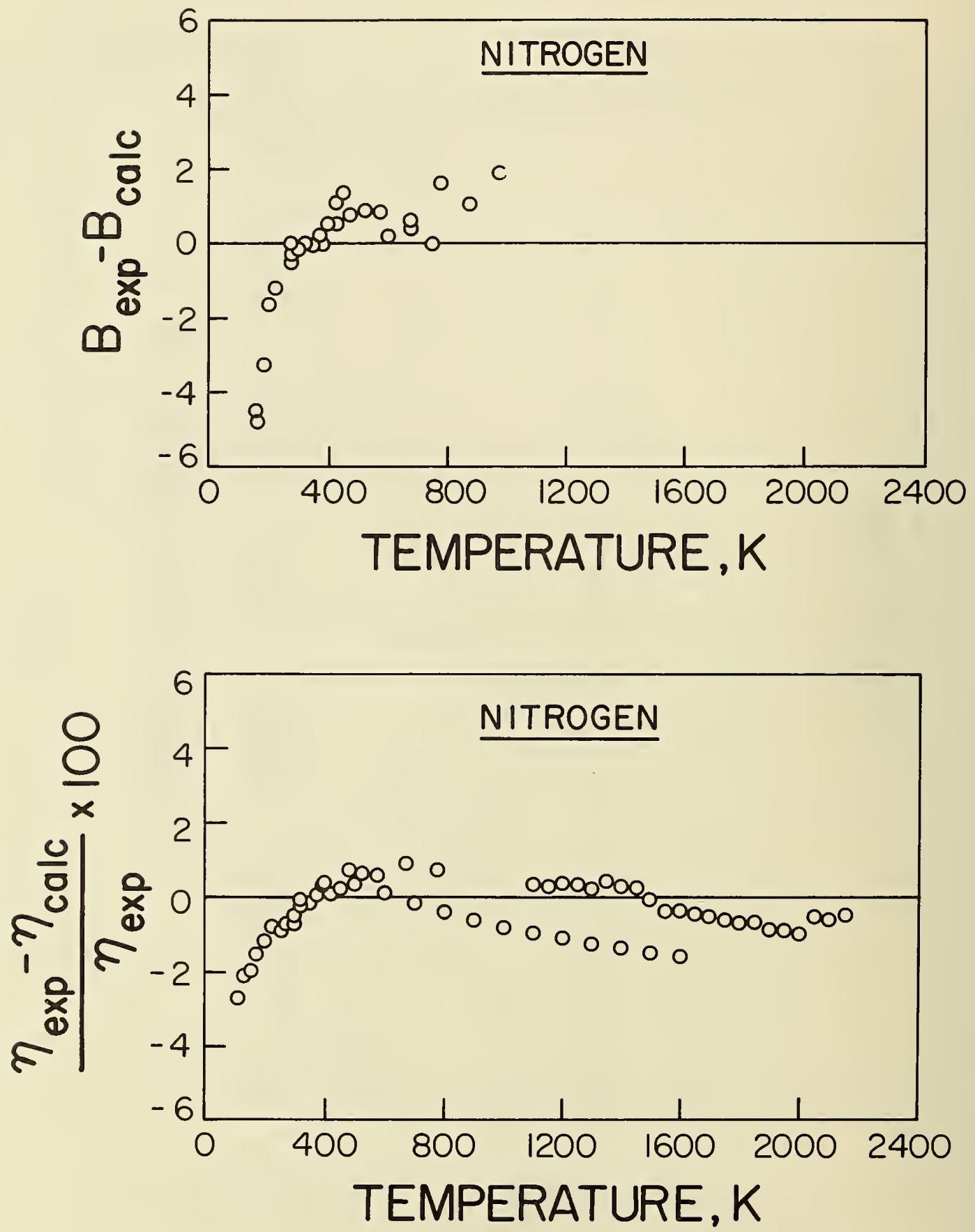

Figure 21. Deviation curves for the viscosity and second virial coefficients of nitrogen based on a simultaneous fit. Parameters: $m=10, \gamma=1.0, \sigma=3.694 \AA$ and $\varepsilon / k=87.0 \mathrm{~K}$. Data (not distinguished): viscosity [13-16], second virial coefficient [17]. 

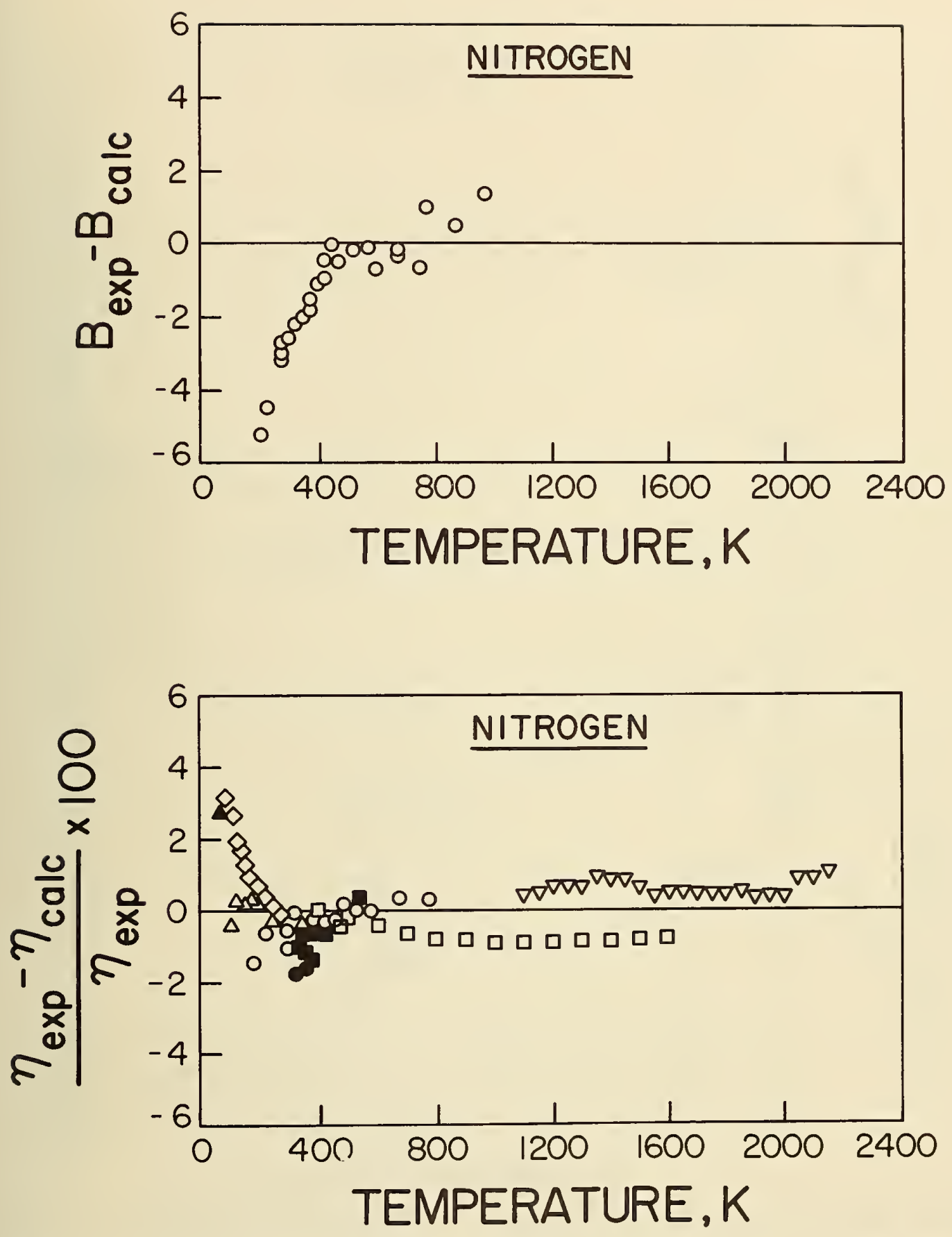

F1gure 22. Fits of the viscosity and second virial coefficients of nitrogen based on a fit of the viscosity data. Parameters $m=12, \gamma=2.0, \sigma=3.54 \AA, \varepsilon / \mathrm{k}=$ $118.0 \mathrm{~K}$. Viscosity data, $\nabla[13], \Delta[14], \square[15], 0[16], \square[22], \circlearrowleft[56]$, $\Delta[57], \quad[58]$. 

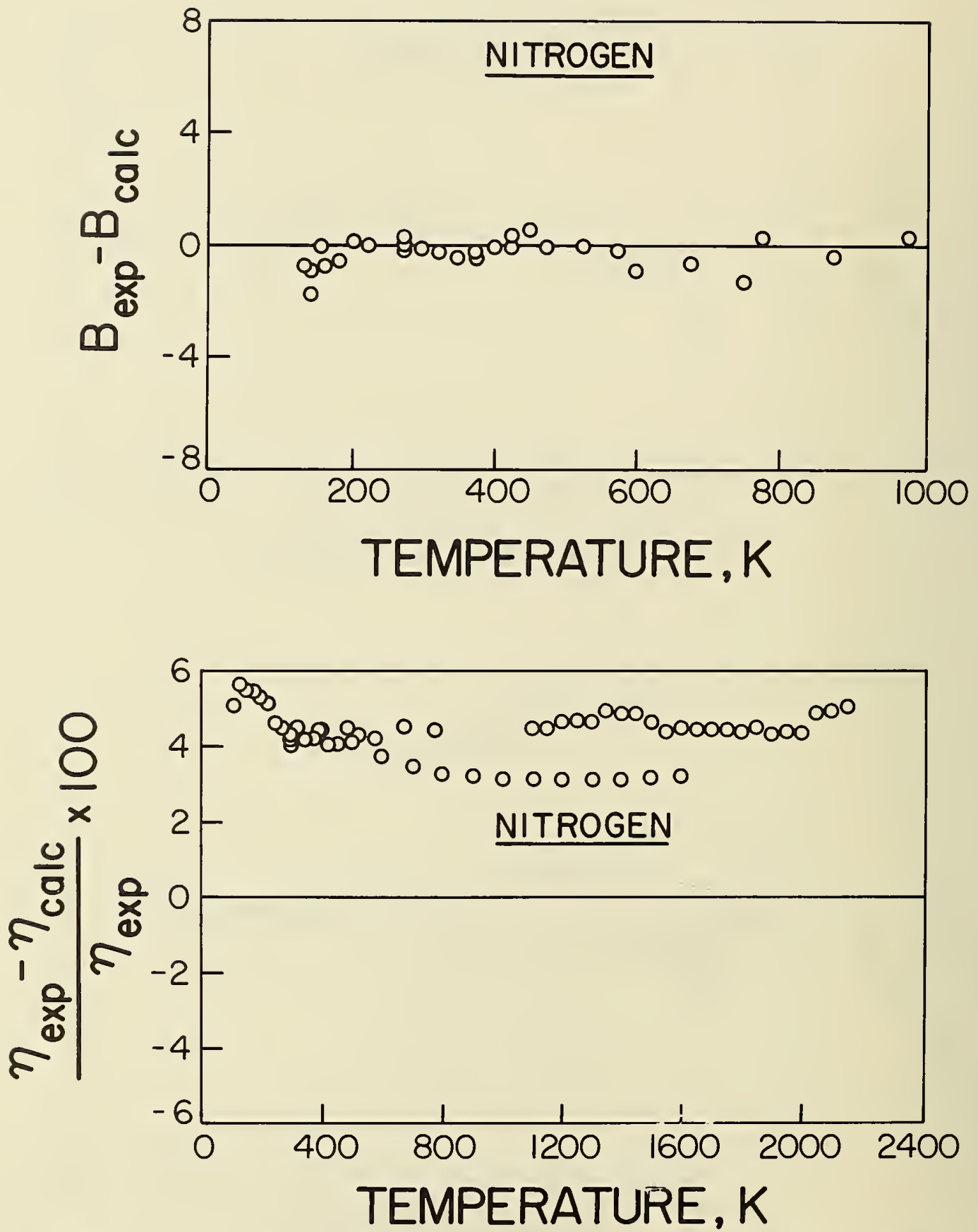

Figure 23. Deviation curves for the viscosity and second virial coefficients of nitrogen based on a fit of the second virial coefficient alone. Parameters, $m=12$, $\gamma=2.0, \sigma=3.60 \AA, \varepsilon / \mathrm{k}=118.0 \mathrm{~K}$. Note (a) the unusual deviation pattern for the viscosity, (b) that the potentials used here and in figure 22 differ only by a small amount in $\sigma$. 


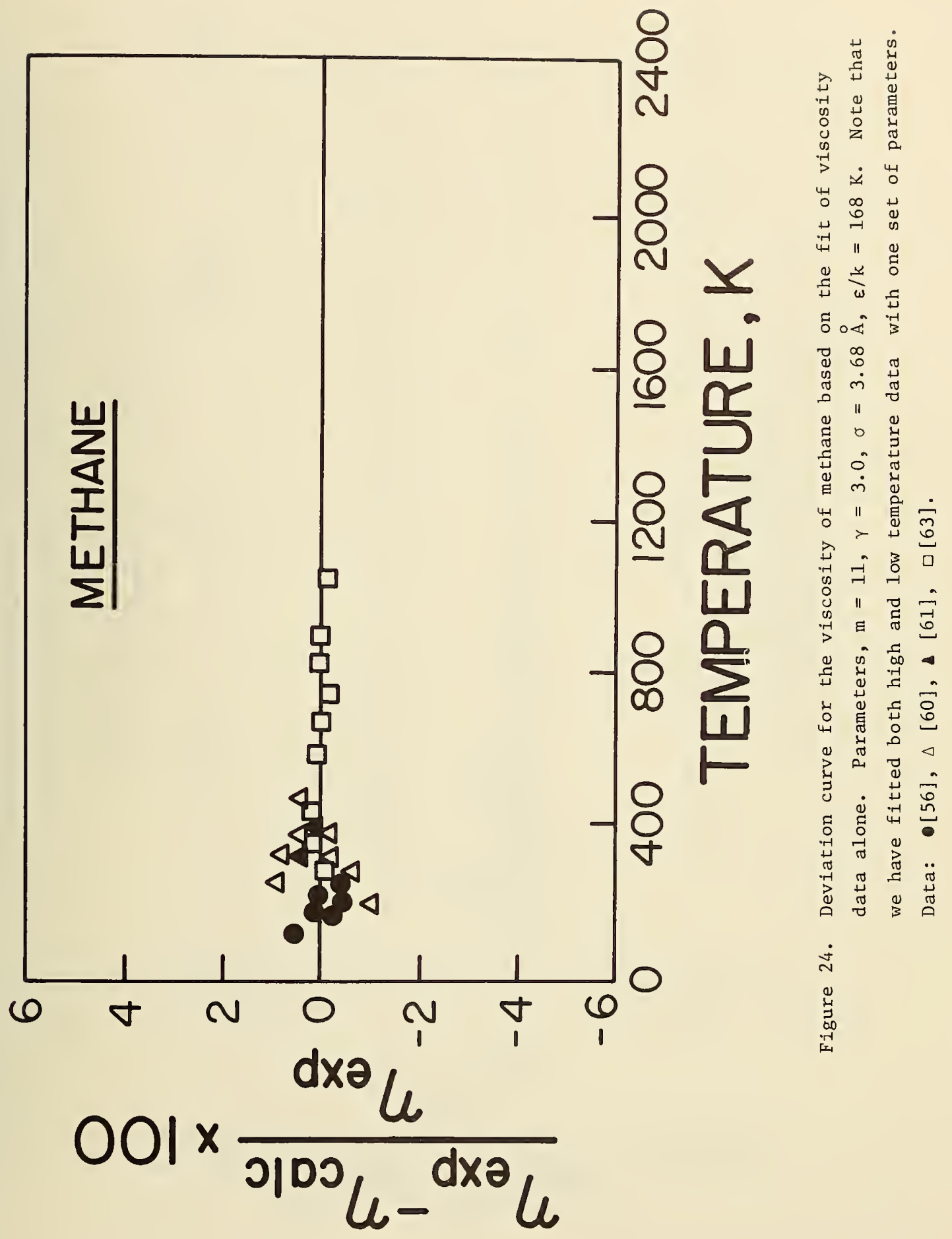




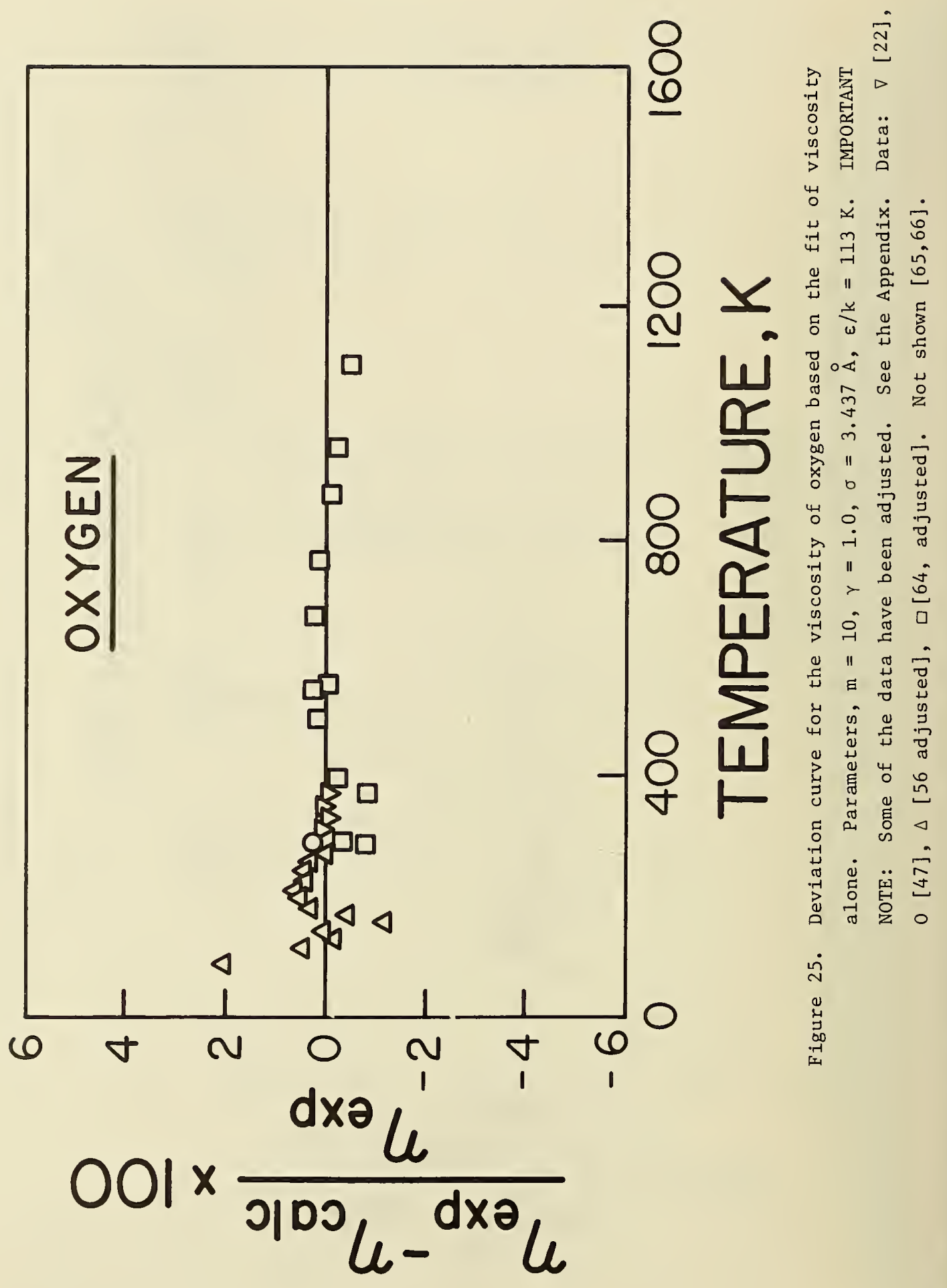




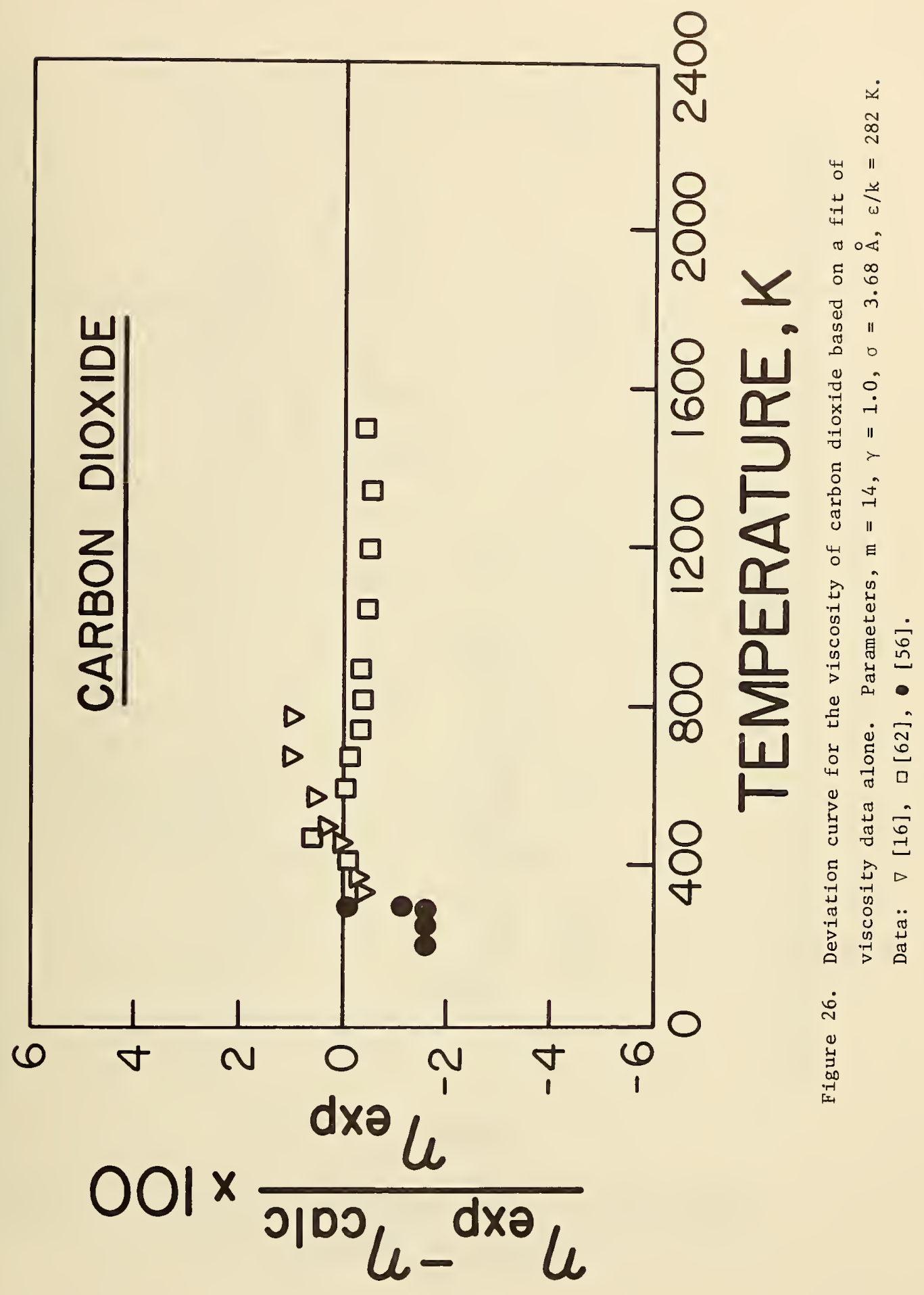




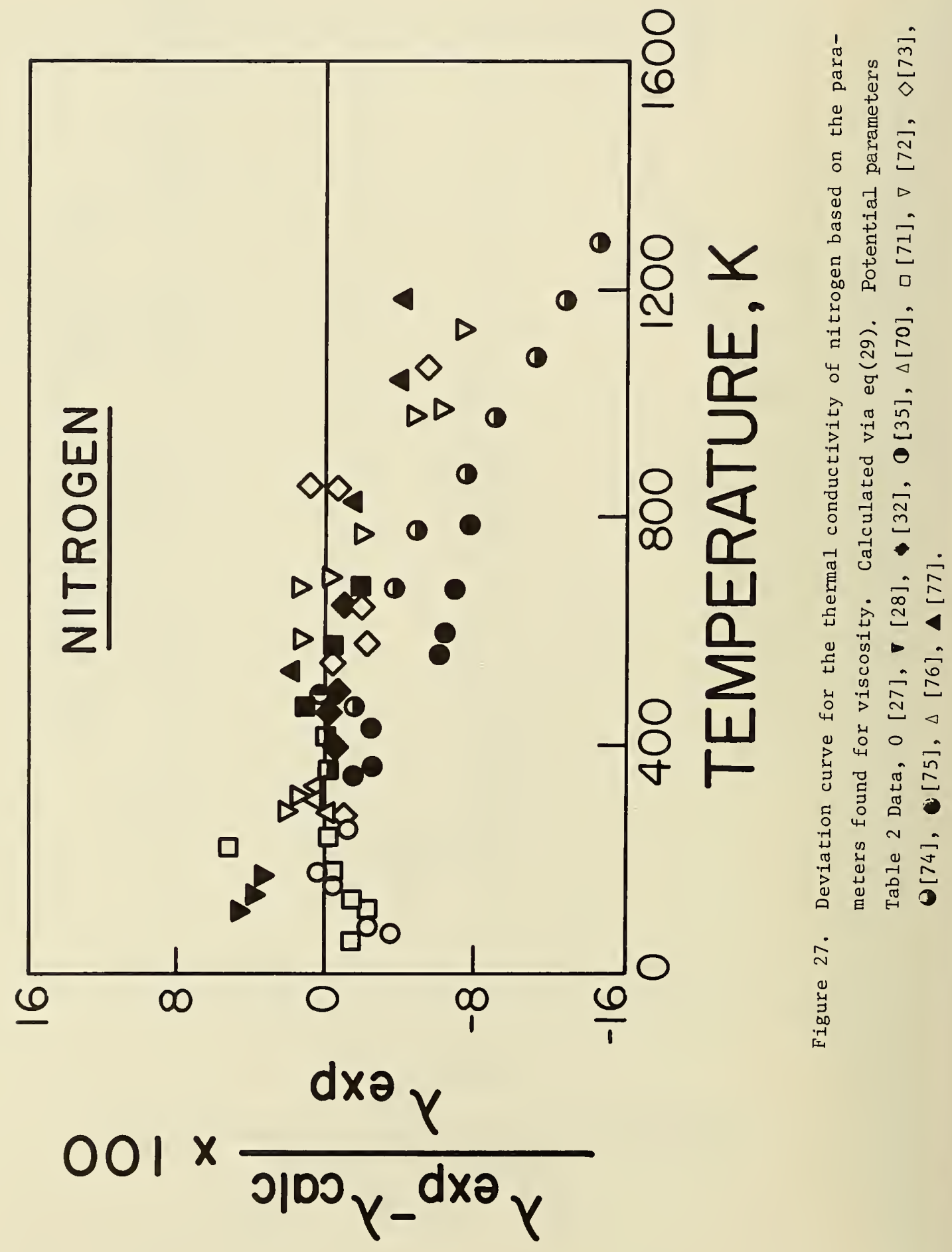




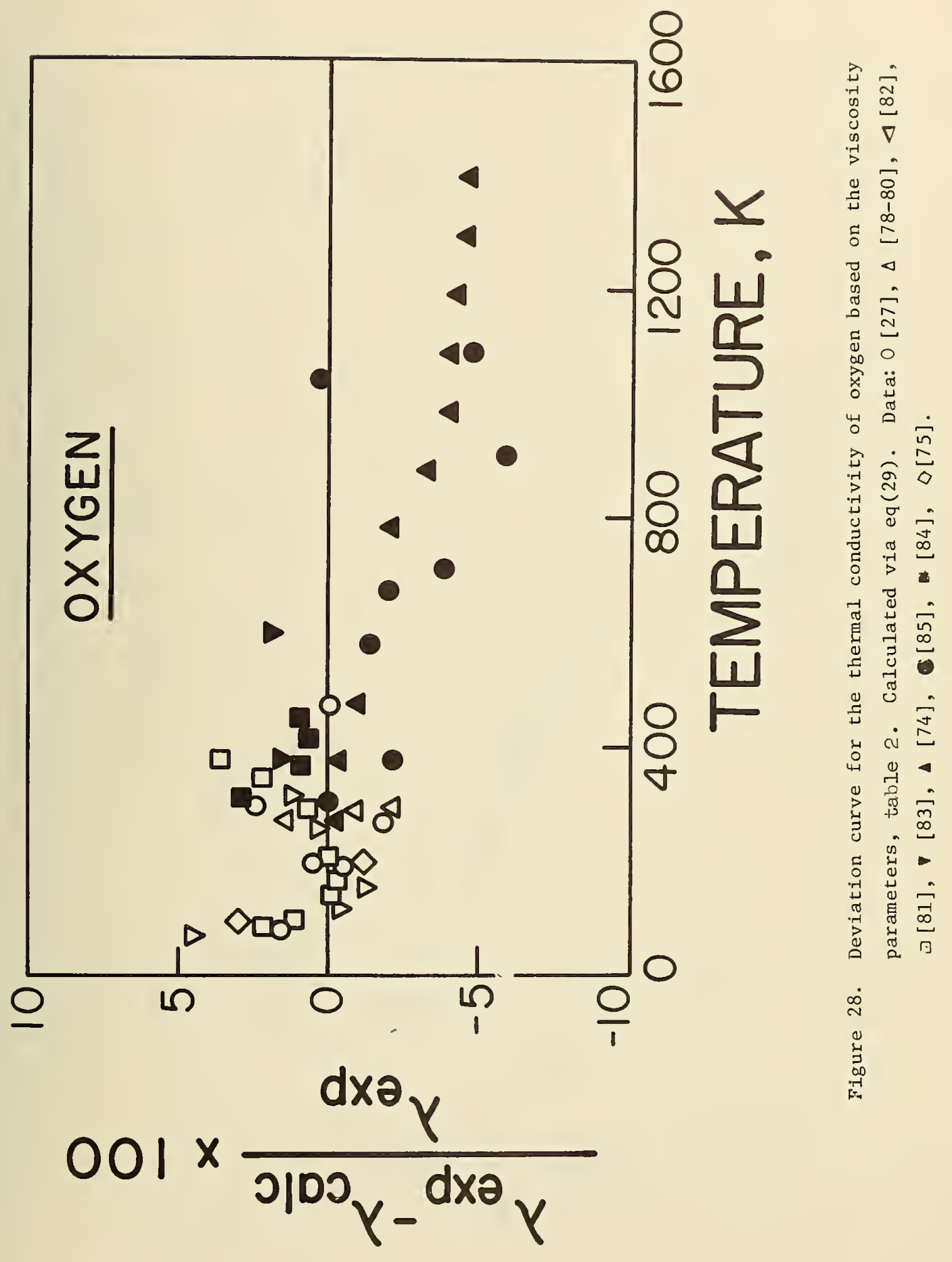




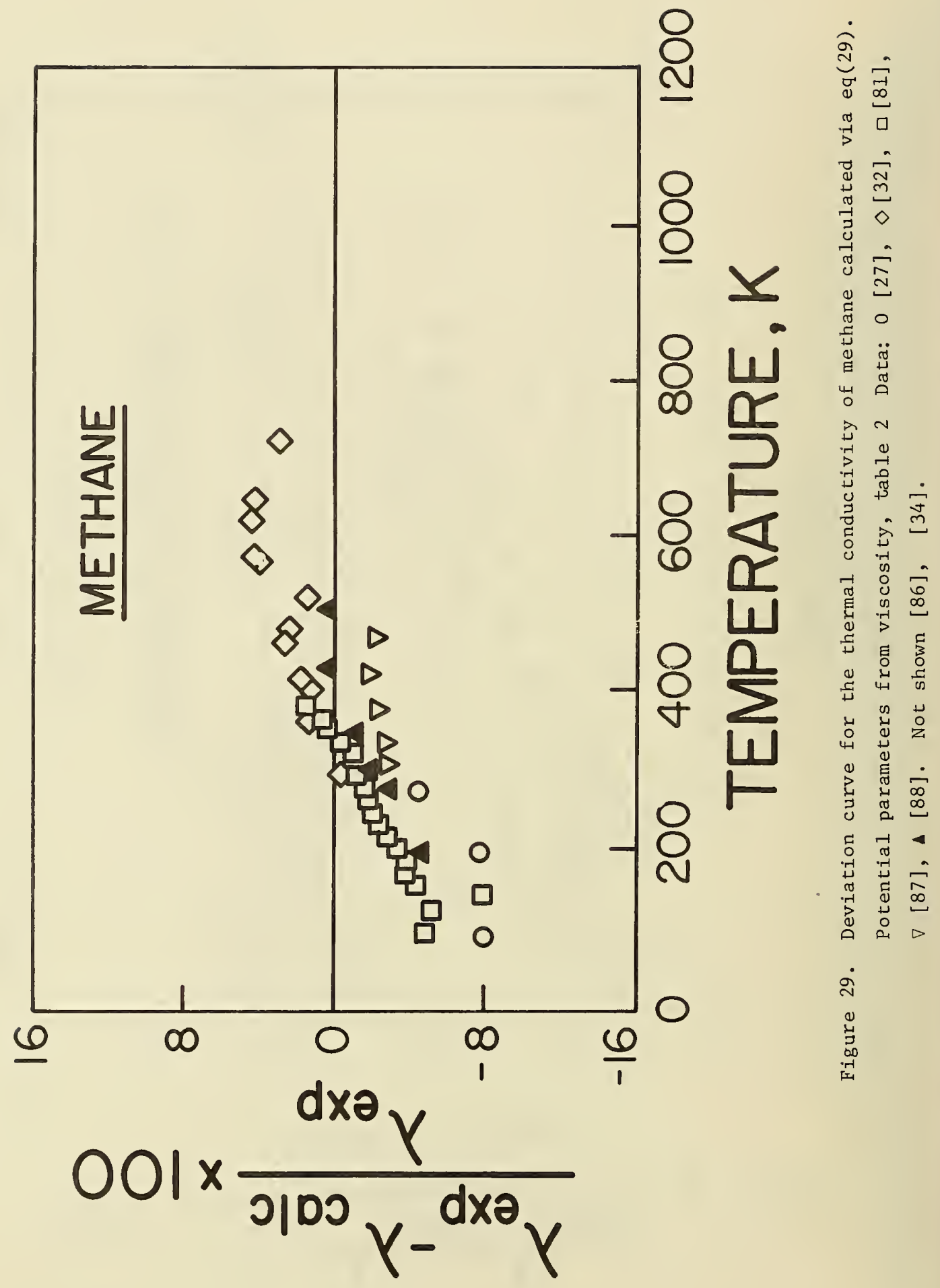




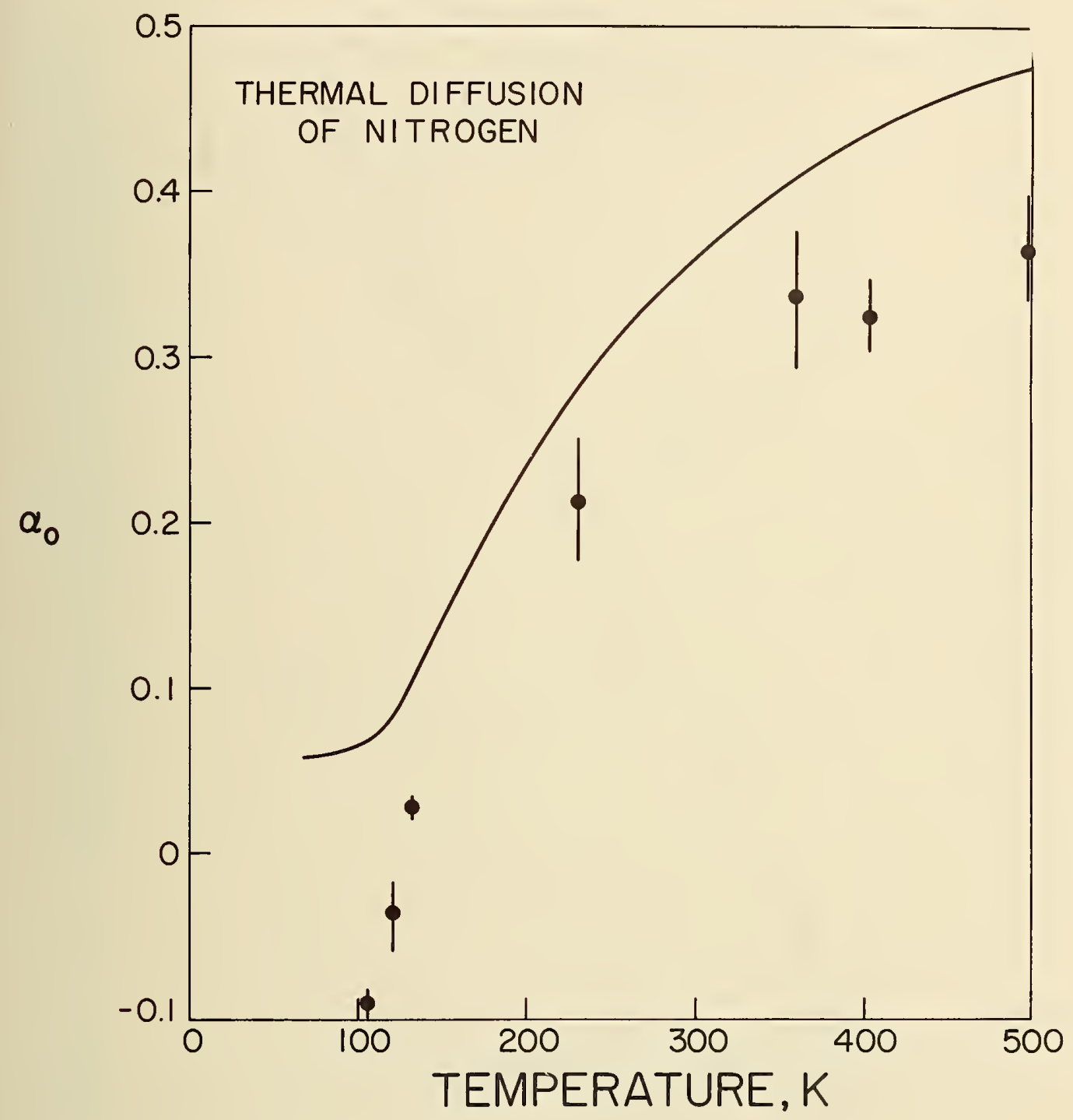

Figure 30. Isotopic thermal diffusion factor for nitrogen calculated from eq(16) with the potential parameters used for viscosity. Data from reference [92]. 


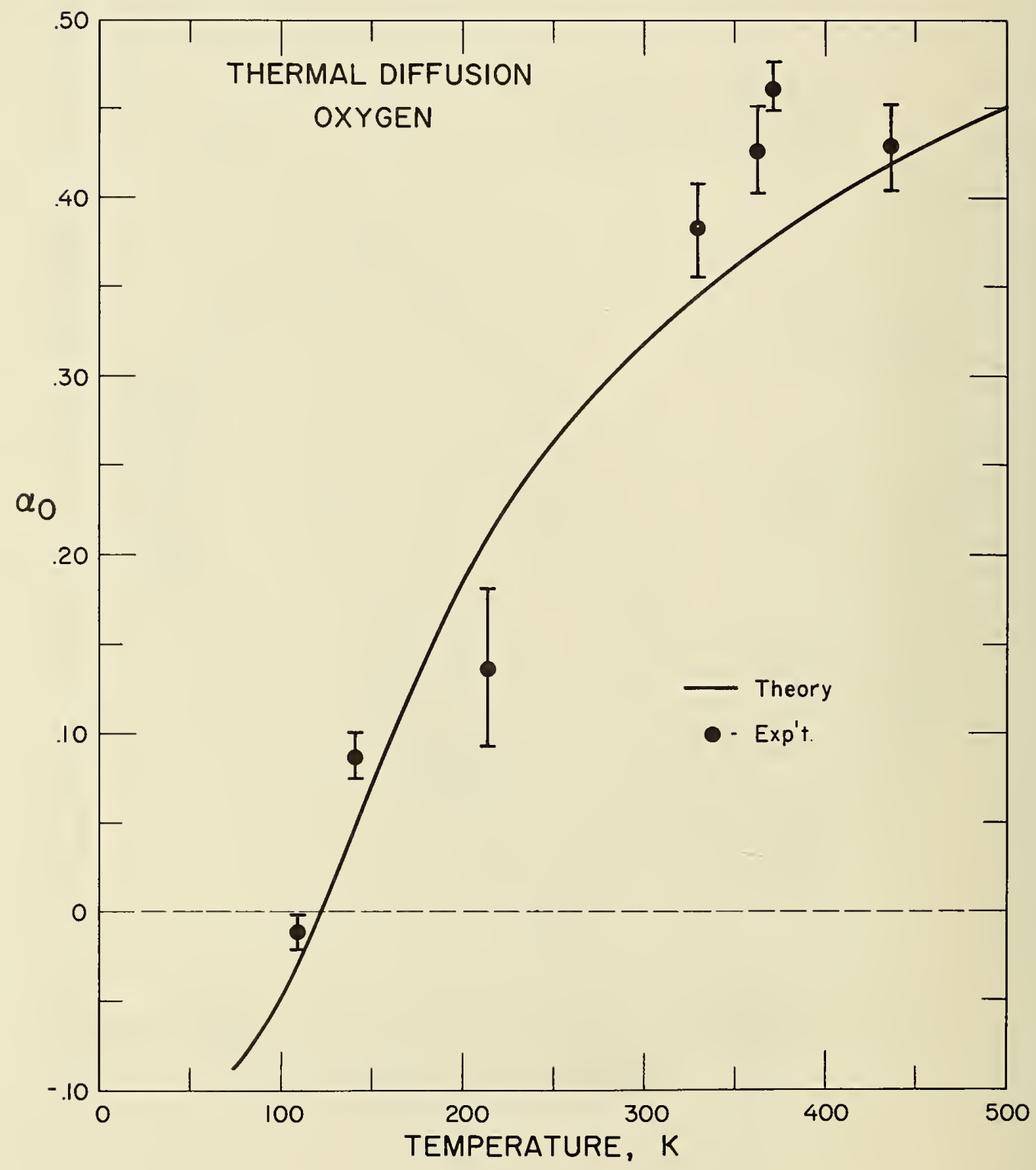

Figure 31. Isotopic thermal diffusion factor for oxygen calculated from eq(16) with the viscosity potential parameters. Data from reference [93]. 


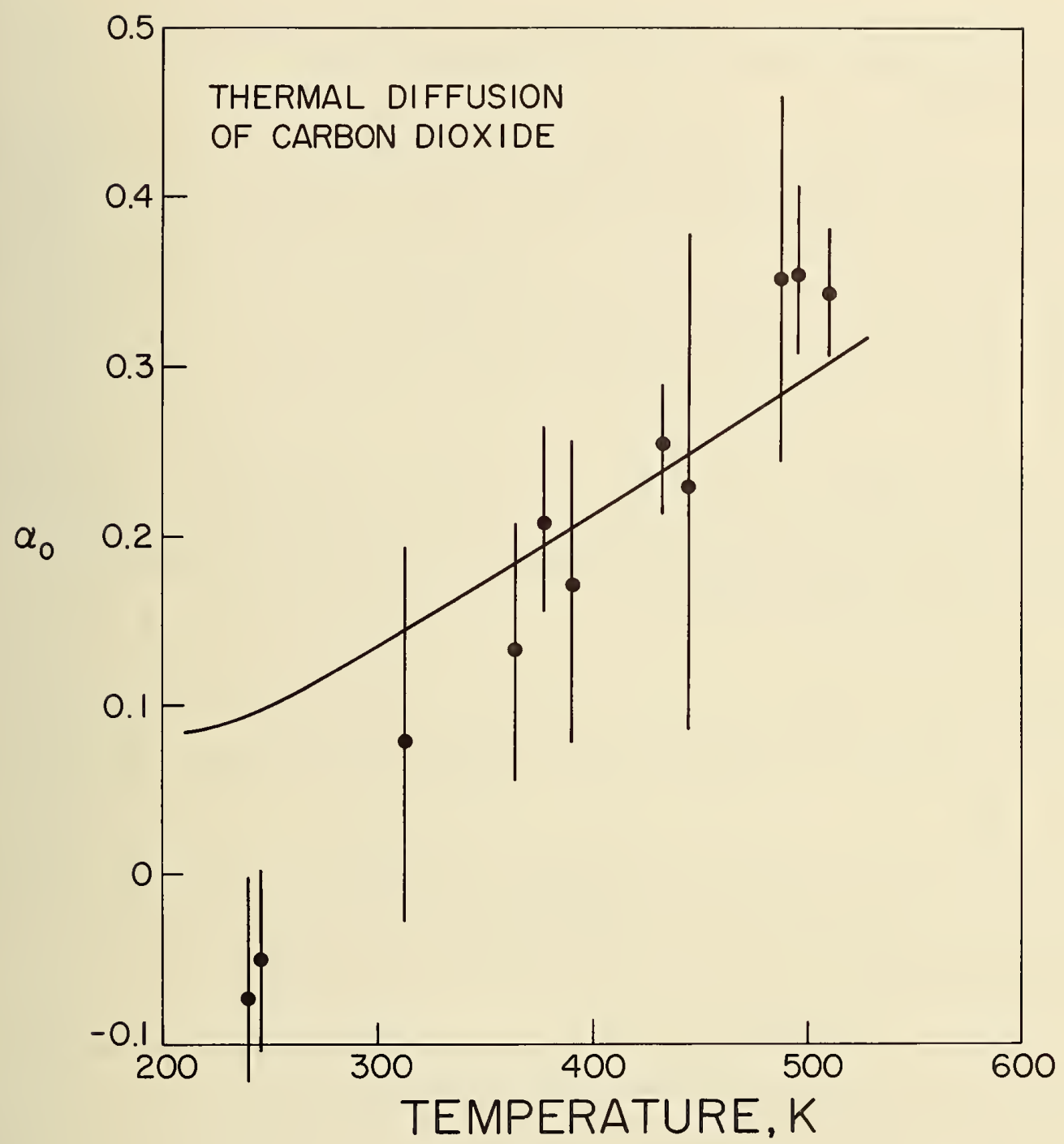

Figure 32. Isotopic thermal diffusion factor for carbon dioxide calculated from eq(16) with the viscosity potential parameters. Data from reference [94]. 


\section{References}

1. Hanley, H.J.M. and Klein, M., On the Selection of the Intermolecular Potential Function: Application of Statistical Mechanical Theory to Experiment, Nat. Bur. Stand., Tech. Note 360 (Nov. 1967)

2. Klein, Max and Hanley, H.J.M., Selection of the Intermolecular Potential, Part 2, From Data of State and Transport Properties Taken in Pairs, Trans. Faraday Soc. $\underline{64}$, 2927-2938 (1968)

3. Hanley, H.J.M. and Klein, M., Selection of the Intermolecular Potential Function, III; From the Isotopic Thermal Diffusion Factor, J. Chem. Phys. 50, 4765-4770 (1969).

4. The particular choice of reducing $T$ is made for convenience only; there is no special significance in the use of the $12-6$ potential.

5. Barker, J.A. and Pompe, A., Atomic Interactions in Argon, Aust. J. Chem. 21, 1683-1694 (1968). See also reference 43.

6. For example: Mason, E.A., Munn, R.J. and Smith, F.J., Recent Work on the Determina-tion of the Intermolecular Potential Function, Discussions Faraday Soc. 40, 27-34 (1965); Munn, R.J. and Klein, M.L., Interaction Potential of the Inert Gases, II, J. Chem. Phys. $\underline{43}$, 3998-4002 (1965).

7. Dymond, J.H. and Alder, B.J., Pair Potential for Argon, J. Chem. Phys, 51, 309-20 (1969).

8. Klein, Max, Smith, F.J., Hanley, H.J.M. and Holland, P.M., NBS-NSSRS Monograph, In press, 1972.

9. For example, about $1 \%$ precision is required for viscosity, thermal conductivity and diffusion, approximately $10 \%$ for thermal diffusion, and about $0.5 \%$ for the second virial coefficient.

10. Hirschfelder, J.O., Curtiss, C.F. and Bird, R.B., Molecular Theory of Gases and Liquids, John Wiley \& Sons, New York (1964), Second Printing.

11. We have verified that our conclusions obtained by studying the relationship of the potential with the transport properties are not affected by taking the statistical mechanical expressions to the first approximation only.

12. Hanley, H.J.M. and Childs, G.E., Discrepancies Between Viscosity Data for Simple Gases, Science 159, 1114-1116 (1968).

13. Guevara, F.A., McInteer, B.B. and Wageman, W.E., High Temperature Viscosity Ratios for Hydrogen, Helium, Argon, and Nitrogen, Phys. Fluids 12, 2493-2502 (1969). 
14. Clark, A.G. and Smith, E.B., Low Temperature Viscosities of Argon, Krypton and Xenon, J. Chem. Phys. 48, 3988-3991 (1968).

15. Dawe, R.A. and Smith, E.B., Viscosities of the Inert Gases at High Temperatures, J. Chem. Phys. 52, 693-703 (1970).

16. Kestin, J., Wakeham, W. and Watanabe, K., Viscosity, Thermal Conductivity and Diffusion Coefficient $\mathrm{Ar}-\mathrm{Ne}$, and $\mathrm{Ar}-\mathrm{Kr}$, Gaseous Mixtures in the Temperature Range 25-700 ${ }^{\circ}$, J. Chem. Phys. 53, 3773-3750 (1970); Dipippo, R. and Kestin, J., the Viscosity of Seven Gases up to $500^{\circ} \mathrm{C}$ and its Statistical Interpretation, Brown University Report NSF-GK 1305 (1967).

17. Senger, J.M.H. Levelt, Klein, Max and Gallagher, J.S., to appear in the American Institute of Physics Handbook, McGraw-Hill Book Company, New York. Also available as Report AEDC-TR-71-39, Arnold Engineering and Development Center, Tullahoma, Tennessee. This report can be obtained from the Clearing House for Federal Scientific and Technical Information (CFSTI), Springfield, Virginia 22151 as AD 719749.

18. This "turn around" was predicted in [2] from a study of the comparison of the 12-6 potential with the other m-6 potentials but was not observed experimentally up to that time. We have used more recent viscosity data for our examination here, however [14].

19. Johnston, H.L. and Grilly, E.R., Viscosities of Carbon Monoxide, Helium, Neon, and Argon Between $80^{\circ}$ and $300^{\circ} \mathrm{K}$, Coefficients of Viscosity, J. Phys. Chem. 46, 948-963 (1942).

20. Gracki, J.A., Flynn, G.P. and Ross, J., Viscosity of Nitrogen, Helium, Hydrogen and Argon from $-100^{\circ}$ to $25^{\circ} \mathrm{C}$ up to $150-250 \mathrm{~atm} ., \mathrm{J}$. Chem. Phys. 51, 3856-3863 (1969).

21. Timrot, D.L., Sevednitskaya, M.A. and Traktueva, S.A., Teploenergetika 16, 83-84 (1969).

22. Wobser, R. and Muller, F., Die innere Reinbung von Gases and und Dampfen und ihre Messung in Hoppler-Viskosimeter (The Viscosity of Gases and Vapors and Thelr Measurement with the Hoppler Viscometer), Kolloid-Beih. 52, 165-276 (1941).

23. Michels, A., Botzen, A. and Schuurman, W., The Viscosity of Argon at Pressures up to 2000 Atmospheres, Physica 20, 1141-1148 (1954).

24. Keyes, F.G. and Vines, R.G., The Thermal Conductivity of Nitrogen and Argon, J. Heat Transfer $\underline{87}$, No. 2, 177-183 (1965).

25. Michels, A., Sengers, J.V. and Van de Klundert, L.J.M., The Thermal Conductivity of Argon at Elevated Densities, Physica 29, 149-160 (1963). 
26. Uhlir, A., Thermal Conductivity of Fluid Argon and Nitrogen, J. Chem. Phys, 20, 463-472 (1952).

27. Eucken, A., Uber die Temperaturabhangigkeit der Warmeleitfahigkeit einiger Gase (Concerning the Temperature Dependence of Thermal Conductivity of Several Gases), Physik Z. 12, 1101-1117 (1911).

28. Ziebland, H, and Burton, J.T.A., The Thermal Conductivity of Nitrogen and Argon in the Liquid and Gaseous States, Brit. J. Appl. Phys. 9, 52-59 (1958).

29. Ikenberry, L.D. and Rice, S.A., Kinetic Theory of Dense Fluids, XIV. Experimental and Theoretical Studies of Thermal Conductivity in Liquid $\mathrm{Ar}, \mathrm{Kr}$, Xe and $\mathrm{CH}_{4}$, J. Chem. Phys. 39, 1561-1571 (1963).

30. Rothman, A.J., Thermal Conductivity of Gases at High Temperatures, U.S. Atomic Energy Comm. Report UCRL 2339, 8-114 (1953).

31. Kannuluik, W.G. and Carman, E.H., The Thermal Conductivity of Rare Gases, Proc. Phys. Soc. (London) B65, 701-709 (1952).

32. Le Neindre, B., Tufeu, R., Bury, P., Johannin, P. and Vodar, B., Thermal Conductivity Measurements of Some Noble Gases, Proc. $8^{\text {th }}$ Conference on Thermal Conductivity, Purdue Univ., Lafayette, Ind. (1968); Le Neindre, B., Thesis; Univ. of Paris 1970; Le Neindre B., private communication.

33. Vargaftik, N.B, and Zimina, N.Kh., Heat Conduction of Argon at High Temperatures, Teplofiz. Vysok. Temp. 2, 716-724 (1964).

34. Van Dael, W. and Cauwenbergh, Measurements of the Thermal Conductivity of Gases.I, Physica $\underline{40}, 165-172$ (1968).

35. Haarmann, J.W., Thesis, Delft, The Netherlands (1969).

36. Hutchinson, F., Self-Diffusion in Argon, J. Chem. Phys. 17, No. 11, 1081-1086 (1949); Winn, E.B., The Temperature Dependence of the Self-Diffusion Coefficients of Argon Neon, Nitrogen, Oxygen, Carbon Dioxide and Methane, Phys. Rev. 80, 1024-1027 (1950).

37. Vugts, H.F., Boerboom, A.J.H. and Los, J., Measurements of Relative Diffusion Coefficients of Argon,Physica 44, 219-226 (1969). Note, these values are relative measurements, relative to $298.15 \mathrm{~K}$.

38. Paz, M.De., Turi, B. and Klein, M.L., New Self-Diffusion Measurements in Argon Gas, Physica 34, 678-890 (1967).

39. Paul, R., Howard, A.J. and Watson, W.W., Isotopic Thermal Diffusion Factor of Argon, J. Chem. Phys. 39, 3053-3056 (1963). 
40. See, for example, Copeland, D.A. and Kestner, N.R., Accurate "Effective" Intermolecular Pair Potential in Gaseous Argon, J. Chem. Phys. 49, 5214-5222 (1968).

41. I. Amdur and J.E. Jordan In Molecular Beams (Advances in Chemical Physics Vo1. 10), J. Ross, editor, Interscience, New York, 1966, Chapter 2.

42. Margenau, H, and Kestner, N.R., Theory of Intermolecular Forces, Pergamon, New York (1969), page 32. See also the appropriate references quoted therein.

43. Bobetic, M.V. and Barker, J.A., Lattice Dynamics with Three Body Forces: Argon, Phys. Rev. B2, 4169-4175 (1970).

44. Goldblatt, M., Guevara, F.A. and McInteer, B.B., High temperature viscosity ratios for krypton, Phys. Fluids 13, 2873-74 (1970).

45. Goldblatt, M., and Wageman, W.E., High Temperature Viscosity Ratios for Xenon, Phys. F1uids 14, 1024-25 (1971).

46. Rankine, A.0., Über die Anderung der inneren Reibung der Gase der Argongruppe mit der Temperatur (On the Variation with Temperature of the Viscosities of the Gases of the Argon Group), Physik. Z. 11, 745-752 (1910).

47. Kestin, J. and Leidenfrost, W., An Absolute Determination of the Viscosity of Eleven Gases Over a Range of Pressures, Physica 25, 1033-1062 (1959).

48. Saxena, V.K. and Saxena, S.C., Therma1 Conductivity of Krypton and Xenon in the Temperature Range 350-1500 K, J. Chem. Phys. 51, 3361-3368 (1969).

49. Curie, M. and Lepape, A., Conductivilite Thermique des Gaz Rares (Thermal Conductivity of Rare Gases), J. Phys. Radium 2, 392-397 (1931).

50. Keyes, F.G., Thermal Conductivity of Gases, Trans. ASME 77, 1395-1396 (1955).

51. Zaitseva, L.S., An Experimental Investigation of the Heat Conductivity of Monatomic Gases Over Wide Temperature Intervals, Soviet Phys. Tech. Phys. 4, 444-450 (1959).

52. Thornton, E., Viscosity and Thermal Conductivity of Binary Gas Mixtures: XenonKrypton, Xenon-Argon, Xenon-Neon and Xenon-Helium, Proc. Phys. Soc. (London) $\underline{76}$, 104-112 (1960).

53. Paul, R. and Watson, W.W., Isotopic Therman-Diffusion Factor for Krypton, J. Chem, Phys. 45, 4132-4134 (1966).

54. Paul, R., Howard, A.J. and Watson, W.W., Isotopic Thermal-Diffusion Factor for Xenon, J. Chem. Phys. 43, 1890-1894 (1965). 
55. Weissman, S. and Dubro, G.A., Self-Diffusion Coefficient for Krypton, Phys, Fluids 13, 2689-2692 (1970).

56. Johnston, H.L. and Mc Closkey, K.E., Viscosities of Several Common Gases Between $90^{\circ}$ $\mathrm{K}$ and Room Temperature, J. Phys. Chem. 44, 1038-1058 (1940).

57. Johnston, H.L., Mattox, W.R. and Powers, R.W., Viscosities of Air and Nitrogen at Low Pressures, Nat'1 Advisory Comm, Aeronaut. Tech. Note No. 2456 (1951).

58. Lazarre, F. and Vodar, B., Measurement of the Viscosity of Compressed Nitrogen up to 3000 Atmospheres, Proc. Conf. Thermodynamic and Transport Properties of Fluids, London, July 1957, Inst. Mech. Engrs, 159-162 (1958).

59. Also the 12-6-8 potential with $\gamma=2.0$ found for nitrogen is similar to the $11-6-\delta$ with $y=3.0$ found for the rare gases. Thus it seems that nitrogen does not deviate much from a simple law of corresponding states as far as the viscosity is concerned.

60. De Rocco, A. and Halford, J.0., Intermolecular Potential of Argon, Methane and Ethane, J. Chem. Phys. 28, 1152-1154 (1958).

61. Giddings, J.G., Kao, J.T.F. and Kobayashi, R., Development of a High Pressure Capillary-Tube Viscometer and its Application to Methane, Propane and their Mixtures in the Gaseous and Liquid Regions, J. Chem. Phys. 45, 578-586 (1966).

62. Maitland, G.C. and Smith, E.B., La Viscosite $\mathrm{CO}_{2}$ Entre $293 \mathrm{~K}$ et $1500 \mathrm{~K}$ (The Viscosity of $\mathrm{CO}_{2}$ Between $293 \mathrm{~K}$ and $1500 \mathrm{~K}$ ), J. Chim. Phys. 67, 631-632 (1970).

63. Dave, R.A., Maitland, G.C., Rigby, M. and Smith, E.B., High Temperature Viscosities and Intermolecular Forces of Quasi-Spherical Molecules, Trans. Faraday Soc. 66 , 1955-1965 (1970).

64. Trautz, M. and Melster, A., Die Reibung, Warmeleitung und Diffusion in Gasmishungen, $\mathrm{XI}$. Die Reibung von $\mathrm{H}_{2}, \mathrm{~N}_{2}, \mathrm{CO}, \mathrm{C}_{2}, \mathrm{H}_{4}, \mathrm{O}_{2}$ und ihren Binaren Gemischen (The Viscosity Heat Conduction, and Diffusion in Gas Mixtures. XI. The Viscosities of $\mathrm{H}_{2}, \mathrm{~N}_{2}, \mathrm{CO}$, $\mathrm{C}_{2} \mathrm{H}_{4}, \mathrm{O}_{2}$ and their Binary Mixtures), Ann. Physik 7 , 409-426 (1930); Trautz, M. and Zink, R., Die Reibung, Warmeleitung und Diffusion in Gasmischungen. XII. Gasreibung bei hoheren Temperaturen (The Viscosity, Heat Conduction and Diffusion of Gas Mixtures. XII. The Viscosity of Gases at High Temperatures), Ann. Physik $\underline{7}, 427-452$ (1930).

65. Andrussow, L., Conductibilite Thermique, Viscosite et Diffusion en Phase Gaseuse. Memoire 10. Relation entre les Coefficients de ces Phenomones et 1 ' Equation de Maxwell (Thermal Conductivity, Viscosity and Diffusion in the Gas Phase. Report 10. Relation Between the Coefficients of These Phenomena and the Equation of Maxwe11), J. 
Chem. Phys, 52, 295-306 (1955).

66. von Lierde, J, Metinger over de Thermo-Diffusie en de Inwendige Wrijving in Enkele Gosmengsels bij Lage en Zeer Lage Temperaturen, (Measurements of Therma1 Diffusion and Viscosity of Certain Gas Mixtures at Low and Very Low Temperatures), Verhandel. Koninkl. Vlaam. Acad. Wetenschap. Belg. K1. Wetenschap. (24) 9, 7-78 (1947).

67. For details and references see the article by E.A. Mason in Proc. 4th Symp. on Thermophys. Prop., (ASME, New York, 1968), page 21.

68. Carnevale, E.H., Carey, C. and Larson, G., Ultrasonic Determination of Rotational Collision Numbers and Vibration Relaxation Times of Polyatomic Molecules at High Temperatures, J. Chem. Phys. 47, 2829-2835 (1967).

69. Ganzi, G. and Sandler, S.I., Determination of Thermal Transport Properties from Thermal Transpiration Measurements, J. Chem. Phys. 55, 132-140 (1971).

70. Michels, A. and Botzen, A., The Thermal Conductivity of Nitrogen at Pressures up to 2500 Atmospheres, Physica 19, 585-598 (1953).

71. Golubev, I.F. and Kal'sina, M.V., Thermoconductivity of Nitrogen and Hydrogen at Temperatures from 20 to $-195^{\circ} \mathrm{C}$ and Pressures from 1 to 500 Atmospheres, Gaz. Prom. 9, 41-43 (1964), Translation available from SLA translation center, No. LA-TR-65-1.

72. Vargaftik, N.B. and Zimina, N.Kh., Thermal Conductivity of Nitrogen at High Temperatures, High Temp. 2, 782-790 (1964).

73. Westenberg, A.A. and de Haas, N., Gas Thermal Conductivity Studies at High Temperature. Line-Source Technique and Results in $\mathrm{N}_{2}, \mathrm{CO}_{2}$, and $\mathrm{N}_{2}-\mathrm{CO}_{2}$ Mixtures, Phys. Fluids $\underline{5}$, 266-273 (1962).

74. Geier, H. and Schafer, K., Warmeleitfahigkeit von Reinen Gasen und Gasgemischen Zwischen $0^{\circ}$ und $1200^{\circ} \mathrm{C}$ (Thermal Conductivity of Pure Gases and Gas Mixtures Between $0^{\circ}$ and $1200^{\circ} \mathrm{C}$ ), Allgem, Warmetech. 10, 70-75 (1961).

75. Frank, E.U., Thermal Conduction in Highly Compressed Gases, Chem. Eng. Tech. 25, 238-244 (1953).

76. Vines, R.G., Measurements of the Thermal Conductivities of Gases at High Temperatures, Mass. Inst. of Tech., Tech. Report MIT-20-P (Sept. 1958), DDC AD 205694.

77. Nuttall, R.L. and Ginnings, D.C., Thermal Conductivity of Nitrogen from $50^{\circ}$ to $500^{\circ} \mathrm{C}$ and 1 to 100 Atmospheres, J. Res. NBS 58, 271-278 (1957). 
78. Gregory, H. and Marshall, S., Thermal Conductivities of Oxygen and Nitrogen, Proc. Roy. Soc. (London) Al18, 594-607 (1928).

79. Kannuluik, W.G. and Martin, L.H., Thermal Conductivity of Some Gases at $0^{\circ} \mathrm{C}$, Proc. Roy. Soc. (London) A144, 496-513 (1934).

80. Nothdurft, W., Zur Absolutmessung des Warmeleitvermogens von Gasen, (The Absolute Measurements of the Heat Conductivities of Gases), Ann. Physik 28, 137-156 (1937).

81. Johnston, H.L. and Grilly, E.R., The Thermal Conductivities of Eight Common Gases Between $80^{\circ}$ and $380^{\circ} \mathrm{K}, \mathrm{J}$. Chem. Phys. 14, 233-238 (1946).

82. Tsederberg, N.V. and Timrot, D.L., An Experimental Determination of the Thermal Conductivity of Liquid Oxygen, Soviet Phys. Tech. Phys. 1, 1791-1797 (1956), Translation from Zhur, Tekh. Fiz. 26, 1849-1956 (1956).

83. Cheung, H., Thermal Conductivity and Viscosity of Gas Mixtures, Calif. Univ., Lawrence Radiation Lab., Berkeley, Report No. UCRL-8230 (April 1958).

84. Pereira, A.N.G. and Raw, C.J.G., Heat Conductivities of Polyatomic Gases and their Binary Mixtures, Phys. Fluids $\underline{6}$, 1091-1096 (Aug. 1963).

85. Westenberg, A.A. and de Haas, N., Gas Thermal Conductivity Studies at High Temperature. II. Results for $\mathrm{O}_{2}$ and $\mathrm{O}_{2}-\mathrm{H}_{2} \mathrm{O}$ Mixtures, Phys. Fluids $\underline{6}$, 617-620 (1963).

86. Mann, W.B. and Dickins, B.G., The Thermal Conductivities of the Saturated Hydrocarbons in the Gaseous State, Proc. Roy. Soc. A134, 77-96 (1931).

87. Baker, C.E. and Brokaw, R.S., Thermal Conductivities of Ordinary and Isotopically Substituted Polar Gases and their Equimolar Mixtures, J. Chem. Phys. 43, 3519-3528 (1965).

88. Golubev, I.F., A Bicalorimeter for Measuring the Thermal Conductivity of Gases and Liquids at High Pressures and Various Temperatures, Teploenergetika 10, 78-82 (1963).

89. Hilsenrath, J., Beckett, C.W., Benedict, W.S., Fano, L., Hoge, H.J., Masi, J.F., Nutta11, R.L., Touloukian, Y.S, and Woolley, H., Tables of Thermal Properties of Gases, NBS, Circ. No. 564 (Nov. 1955).

90. McDowe11, R.S. and Kruse, F.H., Thermodynamic Functions of Methane, J. Chem, Eng, Data $\underline{8}, 547-548$ (1963).

91. Monchick, L., Munn, R.J. and Mason, E.A., Thermal Diffusion in Polyatomic Gases: A Generalized Stefan-Maxwell Diffusion Equation, J. Chem, Phys. 45, 3051-3058 (1966). 
92. Raman, S., Mathur, B.P., Howard, A.J., Champlin, J.W. and Watson, W.W., Thermal Diffusion in Polyatomic Gases: Isotopic ${ }^{15} \mathrm{~N}_{2}-{ }^{14} \mathrm{~N}_{2}$, J. Chem. Phys. 49, 4877-4879 (1968).

93. Mathur, B.P. and Watson, W.W., Isotopic Thermal Diffusion Factor ${ }^{16} \mathrm{O}_{2}-{ }^{18} \mathrm{O}_{2}$, J. Chem. Phys. 51, 2210-2214 (1969).

94. Mathur, B.P. and Watson, W.W., Isotopic Thermal. Diffusion Factor for $\mathrm{CO}_{2}$, J. Chem. Phys. 51, 5623-5625 (1969).

95. We would obtain negative values of $\alpha_{\sigma}$, however, with potential parameters selected by fitting the second virial and viscosity coefficient simultaneously.

96. The possibility that dimerization occurs at low temperatures is, further, also considered a complicating factor in assessing results for $\alpha_{0}$. See [92-94] and W. Wakeham, private communication.

97. Smith, F.J., Munn, R.J. and Mason, E.A., Transport Properties of Quadrupole Gases, J. Chem. Phys. 46, 317-321 (1967); Spurling, T.H. and Mason, E.A., Determination of Molecular Quadrupole Moments from Viscosities and Second Virial Coefficients, Ibid, 322-326 (1967).

98. See the article by E.A. Mason and T.R. Marrero in Advances in Atomic and Molecular Physics, Academic Press, New York (1970) Ed. D.R. Bates and I. Estermann.

99. While this manuscript was in preparation, we have carried out further tests on the validity of the 11-6-8 argon potential: H.M.H. Hanley, J.A. Barker, J.M. Parson, Max Klein, and Y.T. Lee, Comments on the interatomic potential for argon, Mo1. Phys. (inpress).

100. W. M. Haynes of the Cryogenics Division, NBS, Boulder, has recently measured the viscosity of oxygen. Preliminary dilute gas values are very close to our estimates.

101. G. Starkscha11 and R.G. Gordon, Improved Error Bounds for the long-range forces between atoms, J. Chem. Phys. $\underline{54} 663$ (1971).

102. L. Monchick and E.A. Mason, J. Chem, Phys. 35, 1676 (1961). 


\section{APPENDIX}

\section{Viscosity of Oxygen}

Although oxygen is a common and important fluid, there are very few reliable sets of viscosity data for it. In fact, in our opinion, the reliable data lie in the limited temperature range of about 250 to $400 \mathrm{~K}$. We reject data outside the range for the following reasons:

a) Above $400 \mathrm{~K}$ : Data above $400 \mathrm{~K}$ are available but are due largely to one source - Trautz and co-workers - measured 40 years ago [64]. But Trautz measured the viscosity for many gases and, for gases other than oxygen [Ar, $\mathrm{N}_{2}, \mathrm{He}$, air and so on], modern experiments give results which differ from his. The results differ by about $1-5 \%$ for temperatures up to $1000 \mathrm{~K}$-- the error increasing with temperature. Since there are sound reasons to indicate that the more recent work is more likely to be correct for these other gases [12], we have also to suppose that the old data for oxygen may not be correct.

b) Below $250 \mathrm{~K}$ : Values reported below $250 \mathrm{~K}$ were measured 30 years ago by Johnston and co-workers [56]. There appears to be no more recent work [100]. But, the viscosities of Johnston for gases other than oxygen, differ slightly from more recent data. Since, here again, we feel the more recent data for these gases to be more reliable, we have to suspect the earlier data for oxygen.

Discrepancies between the older and the more recent viscosities seem to depend only on the temperature and not on the gas (at least to a first approximation). We checked this by constructing a deviation curve between old and modern data for argon, neon, nitrogen, krypton, xenon, air, methane and helium. The curve is shown schematically as figure A. . On the basis of this figure we feel justified to adjust the viscosity results for oxygen $[56,64]$ according to the percentage discrepancy indicated at the appropriate temperatures. Adjusted oxygen data are given in table Al.

The adjusted data, together with data from references $[22,47,65,66]$ were then fitted to the m-6-8 potential and the result is shown as a deviation curve, figure 25 , in the main text. 


\section{TABLE A 1}

Adjusted Experimental Viscosities for Oxygen

Temperature
$\begin{aligned} & \text { K } \\ & 90.3 \\ & 118.8 \\ & 131.3 \\ & 144.9 \\ & 158.5 \\ & 172.6 \\ & 184.6 \\ & 400.8 \\ & 500.1 \\ & 550.1 \\ & 556.1 \\ & 675.1 \\ & 769.1 \\ & 881.1 \\ & 963.1 \\ & 1102.1\end{aligned}$

Viscosity
$10^{3} \mathrm{~g} / \mathrm{cm}-\mathrm{s}$
0.0679
0.0890
0.0979
0.108
0.117
0.128
0.137
0.258
0.305
0.327
0.328
0.377
0.411
0.450
0.477
0.521




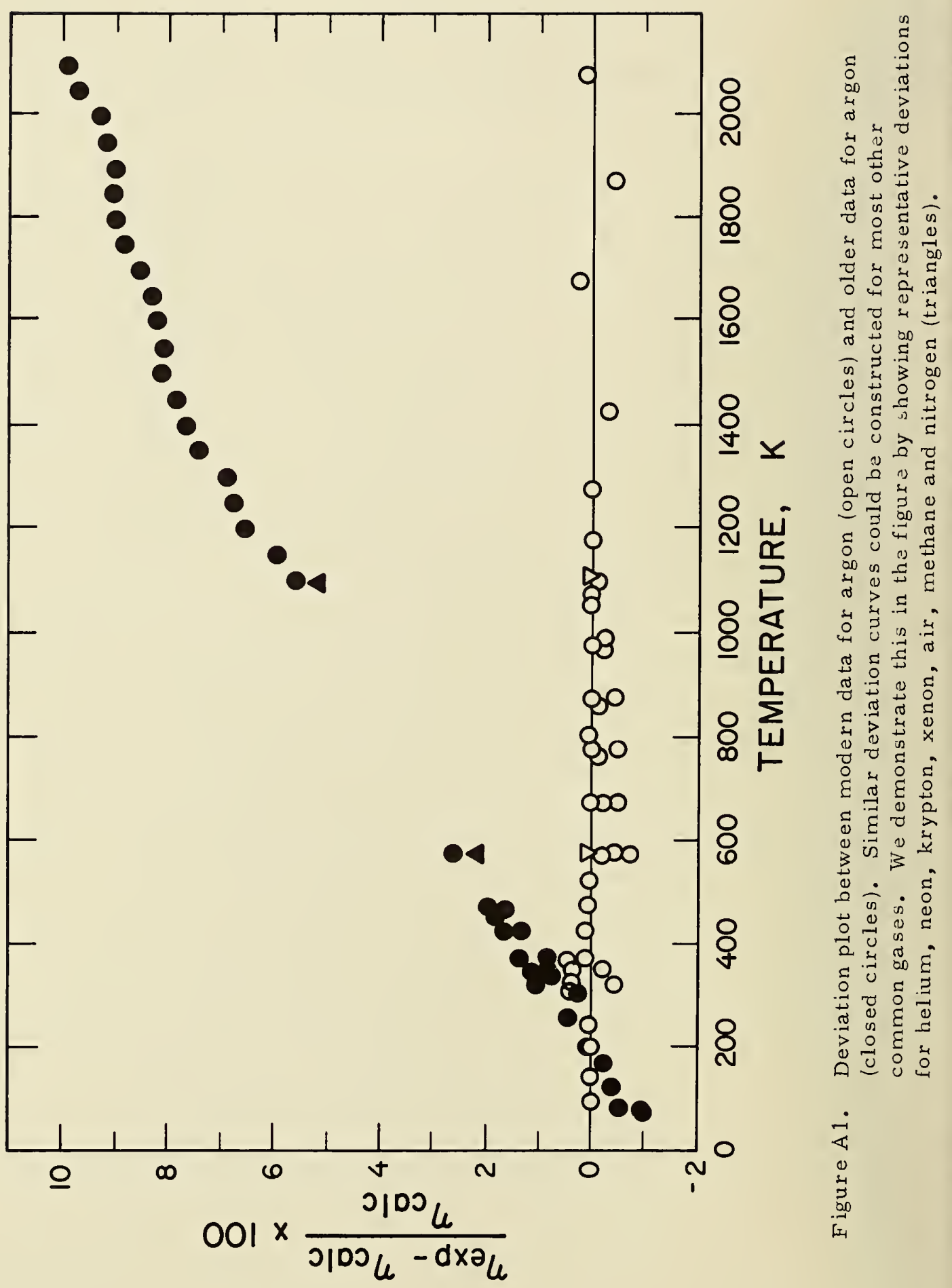


NBS-114A (1.71)

\begin{tabular}{|c|c|c|c|}
\hline $\begin{array}{l}\text { U.S. DEPT. OF COMM. } \\
\text { IBLIOGRAPHIC DATA } \\
\text { SHEET }\end{array}$ & $\begin{array}{l}\text { 1. PUBLICATION OR REPORT NO. } \\
\text { NBS-TN-628 }\end{array}$ & $\begin{array}{l}\text { 2. Gov't Accession } \\
\text { No. }\end{array}$ & 3. Recipient's Accession No. \\
\hline \multirow{2}{*}{\multicolumn{3}{|c|}{$\begin{array}{l}\text { On The UND SUBTITLE } \\
\text { On tility of the m-6-8 Potential Function }\end{array}$}} & $\begin{array}{l}\text { 5. Publication Date } \\
\text { November } 1972\end{array}$ \\
\hline & & & 6. Performing Organization Code \\
\hline $\begin{array}{ll}\text { UTHOR(S) } & \\
& H \cdot \mathrm{J} . \mathrm{M}\end{array}$ & Hanley and Max Klein & & 8. Performing Organization \\
\hline \multicolumn{3}{|c|}{$\begin{array}{l}\text { NATIONAL BUREAU OF STANDARDS, Boulder Labs } \\
\text { DEPARTMENT OF COMMERCE } \\
\text { Boulder, Colorado } 80302\end{array}$} & $\begin{array}{l}\text { 10. Project/Task/Work Unit No. } \\
2750124 / 2210143 \\
11 . \text { Contract/Grant No. }\end{array}$ \\
\hline \multirow{2}{*}{\multicolumn{3}{|c|}{$\begin{array}{l}\text { ponsoring Organization Name and Address } \\
\text { Office of Standard R ef erence Data } \\
\text { National Bureau of Standards } \\
\text { Washington, D. C. } 20234\end{array}$}} & $\begin{array}{l}\text { 13. Type of Report \& Period } \\
\text { Covered }\end{array}$ \\
\hline & & & 14. Sponsoring Agency Code \\
\hline
\end{tabular}

UPPLEMENTARY NOTES

BSTRACT (A 200-word or less factual summary of most significant information. If document includes a significant ibliography or literature survey, mention it here.)

e calculation of transport and equilibrium properties of simple gases with the 6-8 potential function is discussed. Properties referred to specifically are the cosity, diffusion, thermal conductivity and second virial coefficients, and the rmal diffusion factor. Gases referred to are argon, krypton, xenon, nitrogen, rgen, carbon dioxide and methane. We also discuss in detail the general behavior a model potential with respect to the fitting of data and the selection of potential i:ameters. The m-6-8 appears to be the simplest model potential which can isfactorily be used to fit data over a wide temperature range. The relationship of potential to independent theory is briefly examined.

KEY WORDS (Alphabetical order, separated by semicolons) Dispersion coefficients; m-6-8 potential; :ameter selection; second virial coefficients; transport properties.

\begin{tabular}{|c|c|c|}
\hline $\begin{array}{l}\text { AVAILA BILITY STATEMENT } \\
\text { X] UNL IMITED. }\end{array}$ & $\begin{array}{l}\text { 19. SECURITY CLASS } \\
\text { (THIS REPURT) } \\
\text { UNCL ASSIFIED }\end{array}$ & $\begin{array}{l}\text { 21. NO. OF PAGES } \\
77\end{array}$ \\
\hline $\begin{array}{l}\square \text { FOR OF FICIAL DISTRIBUTION. DO NOT RELEASE } \\
\text { TO NTIS. }\end{array}$ & $\begin{array}{l}\text { 20. SECURITY CLASS } \\
\text { (THIS P AGE) } \\
\text { UNCL ASSIFIED }\end{array}$ & $\begin{array}{r}\text { 22. Price } \\
.70\end{array}$ \\
\hline
\end{tabular}





\section{NBS TECHNICAL PUBLICATIONS}

PERIODICALS

JOURNAL OF RESEARCH reports National Bureau of Standards research and development in physics, mathematics, and chemistry. Comprehensive scientific papers give complete details of the work, including laboratory data, experimental procedures, and theoretical and mathematical analyses. Illustrated with photographs, drawings, and charts. Includes listings of other NBS papers as issued.

"ublished in two sections, available separately:

\section{Physics and Chemistry}

Papers of interest primarily to scientists working in these fields. This section covers a broad range of hysical and chemical research, with major emphasis on standards of physical measurement, fundamental constants, and properties of matter. Issued six times a year. Annual subscription: Domestic, $\$ 9.50 ; \$ 2.25$ additional for foreign mailing.

\section{Mathematical Sciences}

Studies and compilations designed mainly for the nathematician and theoretical physicist. Topics in nathematical statistics, theory of experiment design, numerical analysis, theoretical physics and chemisry, logical design and programming of computers and computer systems. Short numerical tables. Issued quarterly. Annual subscription: Domestic, $\$ 5.00$; $\$ 1.25$ additional for foreign mailing.

\section{TECHNICAL NEWS BULLETIN}

The best single source of information concerning the Bureau's measurement, research, developmental, cooperative, and publication activities, this monthly publication is designed for the industry-oriented individual whose daily work involves intimate contact with science and technology-for engineers, chemists, physicists, research managers, product-development managers, and company executives. Includes listing of all NBS papers as issued. Annual subscription: Domestic, $\$ 3.00 ; \$ 1.00$ additional for foreign mailing.

\section{Bibliographic Subscription Services}

The following current-awareness and literaturesurvey bibliographies are issued periodically by the Bureau: Cryogenic Data Genter Current Awareness Service (weekly), Liquefied Natural Gas (quarterly), Superconducting Devices and Materials (quarterly), and Electromagnetic Metrology Current Awareness Service (monthly). Available only from NBS Boulder Laboratories. Ordering and cost information may be obtained from the Program Information Office, National Bureau of Standards, Boulder, Colorado 80302 .

\section{HONPERIODICALS}

Applied Mathematics Series. Mathematical tables, manuals, and studics.

Building Science Series. Research results, test methods, and performance criteria of building materials, components, systems, and structures.

Handbooks. Recommended codes of engineering and industria! practice (including safety codes) developed in cooperation with interested industries, professional organizations, and regulatory bodies.

Special Publications. Proceedings of NBS conferences, bibliographies, annual reports, wall charts, pamphlets, etc.

Monographs. Major contributions to the technical literature on various subjects related to the Bureau's scientific and technical activities.

National Standard Reference Data Series. NSRDS provides quantitative data on the physical and chemical properties of materials, compiled from the world's literature and critically evaluated.

Product Standards. Provide requirements for sizes, types, quality, and methods for testing various industrial products. These standards are developed cooperatively with interested Government and industry groups and provide the basis for common understanding of product characteristics for both buyers and sellers. Their use is voluntary.

Technical Notes. This series consists of conimunications and reports covering both other-agency and NBS-sponsored work) of limited or transitory interest.

Federal Information Processing Standards Publications. This series is the official publication within the Federal Govcrnment for information on standards adopted and promulgated under the Public Law 89--306, and Bureau of the Budget Circular A-86 entitled, Stardardization of Data Elements and Codes in Data Systems.

Consumer Information Series. Practical information, based on NBS research and experience, covering areas of interest to the consumer. Easily understandable language and illustrations provide useful background knowledge for shopping in today's technological marketplace.

\section{CATALOGS GF NBS PUBLICATIONS}

NBS Special Publication 305, Publications of the NBS. 1966-1967. When ordering, include Catalog No. C13.10:305. Price $\$ 2.00 ; 50$ cents additional for foreign mailing.

NBS Special Publication 305, Supplement 1, Publications of the NBS, 1968-1969. When ordering, inchude Catalog No. C13.10:305/Suppl. 1. Price $\$ 4.50 ; \$ 1.25$ additional for foreign mailing.

NBS Special Publication 305, Supplement 2, Publications of the NBS, 1970. When ordering, include Catalog No. C13.10:305/Suppl. 2. Price $\$ 3.25 ; 85$ cents adiditional for forcign mailing. 
U.S. DEPARTMENT OF COMMERCE

National Bureau of Standards

Washington, D.C. 20234

DFFICIAL BUSINESS

Penalty for Private Use, $\$ 300$ 